\title{
Plant Secondary Metabolites of Pharmacological Significance in Reference to Diabetes Mellitus: An Update
}

\author{
Neha Gupta ${ }^{1}$, Tejovathi Gudipati ${ }^{2^{*}}$ and G.B.K.S. Prasad ${ }^{3}$
}

${ }^{1}$ Repository Tomato Genomic Resources, Department of Plant Sciences, University of

Hyderabad, Hyderabad, Telangana-500046, India

${ }^{2}$ Vijayaraje Institute of Science and Management, VISM campus, Tutati, NH-75, Gwalior, Madhya Pradesh-475001, India

${ }^{3}$ School of Studies in Biochemistry, Jiwaji University, Gwalior, Madhya Pradesh-474001, India

*Corresponding author

A B S T R A C T

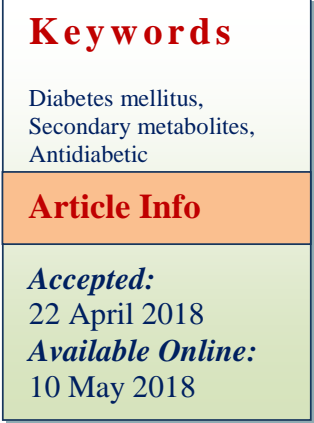

\section{Introduction}

Medicinal plants are the most important source of life saving drugs and since ancient time the plant based medicinal products have been known to mankind. Primary health care needs of more than $70-80 \%$ of world's population basically come from traditional herbal products (Fransworth et al., 1991). Ayurveda has described about 5000 years old rich heritage of plants and their use in the treatment of various human ailments as
Diabetes mellitus is a metabolic disorder characterized by hyperglycemia and alterations in carbohydrate, fat and protein metabolisms. Diabetes is associated with absolute or relative deficiencies in insulin secretion by pancreatic $\beta$-cells and/or insulin action. For the treatment of diabetes large numbers of herbal preparations are in vogue. Plant cells produced secondary metabolites which are biologically active constituents with therapeutic and prophylactic applications in humans. These metabolites includes alkaloides, glycosides, flavonoids, terpenoids, tannins, resins, lignins, saponins etc. majority of the world population depends on herbal drugs for their health care needs.This review gives rmation on secondary metabolites with pharmacological properties, techniques used in isolation and identification and also summaries data on 112 plants, plant parts, their antidiabetic properties with anti glycemic and other chemotherapeutic functions.

alternative medicine. It is estimated that about 7,500 plants are used in local health traditions in India. Whereas the classical systems of medicine such as Ayurveda, Siddha, Amchi, Unani and Tibetan describe medicinal values of about 1,200 plants (Pushpangadan et al., 1995). The demand for application of plant based medicines for treatment of metabolic disorders such as cancer, rheumatoid arthritis, diabetes etc., is gradually increasing (Kalia, 2005). A number of studies have been done for validation of enriched plant preparations 
for therapeutic applications in diverse experimental animals. Growing recognition for the plant products is attributed to their nontoxicity and easy availability at affordable price.

Diabetes mellitus has become the prominent "killer" disease of mankind like cancer, cardiovascular and cerebrovascular diseases (Chauhan et al., 2010). It is estimated that $25 \%$ of the world population is affected by diabetes mellitus (Arumugam et al., 2013). Diabetes mellitus is considered a group of metabolic disorders characterized by high blood sugar (glucose) levels, which result from defects in insulin secretion or action or both. It affects not only carbohydrate but also, protein and fat metabolism (Tripathi, 2003). Insulin is a polypeptide hormone, which is secreted by the $\beta$-cells of the islets of Langerhans of the pancreas. It helps in storing the blood glucose as glycogen in the liver and muscles cells. If the pancreas does not produce enough insulin or the produced insulin does not work properly, the glucose cannot enter to the body cells. So glucose remains in the blood and get converted into unwanted products with detrimental consequences. According to the etiology of Diabetes Mellitus, it can be classified into following major categories:

\section{Type-1}

It also known as "Insulin dependent Diabetes mellitus", which occurs in the childhood, and accounts for 5 to $10 \%$ of all diabetes cases. This is mainly due to destruction of pancreatic $\beta$-cell islets, resulting in absolute insulin deficiency and is positively associated with HLA B8- DR and DR-4. Recent research has shown that there is increased susceptibility to type-1 Diabetes mellitus when the amino acid Asp 57 is absent in DQ B with the presence of Arg 52 in DQ A (Wang and He, 1993; Ronningen et al.,1989).

\section{Type-2}

It also known as "Non insulin dependent Diabetes mellitus," is more associated with adulthood and elderly people. Pathophysiological basis for this is a combination of impaired $\beta$ - cell function, with marked increase in peripheral insulin resistance at receptor/ post receptor levels and increased hepatic glucose output production. This type of disease accounts for 90 to $95 \%$ of all diabetic patients.

\section{Gestational}

Another type of diabetes, diagnosed during the pregnancy (Lokesh and Amit, 2006; Seshiah et al., 2000). It is fully treatable, but requires careful medical supervision throughout the pregnancy. About 20-50\% of affected women develop type 2 diabetes later in life.

The term pre-diabetes is used for the condition in which fasting blood glucose level is $\geq 110$ and $<126 \mathrm{mg} / \mathrm{dl}$. Factors such as Heredity, Age, Obesity, Sex, Diet, Physical Inactivity, sedentary Lifestyle and various stresses etc. are directly or indirectly trigger pre diabetic condition. Persistent hyperglycemia, generates reactive oxygen species (ROS) which may promote peroxidation of lipids, proteins and other biomolecules. The oxidative stress inturn aggravates inflammatory response, which ultimately end up with complications such as cataract, neuropathy and nephropathy over a period of time (Dewanjee et al., 2009).

The ethnobotanical studies report about wide variety of plant species which possess antidiabetic properties (Alarcon et al., 1998; Rashid et al., 2014; Saminathan and Kavimani, 2015). Further an array of plant derived principles mainly belonging to alkaloids, glycosides, galactomannan gum, polysaccharides, hypoglycans, peptidoglycans, guanidine, steroids, glycopeptides, and 
terpenoids have demonstrated bioactivity against hyperglycemia (Ivorra et al., 1988; Maries and Farnsworth, 1995). In this review we tried to provide information on the types of secondary metabolites, their identification techniques and also summarised the description of about 112 medicianal plants with antidiabetic property, their bioactive molecuels, mode of action and also application of in vitro culture techniques used for secondaty metabolites production.

Plants as novel source for bioactive/secondary compounds

Plants produce a vast and diverse variety of organic compounds, the great majority of which do not appear to participate directly in growth and development, traditionally referred to as "secondary metabolites". They are usually classified according to their biosynthetic pathways (Harborne et al., 1999). Based on biosynthetic origins, plant natural products are classified into three major groups: viz., terpenoids, alkaloids, and the phenylpropanoids \& allied phenolic compounds. Terpenoids are derived from the five-carbon precursor isopentenyl diphosphate (IPP). Most of the alkaloids, with one or more nitrogen atoms, are biosynthesized principally from amino acids. While, vast numbers of phenolic compounds are formed either by the shikimic acid pathway or the malonate/acetate pathway (Buchanan et al., 2000).

A brief description of bioactive compounds, their basic nature, their major plant or family and their main Pharmacological properties reported are given in Table 1.

\section{Techniques; identification and characterization of bioactive molecule inherbal preparation}

The extraction process of bioactive compounds depends on the polarity of the molecule and the solvent used. Different solvents such as aqueous, methanol, ethanol, benzene, chloroform, ether etc. have been used for the extraction of bioactive compounds with antidiabetic property from different medicinal plants. Crude extracts contain numerous plants secondary metabolites like alkaloids, glycosides, flavonoids, terpenoids etc. which are reported to regulate the blood glucose level through different mechanism like nourish or stimulate $\beta$-cells, increase in insulin sensitivity, stimulate glycogenesis and/or suppress gluconeogenesis.

Bioactive molecules from the crude extracts can be further separated, isolated and purified by a combination of chromatographic methods and several other techniques depending on the properties of each biomolecule of intrest. Some of the most commonly used techniques for the separation; isolation and identification are given blow.

\section{High Performance Thin Layer Chromatography (HPTLC)}

TLC is the common fingerprint method for herbal analysis. The mobile phase is drawn through the stationary phase by capillary action. Samples are separated according their component's polarity. HPTLC fingerprint is mainly used to study the compounds with low or moderate polarity.

HPTLC technique is widely employed in process development, identification and detection of adulterants in herbal product and helps in identification of pesticide content, mycotoxins and in quality control of herbs and health foods (Soni and Naved, 2010). Crude extracts along with standard molecule are applied and softwares are available to analyze the amount of compounds present in the sample. In this method we can analyze 6-10 samples at a time. 


\section{High Performance Liquid Chromatography (HPLC)}

This method is more refined and accurate as compared to HPTLC. In this technique very fine particles of approximately $10 \mu \mathrm{m}$ in diameter are used as stationary phase and high pressure is used to maintain adequate flow rate of mobile phase along with sample, hence, called High Performance or High Pressure Liquid Chromatography. Small volume of sample is used and one sample at a time is analyzed. At present time, this procedure has been used principally with ion exchange and adsorption chromatography for small molecules, peptides, small carbohydrates and tRNA etc.

Preparative and analytical HPLC are widely used in isolation and purification of herbal compounds. There are basically two types of preparative HPLC: low pressure HPLC (typically under 5 bar) and high pressure HPLC (pressure >20 bar) (Chimezie et al., 2008; Saravanan et al., 2010).

The combination of HPLC and LC/MS is currently the most powerful technique for the quality control of herbal drugs (Zhang and Ye, 2009).

\section{Ultra-Performance Chromatography (UPLC)}

Liquid

Ultra-performance liquid chromatography (UPLC) is another improved LC technique which utilizes $2 \mu \mathrm{m}$ size particles as stationary phase and is more advanced technique with improved resolution, sensitivity and speed, without compromise.

UPLC is used to evaluate decocting-induced chemical transformations and chemical consistency between traditional and dispensing granule decoctions ( $\mathrm{Li}$ et al., 2010a; Li et al., 2010b).
Liquid Chromatography - Mass Spectroscopy (LCMS)

Liquid chromatography-mass spectrometry (LC-MS) is now a routine technique with the development of electrospray ionisation (ESI). LC-MS has become method of choice in many stages of drug development (Mike and Edward, 1999). The use of tandem MS and stable isotope internal standards allows highly sensitive and accurate assays to be developed although some optimization methods are required to minimise ion suppression effects. Fast scanning speeds allow a high degree of multiplexing and many compounds can be measured in a single analytical run. The reasons for choosing LC-MS over LC with conventional detectors are essentially the same as with GC-MS, namely high specificity and the ability to handle complex mixtures.

\section{Liquid Chromatography - Nuclear Magnetic Resonance (LC-NMR)}

LC-NMR is the most versatile analytical technique for complex mixture analysis. Specifically, interfacing liquid chromatography with parallel NMR and mass spectrometry (LC-NMR-MS) gives comprehensive structural data on metabolites of novel drugs in development and applications in natural product. Recent innovations to improve NMR detection include speed and sensitivity of detection and found useful in the areas of pharmacokinetics, toxicity studies, drug metabolism and drug discovery process (Dachtler et al., 2003; Pasch et al., 2008; Patil and Rajani, 2010).

Gas Chromatography (GC) and Gas Chromatography-Mass Spectroscopy (GCMS)

GC-MS is analytical method that combines the features of gas-liquid chromatography and mass spectrometry to identify different 
voletile substances within a test sample. The basic principal of this technique is to measure a sample with an unknown concentration. Applications of GC-MS include; drug detection, environmental analysis, identification and quantification of chemical constituents present in polyherbal oil formulations (Kasthuri et al., 2010).

\section{Supercritical Fluid Chromatography (SFC)}

It is a form of normal phase chromatography, which is used for the analysis and purification of low to moderate molecular weight and thermally labile molecules. It can also be used for the separation of chiral compounds. Basic principles for isolating compounds with SFC are similar to the fundamental rules for largescale preparative liquid chromatography, however SFC typically utilize carbon dioxide as the mobile phase; therefore the entire chromatographic flow path must be pressurized.

Because the supercritical phase represents a state in which liquid and gas properties converge, supercritical fluid chromatography is sometimes called "Convergence Chromatography". SFC permits the separation and determination of a group of compounds that are not conveniently handled by either gas or liquid chromatography. SFC enables the resolution of unknown components and known markers such as azadirachtin A and B, salannin, and nimbin in neem seed extracts (Agrawal et al., 2009).

\section{Capillary Electrophoresis (CE)}

Capillary electrophoresis is the most efficient analytical technique that separates ions based on their electrophoretic mobility with the use of an applied voltage. This method is two times shorter than that of HPLC and solvent consumption was approx 100-fold lesser than HPLC (Sombra et al., 2005). The technique is available for the analysis of both large and small molecules. The electrophoretic mobility of molecules is dependent upon charge, viscosity, and atom's radius. Rate at which the particle moves is directly proportional to the applied electric field. The importance of CE in quality control of herbal medicinal products (Ganzera, 2008) especially in compounds such as alkaloids (Wen et al., 2005) and flavonoids (Pietta et al., 1991).

\section{Infrared spectroscopy}

IR - spectroscopy is an accepted and wide spread analytical method to analyze a lot of chemical substances. The working principle is the excitation of vibrations and rotations of molecules by absorption of infrared radiation. The energy to excite this vibrations and rotations depends on the mass of the atoms and the binding forces between them.

A IR - spectrum of a functional group in a molecule is characteristic for this group, That's why it can be identified with the IR spectrum like a fingerprint of this group. FTIR along with the statistical method 'principal component analysis '(PCA) has been applied to identify and discriminate herbal medicines for quality control in the fingerprint region of 400-2000 cm- ${ }^{1}$.

\section{Diabetes mellitus and its treatment}

Pancreatic $\beta$-cells secretes insulin in response to sugar level of circulating blood, which reduces blood sugar level and allows glucose to more readily enter the cells, and also facilitate the storage of glucose as glycogen. On the other hand low level of insulin in blood leads to brake down of glycogen and reduced ability of cells to absorb sugar. So blood sugar level gets increased. Other than insulin many harmones like glucagon from pancreas, adrenaline and cortisteroids from the adrenal glands also regulate the blood sugar level. 
Table.1 Main groups of bioactive compounds in plants

\begin{tabular}{|c|c|c|c|}
\hline Bioactive compound & Chemical properties & Family of plant sp. Found in & Pharmacological properties \\
\hline Glycoside & $\begin{array}{l}\text { Mono-oligosaccharides + } \\
\text { uronic acid }\end{array}$ & & \\
\hline Cardiac glycoside & $\begin{array}{l}\text { Aglycan part is a steroidal } \\
\text { moiety. } \\
\text { e.g. oleanadrin }\end{array}$ & $\begin{array}{l}\text { Scrophulariaceae } \\
\text { Convallariaceae }\end{array}$ & $\begin{array}{l}\text { Inhibition of } \mathrm{Na}^{+} / \mathrm{K}^{+} \text {ATPase } \\
\text { pumps. }\end{array}$ \\
\hline Cynogenic glycoside & $\begin{array}{l}\text { Derived from amino acids. } \\
\text { e.g.dhurrin }\end{array}$ & Rosaceae & $\begin{array}{l}\text { Release of } \mathrm{HCN} \text {, which is very } \\
\text { toxic and being lethal at high } \\
\text { dosages. }\end{array}$ \\
\hline Glucosinolates & $\begin{array}{l}\text { Derived from } S- \\
\text { containing amino acids. } \\
\text { e.g. sinigrin } \\
\text { ent }\end{array}$ & Brassicaceae & Antioxidant \\
\hline $\begin{array}{l}\text { Saponins } \\
\text { "soap forming } \\
\text { compound" }\end{array}$ & $\begin{array}{l}\text { Consist of either } \\
\text { pentacyclic triterpenoids } \\
\text { or tetracyclic steroids. } \\
\text { e.g. solanine }\end{array}$ & Liliaceae & In vitro hemolysis of RBCs. \\
\hline $\begin{array}{l}\text { Anthraquinone } \\
\text { glycosides }\end{array}$ & $\begin{array}{l}\text { Derived from di, tri or } \\
\text { tetra anthaquinone. } \\
\text { e.g. aloe emodin } \\
\text { OH O OH }\end{array}$ & Polygonaceae & $\begin{array}{l}\text { Induced water and electrolyte } \\
\text { secretion. }\end{array}$ \\
\hline $\begin{array}{l}\text { Flavonoids } \\
\text { and }\end{array}$ & $\begin{array}{l}\text { Central three-ring } \\
\text { (flavone) structure. }\end{array}$ & Fabaceae & $\begin{array}{l}\text { Antioxidant and also reduce } \\
\text { inflammation and carcinogenicity. }\end{array}$ \\
\hline Proanthocyanidins & Oligomers of flavonoids. & & \\
\hline Type I Tannins & $\begin{array}{l}\text { Large polymer of } \\
\text { flavonoids. } \\
\text { e.g. tannic acid }\end{array}$ & $\begin{array}{l}\text { Fagaceae } \\
\text { Polygonaceae }\end{array}$ & $\begin{array}{l}\text { Astringents and used inin cases of } \\
\text { diarrhea, skin bleedings and } \\
\text { transudates. }\end{array}$ \\
\hline Terpenoids & $\begin{array}{l}\text { Derivatives of 5-C } \\
\text { building block isoprene }\end{array}$ & Lamiaceae & $\begin{array}{l}\text { Theyare antineoplastic, } \\
\text { antibacterial, antiviral acitivity } \\
\text { and also stimulate gastro } \\
\text { intestinal secreations. }\end{array}$ \\
\hline
\end{tabular}




\begin{tabular}{|c|c|c|c|}
\hline Diterpenoides & $\begin{array}{l}\text { Composed of 4-isoprene } \\
\text { unit. }\end{array}$ & Coffea Arabica & Antineoplastic activity. \\
\hline Resin & $\begin{array}{l}\text { Complex lipid soluble } \\
\text { mixture of Terpenoids. } \\
\text { e.g. polymer of styrene }\end{array}$ & Most conifers & $\begin{array}{l}\text { They have Antimicrobial and } \\
\text { wound healing activity. Resins are } \\
\text { generally safe, but contact allergy } \\
\text { may occur. }\end{array}$ \\
\hline Lignans & $\begin{array}{l}\text { Composed of two } \\
\text { phenylpropanoid } \\
\text { units,generally lipophilic. } \\
\text { e.g. pinoresinol }\end{array}$ & Oil seeds & $\begin{array}{l}\text { Having phytoestrogenic and } \\
\text { antineoplastic effects. }\end{array}$ \\
\hline Alkaloids & $\begin{array}{l}\text { Heterocyclic, } \mathrm{N} \text { - } \\
\text { containing compounds } \\
\text { drived from amino acids. }\end{array}$ & & \\
\hline Tropane alkaloids & & Solanaceae & $\begin{array}{l}\text { Have Anticholinergic activity and } \\
\text { also used in hypersecretion and } \\
\text { pain. }\end{array}$ \\
\hline $\begin{array}{l}\text { Pyrrolizidine } \\
\text { alkaloids }\end{array}$ & & $\begin{array}{l}\text { Asteraceae } \\
\text { Boraginaceae }\end{array}$ & Hepatotoxicity. \\
\hline $\begin{array}{l}\text { Isoquinoline } \\
\text { alkaloids }\end{array}$ & & Papaveraceae Berberidaceae & $\begin{array}{l}\text { Inhibition of various conditions as } \\
\text { pain, cancer cells and bacteria. }\end{array}$ \\
\hline $\begin{array}{l}\text { Methylxanthine } \\
\text { alkaloids }\end{array}$ & & $\begin{array}{l}\text { Coffea arabica Theobroma } \\
\text { cacao }\end{array}$ & Elicit neurological effects. \\
\hline Pseudoalkaloids & $\begin{array}{l}\text { Have heterocyclic ring } \\
\text { with nitrogen but not } \\
\text { drived from amino acids. } \\
\text { e.g. theophylline }\end{array}$ & Apiaceae & Effect on CNS \\
\hline Furocoumarins & $\begin{array}{l}\text { Furan ring fused with } \\
\text { coumarin. } \\
\text { e.g. psoralen }\end{array}$ & Apiaceae & $\begin{array}{l}\text { Affact the metabolism of certain } \\
\text { drugs. }\end{array}$ \\
\hline Anthraqionones & $\begin{array}{l}\text { Phenolic compounds } \\
\text { based on } 9,10- \\
\text { antheaquinone skeleton. } \\
\text { e.g. Hypericin, a } \\
\text { naphthodianthrones }\end{array}$ & Clusiaceae, Polygonaceae & Antidepressant effect. \\
\hline
\end{tabular}


Table.2 Potential anti-diabetic plants, their active compounds ingredients and pharmaceutical attributes

\begin{tabular}{|c|c|c|c|c|c|c|}
\hline $\begin{array}{l}\text { Plant } \\
\text { Botanical } \\
\text { name/ common } \\
\text { name/ Family }\end{array}$ & $\begin{array}{l}\text { Plant } \\
\text { part } \\
\text { explor } \\
\text { ed }\end{array}$ & $\begin{array}{l}\text { Nature of active } \\
\text { ingredients }\end{array}$ & $\begin{array}{l}\text { Solvent (s) } \\
\text { employed } \\
\text { in various } \\
\text { studies for } \\
\text { extraction }\end{array}$ & $\begin{array}{l}\text { Pharmaceutical } \\
\text { activity attributed }\end{array}$ & $\begin{array}{l}\text { Reported } \\
\text { experimental } \\
\text { validation }\end{array}$ & Reference \\
\hline \multicolumn{7}{|c|}{ Plants which shows the $\alpha$-glucosidase inhibitory activity } \\
\hline $\begin{array}{l}\text { Acacia } \\
\text { auriculiformis } \\
\text { (Northern } \\
\text { black wattle) } \\
\text { Leguminosae }\end{array}$ & $\begin{array}{l}\text { Bark } \\
\text { Pods }\end{array}$ & $\begin{array}{l}\text { Phenolics } \\
\text { Flavonoids } \\
\text { Proanthocyani } \\
\text { dins }\end{array}$ & Acetone & $\begin{array}{l}\text { Antidiabetic } \\
\text { Antioxidant } \\
\text { Anti bacterial } \\
\text { Antifungal } \\
\text { Cardioprotective } \\
\text { Anticancer }\end{array}$ & $\begin{array}{l}\text { Significant } \\
\text { reduction of blood } \\
\text { glucose level was } \\
\text { evident in diabetic } \\
\text { rats at doses of } 250 \\
\text { and } 500 \mathrm{mg} / \mathrm{kg} \text {. }\end{array}$ & $\begin{array}{l}\text { Ray et al., } \\
\text { 2006; Sathya } \\
\text { and } \\
\text { Siddhuraju, } \\
2012\end{array}$ \\
\hline $\begin{array}{l}\text { Canthium } \\
\text { dicoccum } \\
\text { (Bogas) } \\
\text { Rubiaceae }\end{array}$ & Bark & $\begin{array}{l}\text { Alkaloids } \\
\text { Glycosides } \\
\text { Phytosterols } \\
\text { Saponins. }\end{array}$ & Ethanol & $\begin{array}{l}\text { Antifungal } \\
\text { Anti-inflammatory } \\
\text { Antidiabetic } \\
\text { Nephroprotective } \\
\text { Antiarthritic }\end{array}$ & $\begin{array}{l}\text { Ethanolic extract at } \\
\text { doses }(200,400 \mathrm{mg} / \mathrm{kg}) \\
\text { exhibited significant } \\
\text { anti-hyperglycaemic } \\
\text { activity. }\end{array}$ & $\begin{array}{l}\text { Santhan et } \\
\text { al., } 2013 .\end{array}$ \\
\hline $\begin{array}{l}\text { Cassia } \\
\text { auriculata } \\
\text { (Senna, } \\
\text { sunamukhi) } \\
\text { Caesalpiniacea } \\
\text { e/ } \\
\text { Leguminosae }\end{array}$ & $\begin{array}{l}\text { Leaf } \\
\text { Seed } \\
\text { Flower }\end{array}$ & $\begin{array}{l}\text { Terpenoids } \\
\text { Tannin } \\
\text { Flavonoids } \\
\text { Saponin } \\
\text { Cardiac } \\
\text { glycosides } \\
\text { Steroids. }\end{array}$ & $\begin{array}{l}\text { Hexane } \\
\text { Chlorofor } \\
\mathrm{m} \\
\text { Ethyl } \\
\text { acetate } \\
\text { Methanol } \\
\text { Aqueous } \\
\text { Absolute- } \\
\text { alcohol }\end{array}$ & $\begin{array}{l}\text { Antifungal } \\
\text { Antibacterial } \\
\text { Anti-inflammatory } \\
\text { Antioxidant } \\
\text { Hepatoprotective } \\
\text { Antidiabetic }\end{array}$ & $\begin{array}{l}\text { Oral admistration of } \\
\text { aqueous flower extract } \\
\text { in streptozotocin- } \\
\text { induced diabetic rats } \\
\text { shows anti- } \\
\text { hyperglycemic activity. }\end{array}$ & $\begin{array}{l}\text { Harborne, } \\
\text { 1998; Faraz } \\
\text { et al., 2003; } \\
\text { Edeog et al., } \\
2005 .\end{array}$ \\
\hline $\begin{array}{l}\text { Cistus } \\
\text { laurifolius } \\
\text { (laurel- } \\
\text { leaved rock } \\
\text { rose) } \\
\text { Cistaceae }\end{array}$ & leaf & Favonoids & $\begin{array}{l}\text { Ethanol } \\
\text { Aqueous }\end{array}$ & $\begin{array}{l}\text { Anti- } \\
\text { inflammatory } \\
\text { Antirheumatic } \\
\text { Antidiabetic } \\
\text { Antioxidant } \\
\text { Antiulcer }\end{array}$ & $\begin{array}{l}\text { Blood glucose } \\
\text { levels of the } \\
\text { streptozotocin- } \\
\text { induced diabetic } \\
\text { rats were decreased } \\
\text { by ethanol extract } \\
\text { at of } 250 \text { and } \\
500 \mathrm{mg} / \mathrm{kg} \text { doses. }\end{array}$ & $\begin{array}{l}\text { Orhan et al., } \\
2013 .\end{array}$ \\
\hline 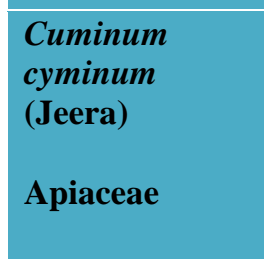 & Seed & $\begin{array}{l}\text { Flavonoids } \\
\text { Polyphenols }\end{array}$ & Ethanol & $\begin{array}{l}\text { Antimicrobial } \\
\text { Antidaibetic } \\
\text { Antifertility } \\
\text { Anticancer } \\
\text { Antioxidant } \\
\text { Immunomodulatory }\end{array}$ & $\begin{array}{l}\text { Oral dose of } 250 \\
\mathrm{mg} / \mathrm{Kg} \text { body weight } \\
\text { shows reduction in } \\
\text { glucose level in } \\
\text { streptozotocin-induced } \\
\text { diabetic rats. }\end{array}$ & $\begin{array}{l}\text { Srivsatava et } \\
\text { al., } 2011 .\end{array}$ \\
\hline $\begin{array}{l}\text { Hunteria } \\
\text { umbellate } \\
\text { (Demouain) } \\
\text { Apocynaceae }\end{array}$ & Seed & $\begin{array}{l}\text { Alkaloidal } \\
\text { Indolealkaloids } \\
\text { Flavonoids } \\
\text { Tannins } \\
\text { Glycosides }\end{array}$ & $\begin{array}{l}\text { Methanol } \\
\text { Aqueous }\end{array}$ & $\begin{array}{l}\text { Antidiabetic } \\
\text { Antioxidant } \\
\text { Antibacterial } \\
\text { Weightloss } \\
\text { Anti-inflammatory } \\
\text { Immune booster. }\end{array}$ & $\begin{array}{l}\text { Oral administration of } \\
400 \mathrm{mg} / \mathrm{kg} \text { of seeds for } \\
14 \text { days was associated } \\
\text { with significantly } \\
\text { reduced blood glucose } \\
\text { and body weight. }\end{array}$ & $\begin{array}{l}\text { Igbe et al., } \\
2009 .\end{array}$ \\
\hline
\end{tabular}




\begin{tabular}{|c|c|c|c|c|c|c|}
\hline $\begin{array}{l}\text { Mukia } \\
\text { madeaspatana } \\
\text { (Melothria) } \\
\text { Cucuerbitaceae }\end{array}$ & Root & $\begin{array}{l}\text { Phenolics } \\
\text { Carotenoids } \\
\text { Flavonoids }\end{array}$ & Methanol & $\begin{array}{l}\text { Antioxidant } \\
\text { Hypotensive } \\
\text { Immunomodulatory } \\
\text { Anti-inflammatory } \\
\text { Hepatoprotective } \\
\text { Antimicrobial } \\
\text { Vasodialatory } \\
\text { Diuretic } \\
\text { Antiasthmatic } \\
\text { Antidiabetic }\end{array}$ & $\begin{array}{l}\text { Methenolic root extract } \\
\text { at a dose of } 500 \mathrm{mg} / \mathrm{kg} \\
\text { to Alloxan induced } \\
\text { diabetic rats showed } \\
\text { significant reduction of } \\
\text { blood glucose, lipid } \\
\text { profile except HDL. }\end{array}$ & $\begin{array}{l}\text { Wani et al., } \\
2011 .\end{array}$ \\
\hline $\begin{array}{l}\text { Rehmania } \\
\text { glutinosa } \\
\text { (Chinese } \\
\text { foxglove) } \\
\text { Scrophulariace } \\
\text { ae }\end{array}$ & Root & $\begin{array}{l}\text { Iridoids } \\
\text { Monoterpenes } \\
\text { Glycosides } \\
\text { Phenols } \\
\text { Flavonoid }\end{array}$ & Ethanol & $\begin{array}{l}\text { Antidiabetic } \\
\text { Antioxidant } \\
\text { Hepatoprotective } \\
\text { Anti-inflammatory } \\
\text { Antimicrobial }\end{array}$ & $\begin{array}{l}\text { Ethanolic extrat at } \\
\text { dose } 100 \mathrm{mg} / \mathrm{kg} \text { for } \\
15 \text { days) showed a } \\
\text { significant } \\
\text { decrease in blood } \\
\text { glucose level. }\end{array}$ & $\begin{array}{l}\text { Zhang et al., } \\
\text { 2004; Jeonga } \\
\text { et al., } 2013 .\end{array}$ \\
\hline $\begin{array}{l}\text { Syzygium } \\
\text { cumini (Black } \\
\text { Plum) } \\
\text { Myrtaceae }\end{array}$ & $\begin{array}{l}\text { Leaf } \\
\text { Stem } \\
\text { Bark } \\
\text { Flower } \\
\text { Root } \\
\text { Fruit }\end{array}$ & $\begin{array}{l}\text { Glycoside } \\
\text { Alkaloids } \\
\text { Flavonoids }\end{array}$ & $\begin{array}{l}\text { Aqueous } \\
\text { Alcohol }\end{array}$ & $\begin{array}{l}\text { Antidiabetic } \\
\text { Diuretic } \\
\text { Antioxidant } \\
\text { Antidiarrhoeal } \\
\text { Antibacterial } \\
\text { Gastroprotective } \\
\text { Redioprotective } \\
\text { Anti-inflammatory }\end{array}$ & $\begin{array}{l}\text { Leaf extract at dose } \\
4 \mathrm{~g} / \mathrm{kg} \text { of body } \\
\text { weight found to } \\
\text { exhibit maximum } \\
\text { hypoglycaemic } \\
\text { effect in rabbits }\end{array}$ & $\begin{array}{l}\text { Nair } \text { et } \\
\text { al.,1986; } \\
\text { Pepato } \text { et al., } \\
\text { 2001; } \\
\text { Ayyanar } \text { et } \\
\text { al., } 2012\end{array}$ \\
\hline $\begin{array}{l}\text { Vaccinium } \\
\text { arctostaphylos } \\
\text { (Caucasian } \\
\text { Whortleberry) } \\
\text { Ericaceae }\end{array}$ & Fruit & Anthocynins & Ethanol & $\begin{array}{l}\text { Antidiabetic } \\
\text { Anti- } \\
\text { inflammatory } \\
\text { Hepatoprotective } \\
\text { Antioxidant } \\
\text { Antibacterial } \\
\text { Antifungal }\end{array}$ & $\begin{array}{l}\text { Ethanolic extract } \\
\text { of fruits showed } \\
\text { postprandial blood } \\
\text { glucose lowering } \\
\text { in alloxan induced } \\
\text { diabetic male } \\
\text { wistar rats }\end{array}$ & $\begin{array}{l}\text { Feshani } e t \\
\text { al., } 2011 .\end{array}$ \\
\hline \multicolumn{7}{|c|}{ Plants which increases the sensitivity of liver, fat and muscle cells to insulin } \\
\hline $\begin{array}{l}\text { Amaranthus } \\
\text { viridis (Cholai) } \\
\text { Amaranthaceae }\end{array}$ & Stem & $\begin{array}{l}\text { Alkaloids } \\
\text { Steroids } \\
\text { Glycosides } \\
\text { Saponins } \\
\text { Tannins }\end{array}$ & $\begin{array}{l}\text { Aqueous } \\
\text { Methanol } \\
\text { Pet-ether }\end{array}$ & $\begin{array}{l}\text { Anti-inflammatory } \\
\text { Diuretic } \\
\text { Antirheumatic } \\
\text { Antidiabetic } \\
\text { Analgesic } \\
\text { Antirheumatic } \\
\text { Antidiabetic }\end{array}$ & $\begin{array}{l}100,200,400 \mathrm{mg} / \mathrm{kg} \\
\text { body weight stem } \\
\text { aqueous extract } \\
\text { significantly decreased } \\
\text { the blood glucose level } \\
\text { in streptozotocin } \\
\text { induced diabetic rats. }\end{array}$ & $\begin{array}{l}\text { Pandhare et } \\
\text { al., } 2012 .\end{array}$ \\
\hline $\begin{array}{l}\text { Acorus } \\
\text { calamus } \\
\text { (Bach) }\end{array}$ & $\begin{array}{l}\text { Rhizo } \\
\text { me }\end{array}$ & $\begin{array}{l}\text { Saponins } \\
\text { Glycosides } \\
\text { Sequiterpenoids }\end{array}$ & $\begin{array}{l}\text { Methanol } \\
\text { Ethyl } \\
\text { acetate }\end{array}$ & $\begin{array}{l}\text { Aphrodisiac } \\
\text { Diuretic } \\
\text { Antisplasmodemic } \\
\text { Antirheumetic } \\
\text { Anti-inflammatory } \\
\text { Antioxidant } \\
\text { Hypoglycemic }\end{array}$ & $\begin{array}{l}200 \mathrm{mg} / \mathrm{kg} \text { of rhizome } \\
\text { extract showed } \\
\text { significant restoration } \\
\text { of the blood glucose } \\
\text { levels in streptozotocin } \\
\text { induced diabetic rats. }\end{array}$ & $\begin{array}{l}\text { David et al., } \\
\text { 2012: Prisilla } \\
\text { et al., } 2012 .\end{array}$ \\
\hline $\begin{array}{l}\text { Bauhinia } \\
\text { forficate } \\
\text { (Paw-of-cow) }\end{array}$ & leaf & Flavonoids & $\begin{array}{l}\text { Aqueous } \\
\text { Ethanol } \\
\text { Hexane }\end{array}$ & $\begin{array}{l}\text { Antidiabetic } \\
\text { Antimutagenic } \\
\text { Antioxidant } \\
\text { Hypolipidimic }\end{array}$ & $\begin{array}{l}\text { Oral admistration of } \\
\text { aqueous, ethanolic and } \\
\text { hexane extract of } \\
\text { leaves at dose } 200 \text { and }\end{array}$ & $\begin{array}{l}\text { Lino et al., } \\
2004 .\end{array}$ \\
\hline
\end{tabular}




\begin{tabular}{|c|c|c|c|c|c|c|}
\hline Fabacae & & & & & $\begin{array}{l}400 \mathrm{mg} / \mathrm{kg} \text { showed } \\
\text { significant reduction in } \\
\text { plasma glucose level } \\
\text { alloxan rats. }\end{array}$ & \\
\hline $\begin{array}{l}\text { Bryophyllum } \\
\text { pinnatum } \\
\text { (Air Plant) } \\
\text { Crassulaceae }\end{array}$ & leaf & $\begin{array}{l}\text { Bryophillin A } \\
\text { Bersaldegenin- } \\
\text { 3-acetate } \\
\text { Bryophillin C } \\
\text { Alkaloids } \\
\text { Triterpenes } \\
\text { Glycosides } \\
\text { Flavonoids } \\
\text { Steroids } \\
\text { Butadienolides } \\
\text { Lipids } \\
\text { Organic acids. }\end{array}$ & $\begin{array}{l}\text { Aqueous } \\
\text { Ethanol }\end{array}$ & $\begin{array}{l}\text { Anthelmentic } \\
\text { Hepatoprotectiv } \\
\text { Anti-inflammatory } \\
\text { Antidiabetic } \\
\text { Diuretic } \\
\text { Antioxidant } \\
\text { Antimicrobial } \\
\text { Analgesic } \\
\text { Antipyretic }\end{array}$ & $\begin{array}{l}200 \mathrm{mg} / \mathrm{kg} \text { aqueous } \\
\text { extract resulted in a } \\
\text { significant drop in } \\
\text { blood sugar level. }\end{array}$ & $\begin{array}{l}\text { Aransiola et } \\
\text { al., } 2014 .\end{array}$ \\
\hline $\begin{array}{l}\text { Cajanus cajan } \\
\text { (pigeon pea/ } \\
\text { arhar) } \\
\text { Papilionaceae/ } \\
\text { Leguminosae }\end{array}$ & $\begin{array}{l}\text { Leaf } \\
\text { Stem } \\
\text { Twig }\end{array}$ & $\begin{array}{l}\text { Flavonoids } \\
\beta \text {-Carotenoids } \\
\text { Glycoside } \\
\text { Resin } \\
\text { Terpenoids } \\
\text { Tannins }\end{array}$ & $\begin{array}{l}\text { Methanol } \\
\text { Ethanol } \\
\text { Aqueous }\end{array}$ & $\begin{array}{l}\text { Antidiabetic } \\
\text { Hepatoprotective } \\
\text { Anti-viral } \\
\text { Anti-bacterial } \\
\text { Nuroprotective } \\
\text { Antioxident } \\
\text { Anticancer }\end{array}$ & $\begin{array}{l}\text { Single doses of } \\
\text { unroasted seeds to } \\
\text { normal as well as } \\
\text { alloxanized mice } \\
\text { shows significant } \\
\text { reduction in the serum } \\
\text { glucose levels }\end{array}$ & $\begin{array}{l}\text { Ezike } \text { et al., } \\
2010\end{array}$ \\
\hline $\begin{array}{l}\text { Camellia } \\
\text { sininsis (Green } \\
\text { tea) } \\
\text { Theaceae }\end{array}$ & $\begin{array}{l}\text { Leaf } \\
\text { Flower }\end{array}$ & $\begin{array}{l}\text { Epigallocatechin- } \\
\text { gallate } \\
\text { Epicatechin- } \\
\text { gallate } \\
\text { Epicatechin } \\
\text { Catechin } \\
\text { Epigallocatechin } \\
\text { Gallic acid }\end{array}$ & Aqueous & $\begin{array}{l}\text { Anti-aging } \\
\text { Anticancer } \\
\text { Cardioprotective } \\
\text { Antidiabetic }\end{array}$ & $\begin{array}{l}75,150 \text { and } 300 \\
\text { mg/kg body weight } \\
\text { caused a } \\
\text { significant } \\
\text { decrease in blood } \\
\text { glucose levels of } \\
\text { alloxan-induced } \\
\text { diabetic mice. }\end{array}$ & $\begin{array}{l}\text { Han et al., } \\
2011 .\end{array}$ \\
\hline $\begin{array}{l}\text { Colocasia } \\
\text { esculenta } \\
\text { (Arbi) } \\
\text { Araceae }\end{array}$ & leaf & $\begin{array}{l}\text { Cynoglucosides } \\
\text { Flavonoids } \\
\beta \text {-sitosterol } \\
\text { Steroid }\end{array}$ & Ethanol & $\begin{array}{l}\text { Analgesic } \\
\text { Anti- } \\
\text { iinflammatory } \\
\text { Anticancer } \\
\text { Hypolipidemic }\end{array}$ & $\begin{array}{l}\text { Ethanolic extract of } \\
\text { leaves at dose } 450 \\
\mathrm{mg} / \mathrm{kg} \text { showed } \\
\text { significant reduction of } \\
\text { blood glucose levels in } \\
\text { alloxan induced } \\
\text { diabetic rats. }\end{array}$ & $\begin{array}{l}\text { Kumawat et } \\
\text { al., } 2010 .\end{array}$ \\
\hline $\begin{array}{l}\text { Cucumis } \\
\text { trigonus } \\
\text { (Vishala) } \\
\text { Cucurbitaceae }\end{array}$ & fruit & $\begin{array}{l}\text { Emeclocycline } \\
\text { glycodeoxych } \\
\text { olic acid, } \\
3 \alpha, 7 \alpha, 12 \alpha- \\
\text { Trihydroxycop } \\
\text { rostanic acid } \\
\text { Chlortetracycli } \\
\text { ne } \\
\text { Azafrin } \\
\text { Methyl Ester }\end{array}$ & $\begin{array}{l}\text { Ethanol } \\
\text { Aqueous }\end{array}$ & $\begin{array}{l}\text { Antibacterial } \\
\text { Analgesic } \\
\text { Anti- } \\
\text { inflammatory } \\
\text { Diuretic } \\
\text { Antidiabetic } \\
\text { Hepatoprotective }\end{array}$ & $\begin{array}{l}\text { Oral admistration } \\
\text { of aqueous extract } \\
\text { to normal and } \\
\text { streptozotocin } \\
\text { induced diabetic } \\
\text { rats at dose of } \\
500 \mathrm{mg} / \mathrm{kg} \text { shows } \\
\text { reduction in blood } \\
\text { glucose level. }\end{array}$ & $\begin{array}{l}\text { Salahuddin et } \\
\text { al., } 2010 \text {. }\end{array}$ \\
\hline
\end{tabular}




\begin{tabular}{|c|c|c|c|c|c|c|}
\hline & & $\begin{array}{l}\text { Giganteumgen } \\
\text { in N, phorbol } \\
\text { 12,13- } \\
\text { Dihexanoate } \\
\text { Astaxanthin } \\
\text { Tetrahydro } \\
\text { spirillo xanthin }\end{array}$ & & & & \\
\hline $\begin{array}{l}\text { Cynodon } \\
\text { datylon } \\
\text { (Doob) } \\
\text { Poaceae }\end{array}$ & Leaf & $\begin{array}{l}\text { Alkaloids } \\
\text { Tannins } \\
\text { Saponins } \\
\text { Carbohydrates } \\
\text { Glycosides } \\
\text { Steroids } \\
\text { Terpenoids }\end{array}$ & Aqueous & $\begin{array}{l}\text { Hypoglycemic } \\
\text { Hypolipidimic } \\
\text { Woundhealing } \\
\text { Antibacterial } \\
\text { Antiviral } \\
\text { Anti-inflammatory }\end{array}$ & $\begin{array}{l}\text { Aqueous extract of } \\
\text { leaves at dose } 500 \\
\mathrm{mg} / \mathrm{kg} \text { body weight } \\
\text { significantly reduced } \\
\text { blood glucose level. }\end{array}$ & $\begin{array}{l}\text { Singhet al., } \\
2007 ; \\
\text { Vijayan et } \\
\text { al., } 2014 .\end{array}$ \\
\hline $\begin{array}{l}\text { Emblica } \\
\text { officinalis/ } \\
\text { Phyllanthus } \\
\text { Emblica } \\
\text { (Amla) } \\
\text { Euphorbiaceae }\end{array}$ & $\begin{array}{l}\text { Fruit } \\
\text { Leaf } \\
\text { Seed }\end{array}$ & $\begin{array}{l}\text { Tannins } \\
\text { Alkaloids } \\
\text { Phenolics } \\
\text { Flavonoids }\end{array}$ & $\begin{array}{l}\text { Aqueous } \\
\text { Ethanol } \\
\text { Butanol }\end{array}$ & $\begin{array}{l}\text { Antioxidant } \\
\text { Immunomodulatory } \\
\text { Hepatoprotective } \\
\text { Antimicrobial } \\
\text { Anti-inflammatory } \\
\text { Radioprotective } \\
\text { Antitumor } \\
\text { Antimutagenic }\end{array}$ & $\begin{array}{l}\text { Oral administration } \\
100 \mathrm{mg} / \mathrm{kg} \text { body } \\
\text { weight reduced the } \\
\text { blood sugar level in } \\
\text { normal and in alloxan } \\
\text { induced diabetic rats. }\end{array}$ & $\begin{array}{l}\text { Jain and } \\
\text { Khurdiya, } \\
\text { 2004; } \\
\text { Suryanarayan } \\
\text { et al., 2007; } \\
\text { Khan, 2009; } \\
\text { Tirgar } \text { et al., } \\
2011 \text {. }\end{array}$ \\
\hline $\begin{array}{l}\text { Foenum } \\
\text { graceum } \\
\text { (Methi) } \\
\text { Fabaceae }\end{array}$ & $\begin{array}{l}\text { Seed } \\
\text { Leaf }\end{array}$ & $\begin{array}{l}\text { Flavonoids } \\
\text { Saponins } \\
\text { Alkaloids } \\
\text { Trigonelline } \\
\text { Choline. }\end{array}$ & $\begin{array}{l}\text { Petroleu } \\
\mathrm{m} \text { ether } \\
\text { Chlorofor } \\
\mathrm{m} \\
\text { Ethyl } \\
\text { acetate } \\
\text { Methanol } \\
\text { Ethanol }\end{array}$ & $\begin{array}{l}\text { Hypoglycemic } \\
\text { Hypocholestrolemic } \\
\text { Immunomodulatory } \\
\text { Antiulcerative } \\
\text { Antibacterial } \\
\text { Antihypertensive } \\
\text { Anticarcinogenic } \\
\text { Antioxidant } \\
\text { Diuretic. }\end{array}$ & $\begin{array}{l}\text { Oral admistration of } \\
\text { ethanol extract of seed } \\
\text { at } 2 \mathrm{~g} / \mathrm{kg}, 1 \mathrm{~g} / \mathrm{kg}, 0.5 \\
\mathrm{~g} / \mathrm{kg} \text { and } 0.1 \mathrm{~g} / \mathrm{kg} \text { dose, } \\
\text { in diabetic rats. }\end{array}$ & $\begin{array}{l}\text { Sarasa et al., } \\
2012 .\end{array}$ \\
\hline $\begin{array}{l}\text { Hypoxis } \\
\text { hemerocallidea } \\
\text { (yellow } \\
\text { stars) } \\
\text { Hypoxidaceae }\end{array}$ & Corm & $\begin{array}{l}\beta \text {-Sitosterol } \\
\text { Ergosterol } \\
\text { Stigmasterol }\end{array}$ & Aqueous & $\begin{array}{l}\text { Anti-inflammatory } \\
\text { Antidiabetic } \\
\text { Antioxidant }\end{array}$ & $\begin{array}{l}\text { Aqueous extract } \\
50-800 \mathrm{mg} / \mathrm{kg} \\
\text { produced dose- } \\
\text { dependent, } \\
\text { hypoglycaemia in } \\
\text { normal and } \\
\text { streptozotocin } \\
\text { induced diabetic } \\
\text { rats. }\end{array}$ & $\begin{array}{l}\text { Ojewole, } \\
2006 .\end{array}$ \\
\hline $\begin{array}{l}\text { Ipomoea } \\
\text { reniformis } \\
\text { (musakani) } \\
\text { Convolvulus }\end{array}$ & $\begin{array}{l}\text { Stem } \\
\text { Leaf }\end{array}$ & $\begin{array}{l}\text { Caffeic } \\
\text { P-Coumaric } \\
\text { Ferulic } \\
\text { Sinapic acids } \\
\text { Phthalate } \\
\text { Resins } \\
\text { Glycosides } \\
\text { Tannins }\end{array}$ & $\begin{array}{l}\text { Ethanol } \\
\text { Aqueous }\end{array}$ & $\begin{array}{l}\text { Antihyperglycemic } \\
\text { Antihyperlipidaemic } \\
\text { Diuretic } \\
\text { Laxative } \\
\text { Anti-Inflammatory } \\
\text { Antipyretic }\end{array}$ & $\begin{array}{l}\text { Ethanol extract of } \\
\text { leaves at }(400 \mathrm{mg} / \mathrm{kg}) \\
\text { dose in alloxan } \\
\text { induced diabetic rats } \\
\text { showed significant } \\
\text { reduction in blood } \\
\text { glucose level. }\end{array}$ & $\begin{array}{l}\text { Bothara and } \\
\text { Vaidya, } \\
2016 .\end{array}$ \\
\hline
\end{tabular}




\begin{tabular}{|c|c|c|c|c|c|c|}
\hline $\begin{array}{l}\text { Juglans regia } \\
\text { (walnut) } \\
\text { Juglandaceae }\end{array}$ & Leaf & $\begin{array}{l}\text { Linoleic acid } \\
\text { Oleic acid } \\
\text { Linolenic acid } \\
\text { Palmitic acids }\end{array}$ & Alchohol & $\begin{array}{l}\text { Antioxidant } \\
\text { Antibacterial } \\
\text { Antidiabetic }\end{array}$ & $\begin{array}{l}\text { Alchoholic leaf extract } \\
\text { at dose } 200 \text { and } 400 \\
\mathrm{mg} / \mathrm{kg} \text { body weight to } \\
\text { streptozotocin induced } \\
\text { male wistar rat showed } \\
\text { significant reduction in } \\
\text { blood glucose level. }\end{array}$ & $\begin{array}{l}\text { Mohammadi } \\
\text { et al., } 2011 .\end{array}$ \\
\hline $\begin{array}{l}\text { Lantana } \\
\text { aculeate } \\
\text { (Red sage) } \\
\text { Verbenaceae }\end{array}$ & Roots & Oleanolic acid & Ethanol & $\begin{array}{l}\text { Anticancer } \\
\text { Antiulcer } \\
\text { Anti-hyperglycemic } \\
\text { Termiticidal }\end{array}$ & $\begin{array}{l}\text { Ethanolic extract at } \\
\text { the doses of } 25,50 \\
\text { and } 100 \mathrm{mg} / \mathrm{kg} \text { to } \\
\text { diabetic rats, } \\
\text { significantly } \\
\text { reduced the level } \\
\text { of glucose, total } \\
\text { cholesterol and } \\
\text { triglycerides. }\end{array}$ & $\begin{array}{l}\text { Kumar et al., } \\
2010\end{array}$ \\
\hline $\begin{array}{l}\text { Phyllanthus } \\
\text { neruri } \\
\text { (Jangli amla) } \\
\text { Euphorbiaceae }\end{array}$ & $\begin{array}{l}\text { Root } \\
\text { Stem } \\
\text { Leaf }\end{array}$ & $\begin{array}{l}\text { Flavonoids } \\
\text { Alkaloids } \\
\text { Terpenoids } \\
\text { Lignin } \\
\text { Polyphenols } \\
\text { Tannins } \\
\text { Coumarins } \\
\text { Saponins }\end{array}$ & $\begin{array}{l}\text { Acetone } \\
\text { Aqueous }\end{array}$ & $\begin{array}{l}\text { Anti-inflammatory } \\
\text { Antidiabetic } \\
\text { Antimicrobial } \\
\text { Antihyperlipidaemic } \\
\text { Antioxidant } \\
\text { Anticancer } \\
\text { Hepatoprotective } \\
\text { Antiviral } \\
\text { Diuretic }\end{array}$ & $\begin{array}{l}\text { Oral Administration at } \\
\text { dose } 471.2 \mathrm{mg} / \mathrm{kg} \text { body } \\
\text { weight caused a } \\
\text { significant dose-related } \\
\text { reduction in blood } \\
\text { glucose levels in } \\
\text { diabetic and } \\
\text { normoglycaemic rats. }\end{array}$ & $\begin{array}{l}\text { Okoli et al., } \\
2010 .\end{array}$ \\
\hline $\begin{array}{l}\text { Zizyphus } \\
\text { mauritiana } \\
\text { (Ber) }\end{array}$ & Seed & $\begin{array}{l}\text { Alkaloids } \\
\text { Flavonoids } \\
\text { Glycosides } \\
\text { Saponins } \\
\text { Sterols } \\
\text { Tannins } \\
\text { Lignin } \\
\text { Phenols }\end{array}$ & $\begin{array}{l}\text { Petroleu } \\
\text { m ether } \\
\text { Aqueous }\end{array}$ & $\begin{array}{l}\text { Haemolytic } \\
\text { Sedative } \\
\text { Alkaloids } \\
\text { Antimicrobial } \\
\text { Hypoglycemic } \\
\text { Antiplasmodial } \\
\text { Antidiabetic } \\
\text { Diuretic } \\
\text { Analgesic } \\
\text { Anti- } \\
\text { inflammatory }\end{array}$ & $\begin{array}{l}\text { Aqueous extracts } \\
\text { of seeds at dose } \\
\text { levels, } 200 \text { and } \\
400 \mathrm{mg} / \mathrm{kg} \text {, showed } \\
\text { hypoglycaemic } \\
\text { effect in allaxon } \\
\text { induced diabetic } \\
\text { mice. }\end{array}$ & $\begin{array}{l}\text { Bhatia and } \\
\text { Mishra, } \\
2010 .\end{array}$ \\
\hline \multicolumn{7}{|c|}{ Plants which stimulates the $\beta$-cells in the pancreas to release more insulin } \\
\hline $\begin{array}{l}\text { Acacia arabica } \\
\text { (Babul) } \\
\text { Fabaceae }\end{array}$ & $\begin{array}{l}\text { Leaf } \\
\text { Seed } \\
\text { Pod } \\
\text { Bark } \\
\text { Gum }\end{array}$ & $\begin{array}{l}\text { Flavonoids } \\
\text { Gallic acid } \\
\text { Isoquercitin } \\
\text { Leucocyanadin } \\
\text { Glucopyranoside } \\
\text { Rutin } \\
\text { Glucopyranoside }\end{array}$ & $\begin{array}{l}\text { Methanol } \\
\text { Ethanol } \\
\text { Aqueous }\end{array}$ & $\begin{array}{l}\text { Antidiarrhoeal } \\
\text { Antidiabetic } \\
\text { Antifungal } \\
\text { Antiviral } \\
\text { Antimutagenic } \\
\text { Antifertility } \\
\text { Antibacterial }\end{array}$ & $\begin{array}{l}\text { About } 94 \% \text { seed diet } \\
\text { showed hypoglycemic } \\
\text { effect in rats. }\end{array}$ & $\begin{array}{l}\text { Singh et al., } \\
\text { 2009; Singh., } \\
2011\end{array}$ \\
\hline $\begin{array}{l}\text { Agrimony } \\
\text { eupatorium } \\
\text { (Agrimony) } \\
\text { Rosaceae }\end{array}$ & $\begin{array}{l}\text { Leaf } \\
\text { Stem }\end{array}$ & $\begin{array}{l}\text { Catechin } \\
\text { Palmitic-acid } \\
\text { Quercitrin } \\
\text { Silicic-acid } \\
\text { Tannin }\end{array}$ & Aqueous & $\begin{array}{l}\text { Anticancer } \\
\text { Astringent } \\
\text { Diuretic } \\
\text { Antidiabetic } \\
\text { Antioxidant }\end{array}$ & $\begin{array}{l}\text { Agrimony } \\
\text { incorporated into } \\
\text { the diet }(62.5 \mathrm{~g} / \mathrm{kg}) \\
\text { showed the anit- } \\
\text { hyperglycemic }\end{array}$ & $\begin{array}{l}\text { Gray and } \\
\text { Flatt, } 1998 .\end{array}$ \\
\hline
\end{tabular}




\begin{tabular}{|c|c|c|c|c|c|c|}
\hline & & $\begin{array}{l}\text { Thiamin } \\
\text { Ursolic-acid }\end{array}$ & & & $\begin{array}{l}\text { effect on } \\
\text { streptozotocin } \\
\text { induced diabetic } \\
\text { mice. }\end{array}$ & \\
\hline $\begin{array}{l}\begin{array}{l}\text { Alangium } \\
\text { salvifolium } \\
\text { (Ankola) }\end{array} \\
\text { Alangiacea }\end{array}$ & $\begin{array}{l}\text { Leaf } \\
\text { Seed } \\
\text { Bark }\end{array}$ & $\begin{array}{l}\text { Tannins } \\
\text { Flavonoids } \\
\text { Glycoside } \\
\text { Alkaloids } \\
\text { Gum } \\
\text { Mucilage }\end{array}$ & Methanol & $\begin{array}{l}\text { Antipyretic } \\
\text { Laxative } \\
\text { Astringent } \\
\text { Antirheumatic } \\
\text { Analgesic } \\
\text { Antidiarrheal } \\
\text { Antifungal } \\
\text { Hepatoprotective } \\
\text { Antidiabetic }\end{array}$ & $\begin{array}{l}\text { Methanolic extract at } \\
\text { dose } 500 \mathrm{mg} / \mathrm{kg} \text { in } \\
\text { normal rats showed } \\
\text { hyperglycaemic effect. }\end{array}$ & $\begin{array}{l}\text { Mishra and } \\
\text { Gary, } 2011\end{array}$ \\
\hline $\begin{array}{l}\text { Allium sativum } \\
\text { (Garlic) } \\
\text { Alliaceae/ } \\
\text { Liliaceae }\end{array}$ & $\begin{array}{l}\text { Clove } \\
\text { Leaf } \\
\text { Root }\end{array}$ & $\begin{array}{l}\text { Alliin } \\
\text { (diallyldisulfide } \\
\text { oxide) } \\
\text { Allicin } \\
\text { APDS (allyl } \\
\text { propyl disulfide) } \\
\text { S-allyl cysteine } \\
\text { S-allyl } \\
\text { mercaptocysteine }\end{array}$ & $\begin{array}{l}\text { Aqueous } \\
\text { Methanol }\end{array}$ & $\begin{array}{l}\text { Lipid-Lowering } \\
\text { Hypotensive } \\
\text { Anticancer } \\
\text { Antioxidant } \\
\text { Antimicrobial }\end{array}$ & $\begin{array}{l}\text { Oral dose of } 0.25 \\
\mathrm{mg} / \mathrm{kg} \text { of ethanol, } \\
\text { petroleum ether and } \\
\text { ethyl acetate extract in } \\
\text { alloxanized rabbits, } \\
\text { shows } \\
\text { Antihyperglycemic } \\
\text { activity. }\end{array}$ & $\begin{array}{l}\text { Eidia } \text { et al., } \\
2006 ; \\
\text { Younas and } \\
\text { Hussain, } \\
2014 .\end{array}$ \\
\hline $\begin{array}{l}\text { Aloe vera } \\
\text { (Aloe) }\end{array}$ & Leaf & $\begin{array}{l}\text { Pentosides- } \\
\text { Barbaloin } \\
\text { Isobarbaloin } \\
\text { Aloin } \\
\text { Betabarbaloin } \\
\text { Anthraquinones } \\
\text { Saponins } \\
\text { Lignin } \\
\text { Salicylic acid }\end{array}$ & Aqueous & $\begin{array}{l}\text { Cardioprotective } \\
\text { Antitumor } \\
\text { Antioxidant } \\
\text { Anti-inflammatory } \\
\text { Hepatoprotective } \\
\text { Immunomodulatory } \\
\text { Antifungal }\end{array}$ & $\begin{array}{l}\text { Aloe vera extract was } \\
\text { orally administered at } \\
0.5 \mathrm{ml} / 100 \mathrm{gm} \text { body } \\
\text { weight showed anti } \\
\text { hyperglycemic effect. }\end{array}$ & $\begin{array}{l}\text { Chauhan. et } \\
\text { al., 2010; } \\
\text { Singh et al., } \\
\text { 2010; Saghir } \\
\text { et al.,2011 }\end{array}$ \\
\hline $\begin{array}{l}\text { Aralia } \\
\text { cachemirica } \\
\text { (Aralia) } \\
\text { Araliaceae }\end{array}$ & Root & $\begin{array}{l}\text { Essential oils } \\
\alpha \text {-Thujene } \\
\alpha \text {-Pinene } \\
\text { Camphene } \\
\text { Sabinene } \\
\text { B-Pinene } \\
\text { Myrcene } \\
\alpha \text {-Phellandrene } \\
\alpha \text {-Terpinene } \\
\text { Limonene } \\
\text { Cineole } \\
\text { Ocimene } \\
\text { Linalool } \\
\text { Campholenal } \\
\text { Camphor } \\
\text { Borneol } \\
\text { Terpinen-4-ol } \\
\text { (Z)-Piperitol }\end{array}$ & $\begin{array}{l}\text { Aqueous } \\
\text { Alchhol }\end{array}$ & $\begin{array}{l}\text { Anti gastritis } \\
\text { Anti rheumatic } \\
\text { Anti arthritic } \\
\text { Anti-inflammatory } \\
\text { Anti diabetic }\end{array}$ & $\begin{array}{l}\text { The aqueous and } \\
\text { alcoholic extracts at a } \\
\text { dose of } 250 \mathrm{mg} / \mathrm{kg} \\
\text { showed significant } \\
\text { hypoglycaemic activity } \\
\text { in normal fasted and } \\
\text { glucose induced } \\
\text { hyperglycaemic rats. }\end{array}$ & $\begin{array}{l}\text { Bhat } \text { et al., } \\
\text { 2005: } \\
\text { Verma et al., } \\
2010 .\end{array}$ \\
\hline
\end{tabular}




\begin{tabular}{|c|c|c|c|c|c|c|}
\hline $\begin{array}{l}\text { Asparagus } \\
\text { racemosus } \\
\text { (Satavari) } \\
\text { Liliaceae }\end{array}$ & $\begin{array}{l}\text { Root } \\
\text { Flower } \\
\text { Fruit } \\
\text { Leaf }\end{array}$ & $\begin{array}{l}\text { Alkaloid } \\
\text { Asparagamine } \\
\text { Spirostanosides } \\
\text { Sparagine } \\
\text { Flavonoids } \\
\text { Resin } \\
\text { Tannin }\end{array}$ & $\begin{array}{l}\text { Aqueous } \\
\text { Ethanol } \\
\text { Alcohol } \\
\text { Chlorofor } \\
\mathrm{m} / \\
\text { Methanol } \\
(1: 1)\end{array}$ & $\begin{array}{l}\text { Hepatoprotective } \\
\text { Immunomodulatory } \\
\text { Hypoglycemic } \\
\text { Diuretic }\end{array}$ & $\begin{array}{l}\text { Daily administration to } \\
\text { type } 2 \text { diabetic rats for } \\
28 \text { day, decreased } \\
\text { serum glucose. }\end{array}$ & $\begin{array}{l}\text { Shao, et al., } \\
1997 .\end{array}$ \\
\hline $\begin{array}{l}\text { Atriplex } \\
\text { halimus L. } \\
\text { (Sea orache } \\
\text { /Shrubby } \\
\text { orache) } \\
\text { Chenopodiac } \\
\text { eae }\end{array}$ & Leaf & $\begin{array}{l}\text { Tannins } \\
\text { Flavonoids } \\
\text { Saponins } \\
\text { Alkaloids } \\
\text { Resins }\end{array}$ & $\begin{array}{l}\text { Aqueous } \\
\text { Methanol }\end{array}$ & $\begin{array}{l}\text { Antioxidants } \\
\text { Hypoglycemic } \\
\text { Hypolipidemic }\end{array}$ & $\begin{array}{l}\text { Aqueous extract at } \\
\text { dosage of } 20 \mathrm{mg} / \mathrm{kg} \\
\text { weight to } \\
\text { streptozotocin induced } \\
\text { diabetic rats } \\
\text { significantly shows the } \\
\text { glucose lowering } \\
\text { effect. }\end{array}$ & $\begin{array}{l}\text { Chikhi et al., } \\
2014 .\end{array}$ \\
\hline $\begin{array}{l}\text { Bauhinia } \\
\text { variegate } \\
\text { (Orchid/ } \\
\text { Kachnar) } \\
\text { Fabaceae }\end{array}$ & $\begin{array}{l}\text { Leaf } \\
\text { Stem } \\
\text { Bark }\end{array}$ & $\begin{array}{l}\text { Lupeol } \\
\beta \text {-sitosterol } \\
\text { Tannins } \\
\text { Kaempferol-3- } \\
\text { glucoside } \\
\text { Amides } \\
\text { Rutin } \\
\text { Apigenin } \\
\text { Apigenin -7-O- } \\
\text { glucoside. }\end{array}$ & $\begin{array}{l}\text { Ethanol } \\
\text { Aqueous }\end{array}$ & $\begin{array}{l}\text { Antiophidian } \\
\text { Antidiabetic } \\
\text { Antimalarial } \\
\text { Antimicrobial } \\
\text { Antioxidant }\end{array}$ & $\begin{array}{l}200 \text { and } 400 \\
\mathrm{mg} / \mathrm{kg} \text { aqueous extract } \\
\text { of bark showed } \\
\text { significant } \\
\text { antihyperglycemic } \\
\text { activity in Allaxon } \\
\text { induced } \\
\text { hyperglycaemic rats. }\end{array}$ & $\begin{array}{l}\text { Kumer et al., } \\
2012 \text {; } \\
\text { Gunalan } \text { et } \\
\text { al., } 2012 \text {. }\end{array}$ \\
\hline $\begin{array}{l}\text { Biophytum } \\
\text { sensitivum } \\
\text { (Lajvanti) } \\
\text { Oxalidaceae }\end{array}$ & Leaf & $\begin{array}{l}\text { Amentoflavone } \\
\text { Cupressuflavone } \\
\text { Isoorientin } \\
\text { Flavonoids } \\
\text { Phenolics } \\
\text { Steroids }\end{array}$ & $\begin{array}{l}\text { Aqueous } \\
\text { Methanol }\end{array}$ & $\begin{array}{l}\text { Antibacterial } \\
\text { Antioxidant } \\
\text { Anti- } \\
\text { inflammatory } \\
\text { Antitumor } \\
\text { Radioprotective } \\
\text { Chemoprotective } \\
\text { Antimetastatic } \\
\text { Anti- } \\
\text { angiogenesis } \\
\text { Wound-Healing } \\
\text { Immunomodulat } \\
\text { ory } \\
\text { Anti-Diabetic } \\
\text { Cardioprotective }\end{array}$ & $\begin{array}{l}\text { Dose of } 200 \mathrm{mg} / \mathrm{kg} \\
\text { body weight was } \\
\text { optimum for } \\
\text { hypoglycemia. }\end{array}$ & $\begin{array}{l}\text { Puri et al., } \\
2001 .\end{array}$ \\
\hline $\begin{array}{l}\text { Catharanthus } \\
\text { roseus } \\
\text { or } \\
\text { Vinca rosea } \\
\text { (Barah masi) } \\
\text { Apocynaceae }\end{array}$ & $\begin{array}{l}\text { Root } \\
\text { Leaf } \\
\text { Stem } \\
\text { Flower }\end{array}$ & $\begin{array}{l}\text { Tannins } \\
\text { Triterpenes } \\
\text { Alkaloids } \\
\text { Flavonoids } \\
\text { Saponins }\end{array}$ & $\begin{array}{l}\text { Aqueous } \\
\text { Ethanol } \\
\text { Acetone } \\
\text { Methanol }\end{array}$ & $\begin{array}{l}\text { hypotensive } \\
\text { Antibacterial } \\
\text { Antifungal } \\
\text { Antiviral } \\
\text { Anticancer }\end{array}$ & $\begin{array}{l}\text { Dry leaf powder at } \\
\text { dose } 3 \mathrm{mg} / \mathrm{kg} \text { shows } \\
\text { significant antidiabetic } \\
\text { effect in streptozotocin } \\
\text { induced diabetic rats. }\end{array}$ & $\begin{array}{l}\text { EL-Sayed } \\
\text { and Cordell, } \\
\text { 1981; Nayak } \\
\text { and Lexley, } \\
\text { 2006; } \\
\text { Chauhan et } \\
\text { al., 2012. }\end{array}$ \\
\hline
\end{tabular}




\begin{tabular}{|c|c|c|c|c|c|c|}
\hline $\begin{array}{l}\text { Cinnamomum } \\
\text { tamala } \\
\text { (Tejpatra) } \\
\text { Lauraceae }\end{array}$ & $\begin{array}{l}\text { Leaf } \\
\text { Bark }\end{array}$ & $\begin{array}{l}\alpha \text {-pinene } \\
\text { Camphene } \\
\text { Myrcene } \\
\text { limonene } \\
\text { Eugenol } \\
\text { p-cymene } \\
\text { Methyl eugenol } \\
\text { acetate }\end{array}$ & Aqueous & $\begin{array}{l}\text { Antihyperglycemic } \\
\text { Antidiabetic } \\
\text { Antioxidant } \\
\text { Hypolipidemic } \\
\text { Astringent } \\
\text { Anti-inflammatory } \\
\text { Anti-arthritic }\end{array}$ & $\begin{array}{l}250 \mathrm{mg} / \mathrm{kg} \text { body weight } \\
\text { of aqueous leaf extract } \\
\text { shows blood glucose } \\
\text { lowring effects in } \\
\text { streptozotocin induced } \\
\text { diabetic rat. }\end{array}$ & $\begin{array}{l}\text { Gupta et al., } \\
2009 ; \\
\text { Chakrabarty } \\
\text { and Das, } \\
2010 .\end{array}$ \\
\hline $\begin{array}{l}\text { Citrullus } \\
\text { colocynthis } \\
\text { (Bitter apple/ } \\
\text { Bitter } \\
\text { cucumber) } \\
\text { Cucurbitaceae }\end{array}$ & Pulp & $\begin{array}{l}\text { Colocynthin } \\
\text { Colocynthein } \\
\text { (Resin) } \\
\text { Colocynthetin } \\
\text { Pectin } \\
\text { Gum }\end{array}$ & Ethanol & $\begin{array}{l}\text { Analgesic } \\
\text { Antibacterial } \\
\text { Anti- } \\
\text { inflammatory } \\
\text { Analgesic } \\
\text { Hair growth- } \\
\text { promoting } \\
\text { Abortifacient } \\
\text { Antiepileptic }\end{array}$ & $\begin{array}{l}\text { Oral admistration of } \\
\text { ethanolic extract of } \\
\text { pulp at doses } 300 \\
\text { mg/kg shows } \\
\text { insulinotropic action in } \\
\text { allaxon induced } \\
\text { diabetic rats. }\end{array}$ & $\begin{array}{l}\text { Dallak et al., } \\
2009 .\end{array}$ \\
\hline $\begin{array}{l}\text { Clausena } \\
\text { lansium } \\
\text { (Wampee) } \\
\text { Rutaceae }\end{array}$ & $\begin{array}{l}\text { Stem } \\
\text { Bark } \\
\text { Fruit }\end{array}$ & $\begin{array}{l}\beta \text {-santalol } \\
\text { Bisabolol } \\
\text { Methyl } \\
\text { santalol ledol } \\
\text { Sinensal } \\
\text { 9- } \\
\text { octadecenamid } \\
\text { e phellandrene } \\
\text { limonene } \\
\text { P-menth-1-en- } \\
\text { 4-ol. }\end{array}$ & Methanol & $\begin{array}{l}\text { Anti-trichomonal } \\
\text { Antidiabetic } \\
\text { Anti-Inflammatory } \\
\text { Hepatoprotective } \\
\text { Antioxidant }\end{array}$ & $\begin{array}{l}100 \mathrm{mg} / \mathrm{kg} \\
\text { Methanolic extract } \\
\text { induced maximum } \\
\text { and significant } \\
\text { anti- } \\
\text { hyperglycaemic } \\
\text { activity compared } \\
\text { to control. }\end{array}$ & $\begin{array}{l}\text { Adebajo et } \\
\text { al., } 2009 .\end{array}$ \\
\hline $\begin{array}{l}\begin{array}{l}\text { Coriandrum } \\
\text { sativum } \mathrm{L} \\
\text { (Coriander/ } \\
\text { Dhaniya) }\end{array} \\
\text { Umbelliferae }\end{array}$ & Seed & $\begin{array}{l}\text { Linalool } \\
\text { Coumarins } \\
\text { Flavonoids } \\
\text { Phenolic Acids } \\
\text { Polyacetylenes } \\
\text { Phthalides } \\
\text { Mucilage }\end{array}$ & Ethanol & $\begin{array}{l}\text { Antioxidant } \\
\text { Antilithogenic } \\
\text { Anti- } \\
\text { inflammatory } \\
\text { Antidiabetics }\end{array}$ & $\begin{array}{l}200 \text { and } 250 \mathrm{mg} / \mathrm{kg} \\
\text { ethanol extract } \\
\text { exhibited a significant } \\
\text { redction in serum } \\
\text { glucose level in } \\
\text { streptozotocin induced } \\
\text { diabetic rats. }\end{array}$ & $\begin{array}{l}\text { Chitra and } \\
\text { Leelamma, } \\
1999 .\end{array}$ \\
\hline $\begin{array}{l}\text { Coscinium } \\
\text { fenestratum } \\
\text { (Jhar haldi) } \\
\text { Menispermaceae. }\end{array}$ & $\begin{array}{l}\text { Whole } \\
\text { plant }\end{array}$ & $\begin{array}{l}\text { Alkaloids } \\
\text { Berberin }\end{array}$ & $\begin{array}{l}\text { Ethanol } \\
\text { Chloroform }\end{array}$ & $\begin{array}{l}\text { Anxiolytic } \\
\text { Antidepressant } \\
\text { Hypoglycemic } \\
\text { Hypotensive } \\
\text { Antidiabetic } \\
\text { Cardioprotective }\end{array}$ & $\begin{array}{l}\text { Ethanolic extract }(250 \\
-1,000 \mathrm{mg} / \mathrm{kg} \text { ) } \\
\text { significantly decreased } \\
\text { plasma glucose } \\
\text { concentrations in a } \\
\text { dose-dependent } \\
\text { manner. }\end{array}$ & $\begin{array}{l}\text { Sirintorn et } \\
\text { al., } 2009\end{array}$ \\
\hline $\begin{array}{l}\text { Ginkgo biloba } \\
\text { (Maiden hair } \\
\text { tree) } \\
\text { Gingoaceae }\end{array}$ & Leaf & Polyphenol & Aqueous & $\begin{array}{l}\text { Antioxidant } \\
\text { Antihyperglycem } \\
\text { ic } \\
\text { Antihyperlipidem } \\
\text { ia }\end{array}$ & $\begin{array}{l}\text { Leaves at dose of } 100 \\
\mathrm{mg} / \mathrm{kg} \text { gives a } \\
\text { significant reduction in } \\
\text { fasting blood sugar. }\end{array}$ & $\begin{array}{l}\text { Shankar et } \\
\text { al., } 2005 .\end{array}$ \\
\hline
\end{tabular}




\begin{tabular}{|c|c|c|c|c|c|c|}
\hline $\begin{array}{l}\text { Gmelina arborea } \\
\text { (Gamar/Gumhar } \\
\text { ) } \\
\text { Verbenaceae }\end{array}$ & $\begin{array}{l}\text { Leaf } \\
\text { Bark } \\
\text { Root }\end{array}$ & $\begin{array}{l}\text { Alkaloids } \\
\text { Flavonoids } \\
\text { Phenolics } \\
\text { Saponins } \\
\text { Steroid } \\
\text { Glycoside }\end{array}$ & $\begin{array}{l}\text { Methanol } \\
\text { Chloroform } \\
\text { Ethanol }\end{array}$ & $\begin{array}{l}\text { Antioxidant } \\
\text { Antimicrobial } \\
\text { Diuretic } \\
\text { Cardioprotective } \\
\text { Immunomodulatory } \\
\text { Antipyretic } \\
\text { Analgesic }\end{array}$ & $\begin{array}{l}\text { The highest depletion } \\
\text { in blood glucose } \\
\text { recorded in the } 400 \\
\mathrm{mg} / \mathrm{kg} \text { body weight } \\
\text { dosage in } \\
\text { streptozotocin induced } \\
\text { diabetic rats. }\end{array}$ & $\begin{array}{l}\text { Punitha et } \\
\text { al., } 2012 .\end{array}$ \\
\hline $\begin{array}{l}\text { Hibiscus rosa } \\
\text { sinensis } \\
\text { (China Rose) } \\
\text { Malvaceae }\end{array}$ & $\begin{array}{l}\text { Whole } \\
\text { Plant } \\
\text { Leaf } \\
\text { Flower }\end{array}$ & $\begin{array}{l}\text { Cyaniding } \\
\text { Quercetin } \\
\text { Hentriacontane }\end{array}$ & $\begin{array}{l}\text { Aques } \\
\text { Methanol }\end{array}$ & $\begin{array}{l}\text { Anticomplimentary } \\
\text { Antidiarrhetic } \\
\text { Antimicrobial } \\
\text { Antioxidant } \\
\text { antidiabetic }\end{array}$ & $\begin{array}{l}\text { Oral dose of } 100 \text { and } \\
200 \mathrm{mg} / \mathrm{kg} \text { body } \\
\text { weight to non obese } \\
\text { diabetic mice shows } \\
\text { significant reduction in } \\
\text { blood glucose level. }\end{array}$ & $\begin{array}{l}\text { Moqbel et } \\
\text { al., } 2011 .\end{array}$ \\
\hline $\begin{array}{l}\text { Momordica } \\
\text { charantia } \\
\text { (Karela/ Bitter } \\
\text { gourd) } \\
\text { Cucurbitaceae }\end{array}$ & $\begin{array}{l}\text { Fruit } \\
\text { Seed } \\
\text { Leaf } \\
\text { Root }\end{array}$ & $\begin{array}{l}\text { Charantin } \\
\text { Polypeptide } \\
\text { Polypeptide-p } \\
\text { Vicine } \\
\text { Momordicine }\end{array}$ & $\begin{array}{l}\text { Aqueous } \\
\text { Methanol }\end{array}$ & $\begin{array}{l}\text { Antidiabetic } \\
\text { Hypoglycaemic } \\
\text { Hepatoprotective } \\
\text { Anti Bacterial } \\
\text { Anti Viral } \\
\text { Anti tumor }\end{array}$ & $\begin{array}{l}\text { The treatment of } \\
\text { streptpzotocin } \\
\text { induced diabetic } \\
\text { rats with M. } \\
\text { charantia fruit } \\
\text { extract over a 10- } \\
\text { week period } \\
\text { returned the levels } \\
\text { of blood glucose } \\
\text { and lipid profile } \\
\text { close to normal. }\end{array}$ & $\begin{array}{l}\text { Ahmed et al., } \\
\text { 2001; Kumar } \\
\text { et al., } 2010 .\end{array}$ \\
\hline $\begin{array}{l}\text { Mucuna pruriens } \\
\text { (Atmagupta/ } \\
\text { Magic bean) } \\
\text { Leguminosae }\end{array}$ & $\begin{array}{l}\text { Seed } \\
\text { Leaf } \\
\text { Root } \\
\text { Stem }\end{array}$ & $\begin{array}{l}\text { L-DOPA } \\
\text { Tryptamine } \\
\text { Alkaloids } \\
\text { Tannins }\end{array}$ & $\begin{array}{l}\text { Hexane } \\
\text { Chloroform } \\
\text { Methanol } \\
\text { Ethanol }\end{array}$ & $\begin{array}{l}\text { Antibacterial } \\
\text { Antifungal } \\
\text { Hypotensive } \\
\text { Hypoglycemic } \\
\text { Antidiabetic } \\
\text { Antioxidant }\end{array}$ & $\begin{array}{l}100,200 \text { and } 400 \\
\mathrm{mg} / \mathrm{kg} \text { of the extract } \\
\text { Significantly reduced } \\
\text { the fasting blood sugar } \\
\text { levels in alloxan- } \\
\text { induced diabetic rats. }\end{array}$ & $\begin{array}{l}\text { Eze et al., } \\
2012 .\end{array}$ \\
\hline $\begin{array}{l}\text { Panax ginseng } \\
\text { (Korean } \\
\text { ginseng) } \\
\text { Araliacea }\end{array}$ & Fruits & $\begin{array}{l}\text { Steroidal } \\
\text { saponins }\end{array}$ & Ethanol & $\begin{array}{l}\text { Anticancer } \\
\text { Immunomodulat } \\
\text { ory } \\
\text { Antioxidant } \\
\text { Antifatigue } \\
\text { Antimicrobial }\end{array}$ & $\begin{array}{l}150 \mathrm{mg} / \mathrm{kg} \text { extract- } \\
\text { significantly } \\
\text { improved glucose } \\
\text { tolerance in treated } \\
\text { obese diabetic } \\
\text { mice. }\end{array}$ & $\begin{array}{l}\text { Attele } \text { et al., } \\
2002 .\end{array}$ \\
\hline $\begin{array}{l}\text { Quercus } \\
\text { Infectoria } \\
\text { (Oliver) } \\
\text { Fagaceae }\end{array}$ & $\begin{array}{l}\text { Leaf } \\
\text { Gall } \\
\text { Roots }\end{array}$ & $\begin{array}{l}\text { Tannins } \\
\text { Polyphenols } \\
\text { Gallic acids } \\
\text { Tannic acid } \\
\text { Tannins } \\
\text { Flavonoids }\end{array}$ & $\begin{array}{l}\text { Methanol } \\
\text { Ethanol } \\
\text { Hexane } \\
\text { Chloroform } \\
\text { Aqueous }\end{array}$ & $\begin{array}{l}\text { Antibacterial } \\
\text { Antifungal } \\
\text { Antidiabetic } \\
\text { Antiinflammatory } \\
\text { Anti tumor } \\
\text { Antioxidant }\end{array}$ & $\begin{array}{l}\text { Methanolic roots } \\
\text { extract at a dose of } 250 \\
\mathrm{mg} / \mathrm{kg} \text { and } 500 \mathrm{mg} / \mathrm{kg} \\
\text { body weight was } \\
\text { showed the anti- } \\
\text { diabetic activity in } \\
\text { Alloxan-induced } \\
\text { hyperglycaemic rats. }\end{array}$ & $\begin{array}{l}\text { Saini et al., } \\
2012 \text {. }\end{array}$ \\
\hline $\begin{array}{l}\text { Ricinus } \\
\text { communis } \\
\text { (Castor) } \\
\text { Euphorbiaceae) }\end{array}$ & Root & $\begin{array}{l}\text { Phenolic } \\
\text { Lectins } \\
\text { Ricin } \\
\text { Pyridine } \\
\text { Alkaloids } \\
\text { Ricinoleic Acid }\end{array}$ & Ethanol & $\begin{array}{l}\text { Antioxidant } \\
\text { Antitumor } \\
\text { Antinoceciptive } \\
\text { Anti- } \\
\text { Inflammatory } \\
\text { Analgesic }\end{array}$ & $\begin{array}{l}500 \mathrm{mg} / \mathrm{kg} \text { body } \\
\text { weight caused the } \\
\text { maximum lowering } \\
\text { of the fasting blood } \\
\text { glucose }\end{array}$ & $\begin{array}{l}\text { Shokeen et } \\
\text { al., } 2008 .\end{array}$ \\
\hline
\end{tabular}




\begin{tabular}{|c|c|c|c|c|c|c|}
\hline & & Tocopherols & & $\begin{array}{l}\text { Antipyretic } \\
\text { Cardiactonic }\end{array}$ & & \\
\hline $\begin{array}{l}\text { Smallanthus } \\
\text { sonchifolius } \\
\text { (Aricoma) } \\
\text { Asteraceae }\end{array}$ & leaf & $\begin{array}{l}\text { Phenolic } \\
\text { compounds }\end{array}$ & $\begin{array}{l}\text { Methanol } \\
\text { Butanol } \\
\text { Chlorofor } \\
\text { m }\end{array}$ & $\begin{array}{l}\text { Antioxidant } \\
\text { Antilipoperoxidat } \\
\text { ive } \\
\text { Hepatoprotective } \\
\text { Antiinflammator } \\
\text { y } \\
\text { Antidiabetic }\end{array}$ & $\begin{array}{l}\text { Methanol, butanol } \\
\text { and chloroform } \\
\text { extracts showed } \\
\text { effective } \\
\text { hypoglycemic } \\
\text { activity at } \\
\text { minimum doses of } \\
50,10 \text { and } \\
20 \mathrm{mg} / \mathrm{kg} \text { body } \\
\text { weight in } \\
\text { transiently } \\
\text { hyperglycemic and } \\
\text { streptozotocin } \\
\text { diabetic rats. }\end{array}$ & $\begin{array}{l}\text { Susana et al., } \\
2010 .\end{array}$ \\
\hline $\begin{array}{l}\text { Syzygium } \\
\text { jambolaum } \\
\text { or } \\
\text { Eugenia } \\
\text { jambolana } \\
\text { (Jamboon/ sweet } \\
\text { olive) } \\
\text { Myrtaceae }\end{array}$ & $\begin{array}{l}\text { Leaf } \\
\text { Seed } \\
\text { Root }\end{array}$ & $\begin{array}{l}\text { Anthocynins } \\
\text { Glucoside } \\
\text { Alkaloids } \\
\text { Jambosin } \\
\text { Flavonoids }\end{array}$ & $\begin{array}{l}\text { Ethanol } \\
\text { Methanol } \\
\text { Aqueous }\end{array}$ & $\begin{array}{l}\text { Anti septic } \\
\text { Antioxidant } \\
\text { Anti-inflammatory } \\
\text { Antibacterial } \\
\text { Antifungal } \\
\text { Radioprotective }\end{array}$ & $\begin{array}{l}\text { Ethanolic seed extract } \\
\text { at } 100 \mathrm{mg} / \mathrm{kg} \text { of body } \\
\text { weight significantly } \\
\text { decreased the levels of } \\
\text { blood glucose, blood } \\
\text { urea, and cholesterol in } \\
\text { streptozotocin induced } \\
\text { diabetic rats. }\end{array}$ & $\begin{array}{l}\text { Ravi et al., } \\
\text { 2004; } \\
\text { Srivastava et } \\
\text { al., 2012. }\end{array}$ \\
\hline $\begin{array}{l}\begin{array}{l}\text { Taraxacum } \\
\text { officinale } \\
\text { (Dandelion) }\end{array} \\
\text { Asteraceae }\end{array}$ & $\begin{array}{l}\text { Leaf } \\
\text { Root }\end{array}$ & $\begin{array}{l}\text { Phenylpropanoids } \\
\text { Triterpenoids } \\
\text { Sterols } \\
\text { Taraxasterol } \\
\text { Taraxerol } \\
\text { Cycloartenol } \\
\beta \text {-sitosterol }\end{array}$ & $\begin{array}{l}\text { Alcohol } \\
\text { Aqueous }\end{array}$ & $\begin{array}{l}\text { Hypoglycemic } \\
\text { Immuno-modulatory } \\
\text { Anti-inflammatory } \\
\text { Detoxification } \\
\text { Antiviral } \\
\text { Antitumor }\end{array}$ & $\begin{array}{l}\text { Aqueous and ethanolic } \\
\text { extract of leaves and } \\
\text { root at dose } 300 \text { and } \\
500 \mathrm{mg} / \mathrm{kg} \text { body weight } \\
\text { showed significant } \\
\text { antidiabetic effect in } \\
\text { alloxan induced } \\
\text { diabetic rats. }\end{array}$ & $\begin{array}{l}\text { Hussain et } \\
\text { al., 2004; } \\
\text { Nnamdi et } \\
\text { al., } 2012 .\end{array}$ \\
\hline \multicolumn{7}{|c|}{ Plants that shows inhibitory activity on glucose absorption in the small intestine. } \\
\hline $\begin{array}{l}\text { Actinidia } \\
\text { kolomikta } \\
\text { (kiwi) }\end{array}$ & $\begin{array}{l}\text { Root } \\
\text { Leaf }\end{array}$ & $\begin{array}{l}\text { Phenolics } \\
\text { Flavonoid }\end{array}$ & $\begin{array}{l}\text { Aqueous } \\
\text { Ethanol }\end{array}$ & $\begin{array}{l}\text { Hepatotoxicity } \\
\text { Hypoglycaemia } \\
\text { Antitumor } \\
\text { Antiproliferative } \\
\text { Immuno-modulatory } \\
\text { Anti-oxidant } \\
\text { Anti cancer }\end{array}$ & $\begin{array}{l}800 \mathrm{mg} / \mathrm{kg} \text { Aqueous } \\
\text { extracts of leaves } \\
\text { prevented the increase } \\
\text { in blood glucose level } \\
\text { without causing a } \\
\text { hypoglycemic state in } \\
\text { the oral glucose } \\
\text { tolerance test. }\end{array}$ & $\begin{array}{l}\text { Hu et al., } \\
\text { 2013; Yuan } \\
\text { et al., } 2014 .\end{array}$ \\
\hline $\begin{array}{l}\text { Psoralea } \\
\text { corylifolia } \\
\text { (Babchi) }\end{array}$ & Seed & $\begin{array}{l}\text { Flavanoids } \\
\text { Alkaloids } \\
\text { Phenols } \\
\text { Tannins }\end{array}$ & $\begin{array}{l}\text { Chloroform } \\
\text { Ethyal } \\
\text { acetate } \\
\text { Methanol }\end{array}$ & $\begin{array}{l}\text { Laxative } \\
\text { Aphrodisiac } \\
\text { Anthelminitic } \\
\text { Diuretic }\end{array}$ & $\begin{array}{l}\text { The dose of } \\
250 \mathrm{mg} / \mathrm{kg} \text { of body } \\
\text { weight was found }\end{array}$ & $\begin{array}{l}\text { Suhashini et } \\
\text { al., 2014; } \\
\text { Dhar } \text { et al., } \\
2013 \text {. }\end{array}$ \\
\hline
\end{tabular}




\begin{tabular}{|c|c|c|c|c|c|c|}
\hline Fabaceae & & Oils & & $\begin{array}{l}\text { Diaphoretic } \\
\text { Anti-inflammatory }\end{array}$ & $\begin{array}{l}\text { to be the most } \\
\text { effective in } \\
\text { lowering blood } \\
\text { glucose level of } \\
\text { normal, sub, mild } \\
\text { and severely } \\
\text { diabetic rats. }\end{array}$ & \\
\hline $\begin{array}{l}\text { Tamarindus } \\
\text { indica } \\
\text { (Imli) } \\
\text { Caesalpiniaceae }\end{array}$ & $\begin{array}{l}\text { Leaf } \\
\text { Bark Frui }\end{array}$ & $\begin{array}{l}\text { N-Hexacosane } \\
\text { tEicosanoic Acid } \\
\text { B-Sitosterol } \\
\text { Octacosanyl } \\
\text { Ferulate } \\
\text { Apigenin } \\
\text { Catechin } \\
\text { Procyanidin B2 } \\
\text { Taxifolin } \\
\text { Cardiac } \\
\text { Glycosides } \\
\text { Dihydroxyacetophen } \\
\text { one }\end{array}$ & $\begin{array}{l}\text { Acetone } \\
\text { Ethanol } \\
\text { Methanol }\end{array}$ & $\begin{array}{l}\text { Anti-microbial } \\
\text { Antioxidant } \\
\text { Laxative } \\
\text { Woundhealing } \\
\text { Hepatoprotective } \\
\text { Anti-inflammatory } \\
\text { Analgesic }\end{array}$ & $\begin{array}{l}\text { Aqueous methanolic } \\
\text { extract of leaf at the } \\
\text { dose } 200 \mathrm{mg} / \mathrm{kg} \text { body } \\
\text { weight showed blood } \\
\text { glucose lowring } \\
\text { activity in } \\
\text { streptozotocin induced } \\
\text { diabetic rats. }\end{array}$ & $\begin{array}{l}\text { Maiti et al., } \\
2005 \text {; } \\
\text { Ramchander } \\
\text { et al., 2012; } \\
\text { Anzana et } \\
\text { al., 2013. }\end{array}$ \\
\hline $\begin{array}{l}\text { Zea mays (Maize) } \\
\text { Gramineae }\end{array}$ & Corn silk & $\begin{array}{l}\text { Flavonoids } \\
\text { Alkaloids } \\
\text { Phenols } \\
\text { Steroids } \\
\text { Glycosides } \\
\text { Terpenoids } \\
\text { Tannins }\end{array}$ & $\begin{array}{l}\text { Benzene } \\
\text { Chloroform } \\
\text { Ethanol } \\
\text { Ethyl } \\
\text { Acetate } \\
\text { Methanol } \\
\text { Petroleum } \\
\text { ether }\end{array}$ & $\begin{array}{l}\text { Antioxidant } \\
\text { Diuretic } \\
\text { Antidepresent } \\
\text { Antifatigue } \\
\text { Anti-hyperlipidimic } \\
\text { Anti-inflammatory } \\
\text { Neuroprotective }\end{array}$ & $\begin{array}{l}\text { After orally } \\
\text { administration with } \\
\text { corn silk extract, the } \\
\text { blood glucose and } \\
\text { HbAIc were } \\
\text { significantly decreased } \\
\text { in alloxan induced } \\
\text { hyperglycaemic mice. }\end{array}$ & $\begin{array}{l}\text { Ranilla et al., } \\
2009 .\end{array}$ \\
\hline \multicolumn{7}{|c|}{ Improving insulin release in response to meals } \\
\hline $\begin{array}{l}\text { Aegle marmelos } \\
\text { (Bael) } \\
\text { Rutaceae }\end{array}$ & $\begin{array}{l}\text { Flower } \\
\text { Leaf } \\
\text { Fruit } \\
\text { Seed }\end{array}$ & $\begin{array}{l}\text { Ascorbic acid } \\
\text { Aegelin } \\
\text { Coumarins } \\
\text { Alkaloids } \\
\text { Aegeline } \\
\text { Skimmianine } \\
\text { Lupeol } \\
\text { Cineol } \\
\text { Citral } \\
\text { Citronella } \\
\text { Cuminaldehyde } \\
\text { Eugenol } \\
\text { Marmesinine } \\
\text { Fagarine } \\
\text { Marmin } \\
\text { Marmelosin } \\
\text { Luvangetin } \\
\text { Aurapten } \\
\text { Psoralen } \\
\text { Marmelide } \\
\text { Tannin }\end{array}$ & $\begin{array}{l}\text { Aqueous } \\
\text { Alcohol }\end{array}$ & $\begin{array}{l}\text { Anti-hyperglycemic } \\
\text { Hepato-protective } \\
\text { Analgesic } \\
\text { Antifertility } \\
\text { Anti Fungal } \\
\text { Hypolipidemic } \\
\text { Immunomodulatory } \\
\text { Anti-Inflammatory }\end{array}$ & $\begin{array}{l}\text { Oral admistration } \\
\text { of aqueous seeds } \\
\text { extract atdose of } \\
250 \mathrm{mg} / \mathrm{kg} \text { was } \\
\text { found to decreases } \\
\text { blood glucose level } \\
\text { in normal healthy } \\
\text { rats after } 6 \mathrm{~h} \text { of } \\
\text { administration. }\end{array}$ & $\begin{array}{l}\text { Sharma et } \\
\text { al., 2011; } \\
\text { Kesari et al., } \\
2006 .\end{array}$ \\
\hline
\end{tabular}




\begin{tabular}{|c|c|c|c|c|c|c|}
\hline $\begin{array}{l}\text { Alium cepa } \\
\text { (Onion) } \\
\text { Alliaceae/ } \\
\text { Liliaceae }\end{array}$ & $\begin{array}{l}\text { Root } \\
\text { Tuber }\end{array}$ & $\begin{array}{l}\text { Quercetin, } \\
\text { Cysteine } \\
\text { Allyl propyl } \\
\text { disulphide } \\
\text { Allyl propyl } \\
\text { disulfide (APDS) } \\
\text { S-methyl cysteine } \\
\text { sulphoxide Essential } \\
\text { oil }\end{array}$ & $\begin{array}{l}\text { Aqueous } \\
\text { Ethanol } \\
\text { Ether }\end{array}$ & $\begin{array}{l}\text { Hypocholesterola } \\
\text { emic } \\
\text { Fibrinolytic } \\
\text { Antioxidant } \\
\text { Anticancer } \\
\text { Antimutagenic } \\
\text { Hemostatic } \\
\text { Hypoglycaemic } \\
\text { Hypolipidaemic }\end{array}$ & $\begin{array}{l}\text { Hypoglycemic activity } \\
\text { was showed by the } \\
\text { ether soluble fraction } \\
\text { of onion }(0.25 \mathrm{mg} / \mathrm{kg}) \\
\text { in normal rabbits. }\end{array}$ & $\begin{array}{l}\text { Ozougwu et } \\
\text { al., } 2011\end{array}$ \\
\hline $\begin{array}{l}\text { Costus pictus } \\
\text { (Spiral ginger } \\
\text { /Insulin plant) } \\
\text { Zingiberaceae }\end{array}$ & leaf & $\begin{array}{l}\beta \text { - L- } \\
\text { Arabinopyranose } \\
\text { methyl glycoside }\end{array}$ & $\begin{array}{l}\text { Ethanol } \\
\text { Acetone } \\
\text { Aqueous } \\
\text { Ethyl } \\
\text { Acetate } \\
\text { Methanol }\end{array}$ & $\begin{array}{l}\text { Antidiabetic } \\
\text { Antimicrobial } \\
\text { Immunomodulatory }\end{array}$ & $\begin{array}{l}\text { Dosage of } 2 \mathrm{gm} / \mathrm{kg} \\
\text { body weight exhibited } \\
\text { a significant reduction } \\
\text { in fasting blood } \\
\text { glucose level and a } \\
\text { remarkable increase in } \\
\text { serum insulin level. }\end{array}$ & $\begin{array}{l}\text { Sindhu et al., } \\
\text { 2012; Jayasri } \\
\text { et al., } 2008 .\end{array}$ \\
\hline $\begin{array}{l}\text { Ficus religosa } \\
\text { (peepal) }\end{array}$ & $\begin{array}{l}\text { Leaf } \\
\text { Fruit } \\
\text { Bark }\end{array}$ & $\begin{array}{l}\text { Flavonoids } \\
\text { Sterols }\end{array}$ & Ethanol & $\begin{array}{l}\text { Antiulcer } \\
\text { Antibacterial } \\
\text { Antigonorrhe } \\
\text { Antibacterial } \\
\text { Antiprotozoal } \\
\text { Antiviral } \\
\text { Astringent } \\
\text { Antidiarrhoeal }\end{array}$ & $\begin{array}{l}\text { The ethanolic extract } \\
\text { of the fruit, at a dosage } \\
\text { of } 250 \mathrm{mg} / \mathrm{kg} \text { body } \\
\text { weight, showed } \\
\text { antidiabetic activity. }\end{array}$ & $\begin{array}{l}\text { Choudhary et } \\
\text { al., } 2011 .\end{array}$ \\
\hline $\begin{array}{l}\text { Mangifera indica } \\
\text { (Mango) }\end{array}$ & $\begin{array}{l}\text { Leaf } \\
\text { Stem bark }\end{array}$ & $\begin{array}{l}\text { Tannins } \\
\text { Saponins } \\
\text { Glycosides } \\
\text { Phenols }\end{array}$ & $\begin{array}{l}\text { Methanol } \\
\text { Hexane } \\
\text { Ethyl } \\
\text { acetate }\end{array}$ & $\begin{array}{l}\text { Antioxidant } \\
\text { Radioprotective } \\
\text { Immunomodulatory } \\
\text { Anti-allergic } \\
\text { Anti-inflammatory } \\
\text { Anti-tumor } \\
\text { Lipolytic } \\
\text { Antiviral } \\
\text { Antibacterial } \\
\text { Antifungal } \\
\text { Anti nociceptive }\end{array}$ & $\begin{array}{l}\text { Oral administration of } \\
\text { aqueous leaf extract } \\
1 \mathrm{~g} / \mathrm{kg} \text { in } \\
\text { streptozotocin-induced } \\
\text { diabetic rats reduced } \\
\text { blood glucose level }\end{array}$ & $\begin{array}{l}\text { Harbourne, } \\
\text { 1973; Baker } \\
\text { and } \\
\text { Thormsberg, } \\
\text { 1983; Sahm } \\
\text { and } \\
\text { Washington, } \\
\text { 1990; Grover } \\
\text { et al., 2002. }\end{array}$ \\
\hline $\begin{array}{l}\text { Nervilia plicata } \\
\text { (Lotus with singl، } \\
\text { leaf) } \\
\text { Orchidaceae }\end{array}$ & Stem & $\begin{array}{l}\text { Tannins } \\
\text { Gums } \\
\text { Flavonoids } \\
\text { Saponins } \\
\text { Essential oils. }\end{array}$ & Alcohol & $\begin{array}{l}\text { Antidiabetic } \\
\text { Antibacterial } \\
\text { Antifungal }\end{array}$ & $\begin{array}{l}\text { Administration of } \\
5 \mathrm{mg} / \mathrm{kg} \text { of plant } \\
\text { extract showed } \\
\text { decrease in the } \\
\text { blood glucose } \\
\text { levels. in type-II } \\
\text { diabetic rats }\end{array}$ & $\begin{array}{l}\text { Kumar et al., } \\
\text { 2011; }\end{array}$ \\
\hline $\begin{array}{l}\text { Phoenix } \\
\text { dactylifera (Date } \\
\text { Palm) } \\
\text { Arecaceae }\end{array}$ & leaf & $\begin{array}{l}\text { Tannins } \\
\text { Alkaloids } \\
\text { Trepenoids } \\
\text { Flavonoids }\end{array}$ & Aqueous & $\begin{array}{l}\text { Antidiabetic } \\
\text { Antibacterial } \\
\text { Antiinflamatory } \\
\text { Antiasthamatic } \\
\text { Nephroprotective } \\
\text { Hepatoprotective }\end{array}$ & $\begin{array}{l}\text { Sub-acute } \\
\text { administration of } \\
\text { leave's extract in } \\
\text { alloxan-induced } \\
\text { diabetic rats } \\
\text { significantly } \\
\text { reduced blood }\end{array}$ & $\begin{array}{l}\text { Seyyed et al., } \\
2010 .\end{array}$ \\
\hline
\end{tabular}




\begin{tabular}{|c|c|c|c|c|c|c|}
\hline & & & & & glucose & \\
\hline $\begin{array}{l}\text { Saliva } \\
\text { lavandulifolia } \\
\text { (Spanish Sage) } \\
\text { Lamiacea }\end{array}$ & Leaf & $\begin{array}{l}\text { Flavonoides } \\
\text { Terpenoids } \\
1,8 \text { - cineole } \\
\alpha \text { - pipene }\end{array}$ & Aqueous & $\begin{array}{l}\text { Spasmolytic } \\
\text { Antiseptic } \\
\text { Analgesic } \\
\text { Sedative } \\
\text { Antioxidant } \\
\text { Antidiabetic } \\
\text { Antiinflammator } \\
\text { y }\end{array}$ & $\begin{array}{l}\text { Daily } \\
\text { administration of } \\
250 \mathrm{mg} / \mathrm{kg} \text { of } \\
\text { infusion resulted in } \\
\text { a } 33 \% \text { decrease in } \\
\text { blood glucose } \\
\text { levels in alloxan- } \\
\text { diabetic rabbits. }\end{array}$ & $\begin{array}{l}\text { Jimenez et } \\
\text { al., } 1986 .\end{array}$ \\
\hline $\begin{array}{l}\text { Stevia rebaudiana } \\
\text { (Meethi tulsi) } \\
\text { Astraceae }\end{array}$ & Leaf & $\begin{array}{l}\text { Stevioside } \\
\text { Rebaudioside A-F } \\
\text { Dlucoside } \\
\text { Steviobioside } \\
\text { Flavonoids } \\
\text { Anthocyanins } \\
\text { Phenolics. }\end{array}$ & $\begin{array}{l}\text { Aqueous } \\
\text { Methanol } \\
\text { Petroleum } \\
\text { ether }\end{array}$ & $\begin{array}{l}\text { Antihyperglycemic } \\
\text { Hypotensive } \\
\text { Antioxidant } \\
\text { Anti-inflammatory } \\
\text { Antibacterial } \\
\text { Gastroprotective } \\
\text { Immuno-modulatory } \\
\text { Cardiovascular } \\
\text { Antihistamin }\end{array}$ & $\begin{array}{l}\text { Oral admistration of } \\
\text { stevioside } 0.5 \mathrm{mg} / \mathrm{kg} \\
\text { body weight, lowered } \\
\text { blood glucose level in } \\
\text { streptozotocin induced } \\
\text { diabetic rat. }\end{array}$ & $\begin{array}{l}\text { Gregersen et } \\
\text { al., } 2004 \text {. }\end{array}$ \\
\hline $\begin{array}{l}\text { Swertia chirata } \\
\text { (Chiratika/ } \\
\text { Kutki) } \\
\text { Gentianaceae }\end{array}$ & $\begin{array}{l}\text { Seed } \\
\text { Root }\end{array}$ & $\begin{array}{l}\text { Alkaloids } \\
\text { Flavonoids } \\
\text { Xanthones } \\
\text { Glycosides } \\
\text { Terpenoids }\end{array}$ & $\begin{array}{l}\text { Aqueous } \\
\text { Ethanol } \\
\text { Methanol }\end{array}$ & $\begin{array}{l}\text { Antipyretic } \\
\text { Anthelminitic } \\
\text { Analgesic } \\
\text { Hypoglycemic } \\
\text { Antifungal } \\
\text { Antibacterial } \\
\text { Anti-inflammatory } \\
\text { Hepato-protective } \\
\text { Cardio-protective }\end{array}$ & $\begin{array}{l}\text { Oral admistration of } \\
\text { the aqueous extract at } \\
\text { dose } 200 \mathrm{mg} / \mathrm{kg} \text { body } \\
\text { weight per day for } 21 \\
\text { days in glebinclamide } \\
\text { induced diabetic albino } \\
\text { rats showed significant } \\
\text { antidiabetic effect. }\end{array}$ & $\begin{array}{l}\text { Sobia et al., } \\
2012 ; \\
\text { Kavitha and } \\
\text { Dattatri, } \\
2013 \text {. }\end{array}$ \\
\hline $\begin{array}{l}\text { Vitellaria } \\
\text { paradoxa } \\
\text { (Shea tree) } \\
\text { Sapotaceae }\end{array}$ & Bark & $\begin{array}{l}\text { Phenolics } \\
\text { Palmetic acid } \\
\text { Stearic acid } \\
\text { Oleic acid } \\
\text { Linoleic acid } \\
\text { Arachidic acid }\end{array}$ & $\begin{array}{l}\text { Aqueous } \\
\text { Ethanolic } \\
\text { Hydro- } \\
\text { ethanol }\end{array}$ & $\begin{array}{l}\text { Antiulcer } \\
\text { Anti malarial } \\
\text { Neuralgia treatment } \\
\text { Antidiabetic } \\
\text { Antioxidant }\end{array}$ & $\begin{array}{l}\text { Hydro-ethanolic } \\
\text { extracts of the bark at a } \\
\text { dose of } 250 \mathrm{mg} / \mathrm{kg} \\
\text { body weight.induce } \\
\text { anti hyper-glycemic } \\
\text { activity in rabbits }\end{array}$ & $\begin{array}{l}\text { Coulibaly et } \\
\text { al., } 2014\end{array}$ \\
\hline $\begin{array}{l}\text { Zizyphus spina- } \\
\text { Christi } \\
\text { (Olive) } \\
\text { Rhamnaceae }\end{array}$ & Leaf & $\begin{array}{l}\text { Saponins } \\
\text { Glycoside } \\
\text { Christinin-A }\end{array}$ & Butanol & $\begin{array}{l}\text { Hepatoprotective } \\
\text { Anti-obesity } \\
\text { Antidiabetic } \\
\text { Antioxidant } \\
\text { Antimicrobial } \\
\text { Antidiarrheal }\end{array}$ & $\begin{array}{l}100 \mathrm{mg} / \mathrm{kg} \text { butanol } \\
\text { extract or } \\
\text { christinin-A } \\
\text { enhanced the } \\
\text { glucose lowering } \\
\text { and insulinotropic } \\
\text { effects in type-II } \\
\text { diabetic rats. }\end{array}$ & $\begin{array}{l}\text { Abdel-Zaher } \\
\text { et al., } 2005 .\end{array}$ \\
\hline
\end{tabular}




\begin{tabular}{|c|c|c|c|c|c|c|}
\hline $\begin{array}{l}\text { Zingiber } \\
\text { officinale } \\
\text { (Ginger) } \\
\text { Zinzibaraceae }\end{array}$ & $\begin{array}{l}\text { Rhizome } \\
\text { Root }\end{array}$ & Phenolic compounds & sAqueous & $\begin{array}{l}\text { Hypoglycemic } \\
\text { Cardiotonic } \\
\text { Antilipemic } \\
\text { Antioxidant } \\
\text { Antineoplastic } \\
\text { Antiviral } \\
\text { Antibacterial } \\
\text { Antifungal }\end{array}$ & $\begin{array}{l}\text { Oral admistration } \\
\text { of the juice ( } 4 \\
\mathrm{ml} / \mathrm{kg} \text { of body } \\
\text { weight/ day) for } 6 \\
\text { weeks on } \\
\text { streptozotocin } \\
\text { induced diabetic } \\
\text { rats significantly } \\
\text { reduced blood } \\
\text { glucose level. }\end{array}$ & $\begin{array}{l}\text { Khani et al., } \\
\text { 2004; Jafri et } \\
\text { al., } 2011 .\end{array}$ \\
\hline \multicolumn{7}{|c|}{ Preserve the function of the $\beta$-cells of the pancreas and Regenerate the damage $\beta$ cells. } \\
\hline $\begin{array}{l}\text { Aerva lanata } \\
\text { (Polpala) } \\
\text { Amaranthaceae }\end{array}$ & $\begin{array}{l}\text { Shoot } \\
\text { Leaf }\end{array}$ & $\begin{array}{l}\text { Alkaloids } \\
\text { Flavonoids } \\
\text { Tannin } \\
\text { Steroid } \\
\text { Saponins } \\
\text { Phenolic } \\
\text { compounds. }\end{array}$ & $\begin{array}{l}\text { Pet-ether } \\
\text { Methanol } \\
\text { Alcohol } \\
\text { Ethanol: } \\
\text { Water }(1: 1)\end{array}$ & $\begin{array}{l}\text { Anti-inflammatory } \\
\text { Diuretic } \\
\text { Hepato-protective } \\
\text { Nephroprotective } \\
\text { Antidiabetic } \\
\text { Antimicrobial } \\
\text { Antihyperlipidaemic } \\
\text { Antiparasitic, }\end{array}$ & $\begin{array}{l}\text { The alcoholic extract at } \\
\text { dose } 500 \mathrm{mg} / \mathrm{kg} \text { body } \\
\text { weight reduces the } \\
\text { blood sugar in alloxan } \\
\text { induced diabetic rats. }\end{array}$ & $\begin{array}{l}\text { Vetrichelvan } \\
\text { and } \\
\text { Jegadeesan., } \\
2002 ; \\
\text { Shirwaikar et } \\
\text { al., } 2004\end{array}$ \\
\hline $\begin{array}{l}\text { Barleria prionitis } \\
\text { (Vjradanti) } \\
\text { Acanthacae }\end{array}$ & $\begin{array}{l}\text { leaf } \\
\text { Root }\end{array}$ & $\begin{array}{l}\text { Sterols } \\
\text { Saponins } \\
\text { Tannins } \\
\text { Flavonides }\end{array}$ & Alcohol & $\begin{array}{l}\text { Diuretic } \\
\text { Hepatoprotectve } \\
\text { Antioxidant } \\
\text { Antifungal } \\
\text { Wound healing }\end{array}$ & $\begin{array}{l}\text { Alcoholic extract of } \\
\text { root and leaves at dose } \\
200 \mathrm{mg} / \mathrm{kg} \text { body weight } \\
\text { to Alloxan induced rat } \\
\text { shows a decrease in } \\
\text { blood glucose level. }\end{array}$ & $\begin{array}{l}\text { Dheer et al., } \\
2010\end{array}$ \\
\hline $\begin{array}{l}\text { Caesalpinia } \\
\text { digyna } \\
\text { (Teri pod/ } \\
\text { Udakiryaka) } \\
\text { Leguminosae }\end{array}$ & $\begin{array}{l}\text { Roots } \\
\text { Bark } \\
\text { Fruit } \\
\text { Gall } \\
\text { Leaf }\end{array}$ & $\begin{array}{l}\text { Caesalpinine A } \\
\text { Cellallocinnine } \\
\text { Ellagic acid } \\
\text { Gallic acid } \\
\text { Bergenin } \\
\text { Nicotinamide } \\
\text { Tannins }\end{array}$ & Alchohol & $\begin{array}{l}\text { Antioxidant } \\
\text { Antipyretic } \\
\text { Astringent } \\
\text { Wound healing } \\
\text { Antidiabetic. }\end{array}$ & $\begin{array}{l}\text { Oral admistration of } \\
750 \mathrm{mg} / \mathrm{kg} \text { for } 14 \text { days } \\
\text { caused a significant } \\
\text { decrease in blood } \\
\text { glucose level in } \\
\text { streptozotocin induced } \\
\text { diabetic rats. }\end{array}$ & $\begin{array}{l}\text { Kumar et al., } \\
2012\end{array}$ \\
\hline $\begin{array}{l}\text { Callistemon } \\
\text { lanceolatus } \\
\text { (Crimson } \\
\text { Bottlebrush) } \\
\text { Myrtaceae }\end{array}$ & leaf & $\begin{array}{l}\text { Phenolic } \\
\text { Saponins Alkaloids } \\
\text { Glycosides } \\
\text { Sterols } \\
\text { Tannins. }\end{array}$ & $\begin{array}{l}\text { Ethanol } \\
\text { Methanol } \\
\text { Hexane } \\
\text { Ethyl } \\
\text { acetate. }\end{array}$ & $\begin{array}{l}\text { Antidiabetic } \\
\text { Antifungal } \\
\text { Antibacterial } \\
\text { Hypolipidemic } \\
\text { Antiaflatoxin } \\
\text { Antioxidant } \\
\text { Cardioprotective } \\
\text { Antiinflammatory } \\
\text { Antithrombin } \\
\text { activity }\end{array}$ & $\begin{array}{l}\text { Oral admistration of } \\
\text { dichloro-methane } \\
\text { exract at dose } 200-400 \\
\mathrm{mg} / \mathrm{kg} \text { body weight for } \\
21 \text { day significantly } \\
\text { decreased the blood } \\
\text { glucose level in } \\
\text { streptozotocin induced } \\
\text { diabetic rats. }\end{array}$ & $\begin{array}{l}\text { Kumar et al., } \\
2011 .\end{array}$ \\
\hline $\begin{array}{l}\text { Ficus amplissima } \\
\text { (kal-itchchi) } \\
\text { Moraceae }\end{array}$ & Bark & Phenolic compounds & sMethanol & $\begin{array}{l}\text { Antidiabetic } \\
\text { Hypololipidimic } \\
\text { Antioxidant } \\
\text { Antiinflammatory } \\
\text { Antibacterial }\end{array}$ & $\begin{array}{l}\text { Oral administration } \\
\text { of methanolic } \\
\text { extract of bark at } \\
\text { the doses of } 50 \text {, } \\
100 \text { and } 150 \mathrm{mg} / \mathrm{kg} \\
\text { showed significant } \\
\text { antidibetic effect } \\
\text { on }\end{array}$ & $\begin{array}{l}\text { Arunachalam } \\
\text { and } \\
\text { Parimelazhag } \\
\text { an, 2013. }\end{array}$ \\
\hline
\end{tabular}




\begin{tabular}{|c|c|c|c|c|c|c|}
\hline & & & & & $\begin{array}{l}\text { streptozotocinindu } \\
\text { ced diabetic rats. }\end{array}$ & \\
\hline $\begin{array}{l}\text { Nymphaea } \\
\text { pubescens (pink } \\
\text { water lily) } \\
\text { Nymphaeaeae }\end{array}$ & $\begin{array}{l}\text { Flower } \\
\text { Tuber }\end{array}$ & $\begin{array}{l}\text { Alkaloids } \\
\text { Flavonoids } \\
\text { Glycosides } \\
\text { Terpenoids } \\
\text { Tannins } \\
\text { Phenols } \\
\text { Saponins } \\
\text { Steroids }\end{array}$ & $\begin{array}{l}\text { Ethanol } \\
\text { Aqueous }\end{array}$ & $\begin{array}{l}\text { Antidiabetic } \\
\text { Hypolipidaemic } \\
\text { Antioxidant }\end{array}$ & $\begin{array}{l}\text { The ethanol extract of } \\
\text { tuber at a dose of } \\
200 \mathrm{mg} / \mathrm{kg} \text { and } \\
500 \mathrm{mg} / \mathrm{kg} \text { body } \\
\text { weight/ day to diabetes } \\
\text { induced rats } \\
\text { significantly increase } \\
\text { in plasma insulin level. }\end{array}$ & $\begin{array}{l}\text { Shajeela et } \\
\text { al., } 2012 .\end{array}$ \\
\hline $\begin{array}{l}\text { Ocimum } \\
\text { gratissimum } \\
\text { (Clove Basil) } \\
\text { Lamiaceae }\end{array}$ & Leaf & $\begin{array}{l}\text { Thymol } \\
\text { Citral } \\
\text { Geraniol }\end{array}$ & Aqueous & $\begin{array}{l}\text { Antimicrobial } \\
\text { Antioxidant } \\
\text { Antibacterial } \\
\text { Antidiabetic } \\
\text { Hepatoprotective }\end{array}$ & $\begin{array}{l}\text { Oral admostration of } \\
\text { aqueous extract at dose } \\
100 \mathrm{mg} / \mathrm{g} \text { produced } \\
\text { transient significant } \\
\text { reduction in blood } \\
\text { glucose in Neonatal } \\
\text { streptozotocin induced } \\
\text { diabetic rat model }\end{array}$ & $\begin{array}{l}\text { Nelson et al., } \\
2012 .\end{array}$ \\
\hline $\begin{array}{l}\text { Otostegia persica } \\
\text { (Goldar) } \\
\text { Labiate }\end{array}$ & $\begin{array}{l}\text { Root } \\
\text { Arial } \\
\text { parts }\end{array}$ & $\begin{array}{l}\text { Polyphenols } \\
\text { Alkaloids } \\
\text { Glycoside } \\
\text { Flavones } \\
\text { Saponins } \\
\text { Tannins }\end{array}$ & Aqueous & $\begin{array}{l}\text { Antihistamin } \\
\text { Antispasmotic } \\
\text { Hepatoprotective } \\
\text { Antioxidant } \\
\text { Antidiabetic }\end{array}$ & $\begin{array}{l}\text { Oral administration of } \\
\text { the aqueous extract of } \\
\text { root at } 200,300 \text { and } \\
400 \mathrm{mg} / \mathrm{kg} \text { body } \\
\text { weight, showed Plasma } \\
\text { glucose lowering } \\
\text { activity in allaxon } \\
\text { induced rat. }\end{array}$ & $\begin{array}{l}\text { Bagherzade } \\
\text { et al., } 2014 .\end{array}$ \\
\hline $\begin{array}{l}\text { Prunella vulgaris } \\
\text { (Self heal) } \\
\text { Labiatae }\end{array}$ & $\begin{array}{l}\text { Leaf } \\
\text { Stem }\end{array}$ & $\begin{array}{l}\text { Rosmarinic acid } \\
\text { Ursolic acid } \\
\text { Oleanolic acid }\end{array}$ & $\begin{array}{l}\text { Aqueous } \\
\text { Ethanol }\end{array}$ & $\begin{array}{l}\text { Anti- } \\
\text { inflammatory } \\
\text { Antiallergic } \\
\text { Anticancer } \\
\text { Wound Healing } \\
\text { Antidiabetic } \\
\text { Hepatoprotective } \\
\text { Antipyretic } \\
\text { Mild Antiseptic } \\
\text { Detoxifier } \\
\text { Diuretic } \\
\text { Haemostatic }\end{array}$ & $\begin{array}{l}\text { Aqueous extract at } \\
\text { dose } 100 \text { and } 200 \\
\mathrm{mg} / \mathrm{kg} / \text { day } \\
\text { suppressed } \\
\text { hyperglycemia in } \\
\text { high fat/ high } \\
\text { cholesterol diet- } \\
\text { mice. }\end{array}$ & $\begin{array}{l}\text { Hwang et al., } \\
2012 \text {. }\end{array}$ \\
\hline 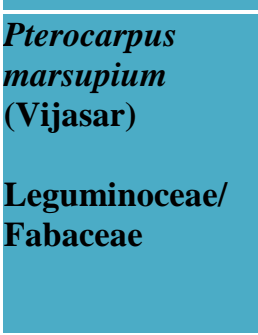 & $\begin{array}{l}\text { Timber } \\
\text { Bark } \\
\text { Leaf } \\
\text { Flower }\end{array}$ & $\begin{array}{l}\text { Glycoside } \\
\text { Flavonoids } \\
\text { Tannins. }\end{array}$ & $\begin{array}{l}\text { Ethanol } \\
\text { Aqueous }\end{array}$ & $\begin{array}{l}\text { Hypolipidemic } \\
\text { Hepato-protective } \\
\text { Antiulcer } \\
\text { Anti-inflammatory } \\
\text { Anti oxidant } \\
\text { Cardiotonic } \\
\text { Antibacterial } \\
\text { Anti-diabetic }\end{array}$ & $\begin{array}{l}\text { Methanol extract at } \\
\text { dose } 300 \mathrm{mg} / \mathrm{kg} \text { body } \\
\text { weight/day showed } \\
\text { normalization of serum } \\
\text { glucose. }\end{array}$ & $\begin{array}{l}\text { Gupta et al., } \\
2009 .\end{array}$ \\
\hline $\begin{array}{l}\text { Selaginella } \\
\text { tamariscina } \\
\text { (Spikemoss) }\end{array}$ & Leaf & Flavonoids & $\begin{array}{l}\text { Aqueous } \\
\text { Ethanol }\end{array}$ & $\begin{array}{l}\text { Vasorelaxant } \\
\text { Antimetastatic } \\
\text { Antidiabetic }\end{array}$ & $\begin{array}{l}\text { Oral doses }(100,200 \\
\text { and } 400 \mathrm{mg} / \mathrm{kg} / \text { day) } \\
\text { for } 8 \text { weeks shows }\end{array}$ & $\begin{array}{l}\text { Zheng et al., } \\
2011 .\end{array}$ \\
\hline
\end{tabular}




\begin{tabular}{|c|c|c|c|c|c|c|}
\hline Selaginellacae & & & & $\begin{array}{l}\text { Antifungal } \\
\text { Antiinflammatory } \\
\text { Antitumor } \\
\text { Cardioprotective } \\
\text { Antioxidant }\end{array}$ & $\begin{array}{l}\text { beneficial effects on } \\
\text { hyperglycemia and } \\
\text { hyperlipoidemia in } \\
\text { streptozotocin induced } \\
\text { diabetic rats }\end{array}$ & \\
\hline $\begin{array}{l}\text { Scoparia dulcis } \\
\text { (Bondhane / } \\
\text { sweet } \\
\text { broomweed) } \\
\text { Scrophulariaceae }\end{array}$ & $\begin{array}{l}\text { Whole } \\
\text { plant }\end{array}$ & $\begin{array}{l}\text { Flavonoids } \\
\text { Saponins } \\
\text { Phenol } \\
\text { Tannins } \\
\text { Alkaloids } \\
\text { Steroids } \\
\text { Terpenes }\end{array}$ & $\begin{array}{l}\text { Hexane } \\
\text { Ethyl } \\
\text { acetate } \\
\text { Methanol } \\
\text { Aqueous }\end{array}$ & $\begin{array}{l}\text { Antidiabetic } \\
\text { Antitumor } \\
\text { Antiviral, } \\
\text { Antiinflammatory } \\
\text { Antioxidant } \\
\text { Neuroprotective }\end{array}$ & $\begin{array}{l}200 \mathrm{mg} / \mathrm{kg} \text { of the } \\
\text { ethanolic extract } \\
\text { showed maximum } \\
\text { reduction in glucose } \\
\text { levels in streptozotocin } \\
\text { induced diabetic rats. }\end{array}$ & $\begin{array}{l}\text { Latha et al., } \\
2004 .\end{array}$ \\
\hline $\begin{array}{l}\text { Tribulus terrestris } \\
\text { (Gokhru) } \\
\text { Zygophyllaceae }\end{array}$ & $\begin{array}{l}\text { Seed } \\
\text { Fruit } \\
\text { Leaf } \\
\text { Root } \\
\text { Stem }\end{array}$ & $\begin{array}{l}\text { Protodioscin } \\
\text { Terrestrosins A-E } \\
\text { Desgalactotigonin } \\
\text { Desglucolanatigonin } \\
\text { Fgitonin } \\
\text { Gitonin } \\
\text { Tigogenin } \\
\text { Furostanol } \\
\text { Glycosides } \\
\text { Sterol } \\
\text { Diosgenin } \\
\text { Hecgenin } \\
\text { Ruscogenin } \\
\text { Kaempferol } \\
\text { Quercetin } \\
\text { Tribulusamides A } \\
\text { and B. }\end{array}$ & Methanol & $\begin{array}{l}\text { Antimicrobial } \\
\text { Cytotoxic } \\
\text { Antihyperlipidaemic } \\
\text { Diuretic } \\
\text { Antiseptic } \\
\text { Anti-inflammatory } \\
\text { Astringent } \\
\text { Analgesic }\end{array}$ & $\begin{array}{l}\text { Oral administration of } \\
50 \mathrm{mg} / \mathrm{kg} \text { body weight } \\
\text { methanolic extracts of } \\
\text { aerial parts of Tribulus } \\
\text { terrestris showed } \\
\text { significant reduction } \\
\text { inblood glucose level } \\
\text { in streptozotocin } \\
\text { induced diabetic rats. }\end{array}$ & $\begin{array}{l}\text { Wu et al., } \\
1999 ; \\
\text { Mahato et } \\
\text { al., } 1981 .\end{array}$ \\
\hline $\begin{array}{l}\text { Withania } \\
\text { somnifera } \\
\text { (ashwagandha) } \\
\text { solanaceae }\end{array}$ & $\begin{array}{l}\text { Root } \\
\text { Fruit } \\
\text { Leaf } \\
\text { Seed }\end{array}$ & $\begin{array}{l}\text { Sitoindosides } \\
\text { Steroidal alkaloids } \\
\text { Steroidal lactones }\end{array}$ & $\begin{array}{l}\text { Aqueous } \\
\text { Alcoholic }\end{array}$ & $\begin{array}{l}\text { Antioxidant } \\
\text { Antitumor } \\
\text { Anti-inflammatory } \\
\text { Immuno-modulatory } \\
\text { Hematopoetic } \\
\text { Antiageing } \\
\text { Anxiolytic } \\
\text { Antdepressive }\end{array}$ & $\begin{array}{l}\text { Oral admistration of } \\
\text { root powder at dose } \\
100 \mathrm{mg} / \mathrm{kg} \text { showed } \\
\text { significant reduction in } \\
\text { blood glucose level in } \\
\text { streptozotocin induced } \\
\text { diabetic rats. }\end{array}$ & $\begin{array}{l}\text { Pradeep et } \\
\text { al., } 2010 .\end{array}$ \\
\hline \multicolumn{7}{|c|}{ Inhibits the activity of hepatic GIucose-6-phosphatase and Increased glycogenesis. } \\
\hline $\begin{array}{l}\text { Annona } \\
\text { squamosa } \\
\text { (custard apple / } \\
\text { Sitafal) } \\
\text { Annonaceae }\end{array}$ & $\begin{array}{l}\text { Leaf } \\
\text { Root } \\
\text { Bark Seed }\end{array}$ & $\begin{array}{l}\text { Annoreticuin } \\
\text { Isoannoreticuin } \\
\text { dAcetogenin } \\
\text { Flavonoids } \\
\text { Alkaloids } \\
\text { Glycoside } \\
\text { Anonaine } \\
\text { 6-Hetriacontanone } \\
\text { Hexacontanol } \\
\text { Higemamine } \\
\text { Isocorydine } \\
\text { Limonine } \\
\text { Linalool acetate }\end{array}$ & $\begin{array}{l}\text { Aqueous } \\
\text { Methanol }\end{array}$ & $\begin{array}{l}\text { Antitumor } \\
\text { Antibacterial } \\
\text { Wound healing } \\
\text { Antiulcer } \\
\text { Anthelmintic } \\
\text { Antioxidant } \\
\text { Antimalarial } \\
\text { Anti HIV Hepato- } \\
\text { protective }\end{array}$ & $\begin{array}{l}\text { Oral admistration of } \\
\text { ethanolic leaf-extract } \\
(350 \mathrm{mg} / \mathrm{kg}) \text { in } \\
\text { streptozotocin diabetic } \\
\text { rats and alloxanized } \\
\text { rabbits shows } \\
\text { antihyperglycemic } \\
\text { activity. }\end{array}$ & $\begin{array}{l}\text { Mohamed., } \\
2011\end{array}$ \\
\hline $\begin{array}{l}\text { Azadirachta } \\
\text { indica } \\
\text { (Neem) }\end{array}$ & $\begin{array}{l}\text { Leaf } \\
\text { Bark } \\
\text { Fruits }\end{array}$ & $\begin{array}{l}\text { Isopreinoids } \\
\text { Azadirone } \\
\text { Azadirachtin }\end{array}$ & $\begin{array}{l}\text { Methanol } \\
\text { Chloroform } \\
\text { Aqueous }\end{array}$ & $\begin{array}{l}\text { Antiinflammatory } \\
\text { Antiarthritic } \\
\text { Antipyretic }\end{array}$ & $\begin{array}{l}\text { Aqueous leaves extract } \\
\text { at a dose of } 250 \mathrm{mg} / \mathrm{kg} \\
\text { body weight for } 16\end{array}$ & $\begin{array}{l}\text { Eshrat et al., } \\
2002 .\end{array}$ \\
\hline
\end{tabular}




\begin{tabular}{|c|c|c|c|c|c|c|}
\hline Meliaceae & $\begin{array}{l}\text { Seed } \\
\text { Oils }\end{array}$ & $\begin{array}{l}\text { Polyphenolic } \\
\text { Flavonoids } \\
\text { Glycoside } \\
\text { Terpenoids } \\
\text { Caumarin } \\
\text { Tannin. }\end{array}$ & & $\begin{array}{l}\text { Hypoglycemic } \\
\text { Antigastric ulcer } \\
\text { Spermicidal } \\
\text { Antifungal } \\
\text { Antibacterial } \\
\text { Diuretic } \\
\text { Immunomodulatory } \\
\text { Anti malarial } \\
\text { Hepatoprotective } \\
\text { Antioxidant }\end{array}$ & $\begin{array}{l}\text { weeks resulted } \\
\text { significant fall in blood } \\
\text { glucose and } \\
\text { improvement in serum } \\
\text { total, LDL and HDL } \\
\text { cholesterol and } \\
\text { triacylglycerol which } \\
\text { increased in diabetic } \\
\text { rats. }\end{array}$ & \\
\hline $\begin{array}{l}\begin{array}{l}\text { Bougainvillea } \\
\text { spectabilis } \\
\text { (Bougainvillea) }\end{array} \\
\text { Nyctaginaceae }\end{array}$ & leaf & $\begin{array}{l}\text { Flavonoids } \\
\text { Tannins } \\
\text { Cardiac-glycosides } \\
\text { Terpenes } \\
\text { Steroids }\end{array}$ & Ethanol & $\begin{array}{l}\text { Hypoglycemic } \\
\text { Hypolipidimic } \\
\text { Antibacterial } \\
\text { Nematicidal } \\
\text { Insecticidal } \\
\text { Antiviral }\end{array}$ & $\begin{array}{l}\text { Ethanolic extract of } \\
\text { stem bark at dose } \\
250 \mathrm{mg} / \mathrm{kg} \text { shows anti } \\
\text { hyperglycaemic effect } \\
\text { in alloxan induced } \\
\text { diabetic rats. }\end{array}$ & $\begin{array}{l}\text { Jawla et al., } \\
2012\end{array}$ \\
\hline $\begin{array}{l}\text { Coccinia indica } \\
\text { (Kundru) } \\
\text { Cucurbitaceae }\end{array}$ & $\begin{array}{l}\text { Leaf } \\
\text { Fruit } \\
\text { Stem } \\
\text { Root }\end{array}$ & $\begin{array}{l}\text { Alkaloids } \\
\text { Steroids } \\
\text { Tannins } \\
\text { Phenolics } \\
\text { Flavonoids } \\
\text { Resins }\end{array}$ & $\begin{array}{l}\text { Aqueous } \\
\text { Ethanol } \\
\text { Petroleum- } \\
\text { ether } \\
\text { Chloroform }\end{array}$ & $\begin{array}{l}\text { Hepatoprotective } \\
\text { Antioxidant } \\
\text { Anti-inflammatory } \\
\text { Anti-nociceptive } \\
\text { Antidiabetic } \\
\text { Hypolipidemic } \\
\text { Antibacterial }\end{array}$ & $\begin{array}{l}\text { Oral administration of } \\
\text { dried extract of } \\
\text { Coccinia indica at } \\
500 \mathrm{mg} / \mathrm{kg} \text {, for } 6 \text { weeks } \\
\text { significantly increased } \\
\text { insulin concentration in } \\
\text { a clinical study. }\end{array}$ & $\begin{array}{l}\text { Joshi et al., } \\
2009 .\end{array}$ \\
\hline $\begin{array}{l}\text { Cucumis sativus } \\
\text { (Cucumber/ } \\
\text { Kheera) } \\
\text { Cucurbitaceae }\end{array}$ & $\begin{array}{l}\text { Fruit } \\
\text { Seed }\end{array}$ & $\begin{array}{l}\text { Steroids } \\
\text { Carotenoids } \\
\text { Flavonoids } \\
\text { Tannins } \\
\text { Resin }\end{array}$ & Ethanol & $\begin{array}{l}\text { Antidiabetic } \\
\text { Anti-hyperlipidemic } \\
\text { Hepatoprotective } \\
\text { Cardioprotective } \\
\text { Diuretic } \\
\text { Laxative }\end{array}$ & $\begin{array}{l}\text { The oral } \\
\text { Administration of } \\
\text { ethanolic fruit's } \\
\text { extracts at } 400 \mathrm{mg} / \mathrm{kg} \\
\text { body weight dose } \\
\text { significantly showed } \\
\text { antidiabetic effects in } \\
\text { Streptozotocin induced } \\
\text { rats. }\end{array}$ & $\begin{array}{l}\text { Karthiyayini } \\
\text { et al., 2009; } \\
\text { Gopalakrishn } \\
\text { an } \text { et al., } \\
2013 \text {. } \\
\text { Sharmin } \text { et } \\
\text { al., 2013. }\end{array}$ \\
\hline $\begin{array}{l}\text { Elephantopus } \\
\text { scaber } \\
\text { (Tutup bumi) } \\
\text { Asteraceae }\end{array}$ & $\begin{array}{l}\text { Leaf } \\
\text { Root }\end{array}$ & $\begin{array}{l}\text { Stigmasterol } \\
\text { Lupeol } \\
\text { Stearic acid } \\
\text { Deoxyelephantopin }\end{array}$ & $\begin{array}{l}\text { Aqueous } \\
\text { Acetone }\end{array}$ & $\begin{array}{l}\text { Astringent } \\
\text { Antipyretic } \\
\text { Antidiabetic } \\
\text { Diuretic } \\
\text { Anticancer } \\
\text { Antibacterial }\end{array}$ & $\begin{array}{l}\text { Oral administration of } \\
\text { aqueous extract of } \\
\text { leaves and rootsat dose } \\
300 \mathrm{mg} / \mathrm{kg} \text { body } \\
\text { weight significantly } \\
\text { reduced serum glucose } \\
\text { leavel in alloxon } \\
\text { induced diabetic rats. }\end{array}$ & $\begin{array}{l}\text { Rajathi et al., } \\
2011 .\end{array}$ \\
\hline $\begin{array}{l}\text { Enicostemma } \\
\text { littorale (Chhota- } \\
\text { chirayta) }\end{array}$ & Leaf & $\begin{array}{l}\text { Alkaloids } \\
\text { Flavonoids } \\
\text { Catechins } \\
\text { Saponins } \\
\text { Sterols } \\
\text { Triterpenoids } \\
\text { Phenolic acids } \\
\text { Xanthones. }\end{array}$ & $\begin{array}{l}\text { Aqueous } \\
\text { Methanol } \\
\text { Ethanol } \\
\text { Ethyl } \\
\text { acetate }\end{array}$ & $\begin{array}{l}\text { Anti-inflammatory } \\
\text { Antiulcer } \\
\text { Hypoglycemic } \\
\text { Anti-malarial } \\
\text { Antioxidant } \\
\text { Anticancer } \\
\text { Anti-nociceptive } \\
\text { Antimicrobial }\end{array}$ & $\begin{array}{l}1.5 \mathrm{~g} \text { dry plant } \\
\text { equivalent extract } / 100 \\
\mathrm{~g} \text { body weight caused } \\
\text { significant increase in } \\
\text { serum insulin levels of } \\
\text { the diabetic rats. }\end{array}$ & $\begin{array}{l}\text { Maroo et al., } \\
2003\end{array}$ \\
\hline $\begin{array}{l}\text { Eugenia } \\
\text { Jambolama or } \\
\text { Syzygium cumini } \\
\text { (Jamun/ Black } \\
\text { plum) }\end{array}$ & $\begin{array}{l}\text { Pulp } \\
\text { Seed } \\
\text { Bark } \\
\text { Leaf }\end{array}$ & $\begin{array}{l}\text { Jamboline-a } \\
\text { Glucoside } \\
\text { Mycaminose }\end{array}$ & $\begin{array}{l}\text { Ethanol } \\
\text { Methanol } \\
\text { Aqueous }\end{array}$ & $\begin{array}{l}\text { Hepato-protective } \\
\text { Antioxidant } \\
\text { Anti-inflammatory } \\
\text { Anti-nociceptive } \\
\text { Antidiabetic }\end{array}$ & $\begin{array}{l}100 \mathrm{mg} / \mathrm{kg} \text { of body } \\
\text { weight of ethanolic } \\
\text { extracts of whole } \\
\text { seeds, kernel showed } \\
\text { hypoglycemic activity }\end{array}$ & $\begin{array}{l}\text { Kumar, et } \\
\text { al., 2008; } \\
\text { Verma et al., } \\
2010 .\end{array}$ \\
\hline
\end{tabular}




\begin{tabular}{|c|c|c|c|c|c|c|}
\hline Myrtaceae & & & & $\begin{array}{l}\text { Hypolipidemic } \\
\text { Antibacterial } \\
\text { Antifungal }\end{array}$ & $\begin{array}{l}\text { in streptozotocin- } \\
\text { induced diabetic rats }\end{array}$ & \\
\hline $\begin{array}{l}\text { Gymnema } \\
\text { montanum } \\
\text { (Gymnema) }\end{array}$ & $\begin{array}{l}\text { Stem } \\
\text { Leaf }\end{array}$ & $\begin{array}{l}\text { Alkaloids } \\
\text { Saponin } \\
\text { Tannins } \\
\text { Glycosides }\end{array}$ & Alchohol & $\begin{array}{l}\text { Antihyperglycemic } \\
\text { Antiperoxidative } \\
\text { Antimicrobial }\end{array}$ & $\begin{array}{l}\text { Oral administration of } \\
200 \mathrm{mg} / \mathrm{kg} \text { body } \\
\text { weight of the alcoholic } \\
\text { extract of the leaf } \\
\text { resulted in a significant } \\
\text { reduction in blood } \\
\text { glucose and an } \\
\text { increase in plasma } \\
\text { insulin level. }\end{array}$ & $\begin{array}{l}\text { Ananthan } \text { et } \\
\text { al., 2003; } \\
\text { Ramkumar et } \\
\text { al., 2011. }\end{array}$ \\
\hline $\begin{array}{l}\text { Psidium guajava } \\
\text { (Guava/ Amrud) } \\
\text { Myrtaceae }\end{array}$ & Stem b & $\begin{array}{l}\text { Phenolics } \\
\text { Glycosides } \\
\text { Carotenoids }\end{array}$ & Ethanol & $\begin{array}{l}\text { Antidihhreal } \\
\text { Hepato-protection } \\
\text { Antioxidant } \\
\text { Anti-inflammatory } \\
\text { Antispasmodic } \\
\text { Anticancer } \\
\text { Antimicrobial } \\
\text { Anti-hyperglycemic } \\
\text { Analgesic }\end{array}$ & $\begin{array}{l}\text { Ethanolic extract of } \\
\text { stem bark at dose } \\
250 \mathrm{mg} / \mathrm{kg} \text { exhibited } \\
\text { significant } \\
\text { hypoglycaemic activity } \\
\text { in alloxan-induced } \\
\text { hyperglycaemic rats }\end{array}$ & $\begin{array}{l}\text { Mukhtar et } \\
\text { al., } 2006 .\end{array}$ \\
\hline $\begin{array}{l}\text { Tinospora crispa } \\
\text { (Akar patawali) } \\
\text { Menispermaceae }\end{array}$ & $\begin{array}{l}\text { Stem } \\
\text { Leaf }\end{array}$ & $\begin{array}{l}\text { Terpenoids } \\
\text { Borapetoside C }\end{array}$ & Aqueous & $\begin{array}{l}\text { Antidiabetic } \\
\text { Hepatoprotective } \\
\text { Antioxidant } \\
\text { Antimicrobial }\end{array}$ & $\begin{array}{l}\text { Acute intra-venous } \\
\text { treatment with the } \\
\text { extract }(50 \mathrm{mg} / \mathrm{kg}) \\
\text { caused an increase in } \\
\text { plasma insulin levels }\end{array}$ & $\begin{array}{l}\text { Noor et al., } \\
1989 ; \\
\text { Lokman et } \\
\text { al., } 2013 .\end{array}$ \\
\hline $\begin{array}{l}\text { Tinospora } \\
\text { cordifolia } \\
\text { (Giloya / guduchi) } \\
\text { Menispermaceae }\end{array}$ & Stem & $\begin{array}{l}\text { Alkaloids } \\
\text { Glycoside } \\
\text { Terpenoids } \\
\text { Lactones } \\
\text { Steroids }\end{array}$ & $\begin{array}{l}\text { Aqueous } \\
\text { Alcohol }\end{array}$ & $\begin{array}{l}\text { Hypolipidemic } \\
\text { Hypoglycemic } \\
\text { Cardioprotective } \\
\text { Hepatoprotective } \\
\text { Antioxidant } \\
\text { Anti-inflammatory }\end{array}$ & $\begin{array}{l}\text { Oral administration of } \\
\text { the aqueous root } \\
\text { extract led to a } \\
\text { decrease in blood and } \\
\text { urine glucose and } \\
\text { lipids level in } \\
\text { alloxanized rats. }\end{array}$ & $\begin{array}{l}\text { Rajalakshmi } \\
\text { et al., } 2009 .\end{array}$ \\
\hline $\begin{array}{l}\begin{array}{l}\text { Vernonia } \\
\text { amygdalina } \\
\text { (Bitter leaf) }\end{array} \\
\text { Asteraceae }\end{array}$ & leaf & $\begin{array}{l}\text { Polyphenols } \\
\text { Alkaloids } \\
\text { Saponins } \\
\text { Tannins } \\
\text { Glycosides }\end{array}$ & Ethanol & $\begin{array}{l}\text { Antioxidant } \\
\text { Antibacterial } \\
\text { Anti-inflammatory } \\
\text { Hepato-protective } \\
\text { Anticarcinogenic } \\
\text { Antifungal } \\
\text { Antiplasmodial } \\
\text { Nephroprotective }\end{array}$ & $\begin{array}{l}\text { Ethanolic leaf extract } \\
\text { at dose } 400 \mathrm{mg} / \mathrm{kg} \\
\text { exhibited a significant } \\
\text { improvement in } \\
\text { glucose tolerance of } \\
\text { the streptozotocin } \\
\text { induced diabetic rats. }\end{array}$ & $\begin{array}{l}\text { Ong et al., } \\
2011 .\end{array}$ \\
\hline \multicolumn{7}{|c|}{ Enhance activity of enzymes involved in bile acid synthesis. } \\
\hline $\begin{array}{l}\text { Berberis aristata } \\
\text { (Daruhaldi) } \\
\text { Berberidaceae }\end{array}$ & $\begin{array}{l}\text { Stem } \\
\text { Root } \\
\text { Seed }\end{array}$ & $\begin{array}{l}\text { Alkaloids } \\
\text { Tannins } \\
\text { Saponins } \\
\text { Glycosides } \\
\text { Sterols } \\
\text { Flavonoids } \\
\text { Terpenoids } \\
\text { Lignin }\end{array}$ & $\begin{array}{l}\text { Methanol } \\
\text { Aqueous } \\
\text { Ethanol } \\
\text { Acetic } \\
\text { anhydride }\end{array}$ & $\begin{array}{l}\text { Anti-inflammatory } \\
\text { hepatoprotective } \\
\text { Hypoglycemic } \\
\text { Antibacterial } \\
\text { Antifungal } \\
\text { Antipyretic } \\
\text { Anticarcer } \\
\text { Immuno-modulatory }\end{array}$ & $\begin{array}{l}\text { Oral administration of } \\
\text { the methanolic extract } \\
\text { at dosen } 250 \text { and } 500 \\
\text { mg/kg effectively } \\
\text { reduced the blood } \\
\text { glucose in diabetic rats. }\end{array}$ & $\begin{array}{l}\text { Upwar et al., } \\
2011\end{array}$ \\
\hline
\end{tabular}




\begin{tabular}{|c|c|c|c|c|c|c|c|}
\hline $\begin{array}{l}\text { Boerhavia diffusa } \\
\text { (Santh/ } \\
\text { punarnava) } \\
\text { Nyctaginaceae }\end{array}$ & $\begin{array}{l}\text { Leaf } \\
\text { Stem } \\
\text { Bark } \\
\text { Root }\end{array}$ & $\begin{array}{l}\text { Alkaloids } \\
\text { Phytosterols } \\
\text { Lignin }\end{array}$ & $\begin{array}{l}\text { Petroleum } \\
\text { ether } \\
\text { Chloroform } \\
\text { Methanol } \\
\text { Aqueous }\end{array}$ & $\begin{array}{l}\text { Hepato-protective } \\
\text { Diuretic } \\
\text { Anti-inflammatory } \\
\text { Antibacterial } \\
\text { Antidiabetic } \\
\text { Anti-urethritis } \\
\text { Anti-asthamic }\end{array}$ & \multicolumn{2}{|c|}{$\begin{array}{l}\text { Oral administration of } \\
\text { aqueous leaf extract } \\
\text { ( } 200 \mathrm{mg} / \mathrm{kg} \text { daily for } 4 \\
\text { weeks) in normal and } \\
\text { alloxan induced diabetic } \\
\text { rats shows } \\
\text { hypoglycemic and } \\
\text { antihyperglycemic } \\
\text { activity. }\end{array}$} & $\begin{array}{l}\text { Santhosha et } \\
\text { al., } 2011 .\end{array}$ \\
\hline $\begin{array}{l}\text { Brassica juncea } \\
\text { (Mustard) } \\
\text { Brassicaceae }\end{array}$ & Seed & $\begin{array}{l}\text { Anthocyanins } \\
\text { Flavonoids } \\
\text { Hydroxycinnamic } \\
\text { acids } \\
\text { Polyphenols }\end{array}$ & $\begin{array}{l}\text { Aqueous } \\
\text { Methanol }\end{array}$ & $\begin{array}{l}\text { Antinociceptive } \\
\text { Anti-hyperglycemic } \\
\text { Antioxidant } \\
\text { Antimicrobial }\end{array}$ & \multicolumn{2}{|c|}{$\begin{array}{l}\text { Dose of } 250,350 \text { and } \\
450 \mathrm{mg} / \mathrm{kg} \text { body weight } \\
\text { of seed extract has } \\
\text { potent hypoglycemic } \\
\text { activity in } \\
\text { streptozotocin induced } \\
\text { diabetic male albino } \\
\text { rats. }\end{array}$} & $\begin{array}{l}\text { Khan et al., } \\
1995 .\end{array}$ \\
\hline \multicolumn{8}{|c|}{ Plants which are shows Potent insulin mimic activity } \\
\hline $\begin{array}{l}\text { Cornus officinalis } \\
\text { (Asiatic } \\
\text { dogwood) } \\
\text { Cornaceae }\end{array}$ & Fruit & $\begin{array}{l}\text { Tannins including } \\
\text { cornusiins A, B and } \\
\text { C } \\
\text { Ursolic acid }\end{array}$ & Methanol & $\begin{array}{l}\text { Antibacterial } \\
\text { Antifungal } \\
\text { Hypotensive } \\
\text { Antitumor } \\
\text { Astringent } \\
\text { Diuretic } \\
\text { Hepatoprotective } \\
\text { Antidiabetic }\end{array}$ & $\begin{array}{l}100 \mathrm{mg} / \mathrm{kg} \text { and } \\
200 \mathrm{mg} / \mathrm{kg} \\
\text { body weight } \\
\text { fruit extract had } \\
\text { a significant } \\
\text { hypoglycemic } \\
\text { effect in } \\
\text { diabetic mice. }\end{array}$ & \multicolumn{2}{|c|}{ Chen et al., 2008.} \\
\hline $\begin{array}{l}\text { Nigella sativa } \\
\text { (kalonji) } \\
\text { Ranunculaceae }\end{array}$ & Seed & $\begin{array}{l}\text { Oil } \\
\text { Isochinoline } \\
\text { Alkaloids }\end{array}$ & $\begin{array}{l}\text { Ethanol } \\
\text { Aqueous }\end{array}$ & $\begin{array}{l}\text { Antidiabetic } \\
\text { Anticancer } \\
\text { Immunomodulatory } \\
\text { Analgesic } \\
\text { Antimicrobial } \\
\text { Anti-inflammatory } \\
\text { Hepato-protective } \\
\text { Anti-hypertensive } \\
\text { Antioxidant }\end{array}$ & $\begin{array}{l}\text { Seed extract at } \\
\text { dose } 5 \mathrm{mg} / \mathrm{kg} \text { of } \\
\text { body weight } \\
\text { significantly } \\
\text { reduced fasting } \\
\text { blood glucose } \\
\text { level. }\end{array}$ & \multicolumn{2}{|c|}{$\begin{array}{l}\text { Alimohammadi et } \\
\text { al., } 2013 \text {. }\end{array}$} \\
\hline $\begin{array}{l}\text { Rosmarinus } \\
\text { officinalis } \\
\text { (Rosemary) }\end{array}$ & Leaf & $\begin{array}{l}\text { Caffeic Acid } \\
\text { Carnasol } \\
\text { Ros-Maridiphenol } \\
\text { Rosmarinic Acid }\end{array}$ & $\begin{array}{l}\text { Aqueous } \\
\text { Ethanol }\end{array}$ & $\begin{array}{l}\text { Antiasthmatic } \\
\text { Cardiotonic } \\
\text { Hypotensive } \\
\text { Memorybuster } \\
\text { Antihyperglycemic } \\
\text { Hepato-protective } \\
\text { Antioxidant } \\
\text { Anti-inflammatory }\end{array}$ & $\begin{array}{l}\text { Water extract of } \\
\text { leaves at dose } \\
200 \mathrm{mg} / \mathrm{kg} \text { body } \\
\text { weight for } 21 \\
\text { days was found } \\
\text { to be } \\
\text { significantly } \\
\text { reducing the } \\
\text { blood sugar } \\
\text { level in } \\
\text { Streptozotocin } \\
\text { induced } \\
\text { diabetic rats. }\end{array}$ & \multicolumn{2}{|c|}{ Khalil et al., 2012.} \\
\hline $\begin{array}{l}\text { Solanum } \\
\text { xanthocarpum } \\
\text { (Kantakari) } \\
\text { Solanaceae }\end{array}$ & leaf & $\begin{array}{l}\text { Olanocarpine } \\
\text { Carpesterol } \\
\text { Solanocarpidine } \\
\text { Diosgenin } \\
\text { Sitosterol } \\
\text { Isochlorogenic acid } \\
\text { Neochronogenic }\end{array}$ & Methanol & $\begin{array}{l}\text { Hypoglycemic } \\
\text { Hypolipidimic } \\
\text { Antioxidant }\end{array}$ & $\begin{array}{l}\text { Methanol } \\
\text { extracts of leaf } \\
\text { was efficient } \\
\text { anti } \\
\text { hyperglycemic } \\
\text { agents at a } \\
\text { concentration }\end{array}$ & \multicolumn{2}{|c|}{$\begin{array}{l}\text { Poongothai et al., } \\
2011 .\end{array}$} \\
\hline
\end{tabular}




\begin{tabular}{|c|c|c|c|c|c|c|}
\hline & & $\begin{array}{l}\text { acid } \\
\text { Chronogenic acid } \\
\text { Caffeic acid } \\
\text { Solasodine } \\
\text { Solasonine } \\
\text { Solamargine } \\
\text { Quercetin } \\
\text { Apigenin } \\
\text { Histamine } \\
\text { Acetylcholine }\end{array}$ & & & $\begin{array}{l}\text { of } 200 \mathrm{mg} / \mathrm{kg} \\
\text { body weight } \\
\text { and posses } \\
\text { potent } \\
\text { antioxidant } \\
\text { activity. }\end{array}$ & \\
\hline $\begin{array}{l}\text { Teucrium polium } \\
\text { (Kalpooreh) } \\
\text { Lamiacea }\end{array}$ & Leaves & $\begin{array}{l}\text { Terpenoids } \\
\text { Flavonoids } \\
\text { Apigenin }\end{array}$ & $\begin{array}{l}\text { Methanol } \\
\text { Aqueous }\end{array}$ & $\begin{array}{l}\text { Hypoglycemic } \\
\text { Hepatoprotective } \\
\text { Analgesic } \\
\text { Antilipidemic }\end{array}$ & $\begin{array}{l}\text { Single dose of } \\
50 \mathrm{mg} / \mathrm{kg} \text { body } \\
\text { weight /day for } \\
\text { a month } \\
\text { significantly } \\
\text { decrease serum } \\
\text { glucose in } \\
\text { streptozotocin } \\
\text { induced } \\
\text { diabetic rats. }\end{array}$ & $\begin{array}{l}\text { Shahraki et al., } \\
2007 .\end{array}$ \\
\hline \multicolumn{7}{|c|}{$\begin{array}{l}\text { Plats which are preserve } \beta \text {-cell function by depletion of antioxidant enzyme cascade and prevent diabetes induced ROS } \\
\text { formation. }\end{array}$} \\
\hline $\begin{array}{l}\text { Curcuma longa } \\
\text { (Turmeric) } \\
\text { Zinzibaraceae }\end{array}$ & Rhizome & $\begin{array}{l}\text { Curcumin } \\
\text { Essential oils }\end{array}$ & $\begin{array}{l}\text { Methanol } \\
\text { Ethanol } \\
\text { Chloroform- } \\
\text { water }\end{array}$ & $\begin{array}{l}\text { Antioxidant } \\
\text { Anti-inflammatory } \\
\text { Anti cancer } \\
\text { Hepato-protective } \\
\text { Anti viral } \\
\text { Anti fungal } \\
\text { Anti bacterial } \\
\text { Antiseptic } \\
\text { Analgesic }\end{array}$ & $\begin{array}{l}\text { Oral } \\
\text { administration } \\
\text { of absolute } \\
\text { ethanol extract } \\
\text { of rhizome and } \\
\text { leaves lowers } \\
\text { blood glucose } \\
\text { in alloxan- } \\
\text { induced } \\
\text { diabetic rabbits. }\end{array}$ & $\begin{array}{l}\text { Sarah et al., 2009; } \\
\text { Sadak et al., } 2010\end{array}$ \\
\hline $\begin{array}{l}\text { Pongamia pinnatc } \\
\text { (Karanj) } \\
\text { Fabaceae/ } \\
\text { Leguminoceae }\end{array}$ & $\begin{array}{l}\text { Root } \\
\text { Fruit } \\
\text { Leaf }\end{array}$ & $\begin{array}{l}\text { Alkaloids } \\
\text { Glycosides } \\
\text { Flavonoids } \\
\text { Flavone derivative } \\
\text { 'pongol' }\end{array}$ & $\begin{array}{l}\text { Ethanol } \\
\text { Methanol }\end{array}$ & $\begin{array}{l}\text { Antitumor } \\
\text { Antiseptic } \\
\text { Anti-inflammatory } \\
\text { Antinociceptive } \\
\text { Antihyperglycemic } \\
\text { Anti-lipidoxidative } \\
\text { Antidiarrhoeal } \\
\text { Antiulcer } \\
\text { Antioxidant. }\end{array}$ & $\begin{array}{l}\text { Ethanolic } \\
\text { extract of } \\
\text { leaves at doses } \\
500 \mathrm{mg} / \mathrm{kg} \text { and } \\
1 \mathrm{~g} / \mathrm{kg} \text { shows } \\
\text { significant } \\
\text { antidiabetic } \\
\text { effect on } \\
\text { streptozotocin } \\
\text { induced male } \\
\text { albino rats. }\end{array}$ & $\begin{array}{l}\text { Kavipriya et al., } \\
2013 .\end{array}$ \\
\hline
\end{tabular}




\begin{tabular}{|c|c|c|c|c|c|c|}
\hline $\begin{array}{l}\text { Diospyros } \\
\text { peregrine (Gaub } \\
\text { persimon) } \\
\text { Ebenaceae }\end{array}$ & Fruit & $\begin{array}{l}\text { Alkaloids } \\
\text { Terpinoids } \\
\text { Polyphenolics } \\
\text { Flavonoids }\end{array}$ & Aqueous & $\begin{array}{l}\text { Antihyperglycemic } \\
\text { Antioxidant } \\
\text { Antihyperlipidimic }\end{array}$ & $\begin{array}{l}\text { Oral } \\
\text { administration } \\
\text { of aqueous fruit } \\
\text { extract at the } \\
\text { doses of } 50 \text { and } \\
100 \mathrm{mg} / \mathrm{kg} \text { body } \\
\text { weight to } \\
\text { streptozotocin- } \\
\text { nicotinamide } \\
\text { induced } \\
\text { diabetic } \\
\text { ratsshows } \\
\text { significant } \\
\text { hypoglycemic } \\
\text { and } \\
\text { hypolipidemic } \\
\text { effect. }\end{array}$ & $\begin{array}{l}\text { Dewanjee et al., } \\
2009 .\end{array}$ \\
\hline $\begin{array}{l}\text { Piper betle (Betel } \\
\text { leaf) } \\
\text { Piperaceae }\end{array}$ & Leaf & $\begin{array}{l}\text { Chavibetol } \\
\text { Chavicol } \\
\text { Eugenol } \\
\text { Lactone } \\
\text { Catechol } \\
\text { Terpinene } \\
\text { Sitosterol } \\
\text { Stigmasterol } \\
\text { Ursolic Acid }\end{array}$ & $\begin{array}{l}\text { Aqueous } \\
\text { Ethanol }\end{array}$ & $\begin{array}{l}\text { Antioxidant } \\
\text { Antifungal } \\
\text { Immuno-modulatory } \\
\text { Antileshmanial } \\
\text { Antiamoebic } \\
\text { Anti-Inflammatory } \\
\text { Antimicrobial } \\
\text { Radioprotective }\end{array}$ & $\begin{array}{l}200 \mathrm{mg} / \mathrm{kg} \text { body } \\
\text { weight of hot } \\
\text { water extract of } \\
\text { leaves showed } \\
\text { anti diabetic } \\
\text { activity in rats. }\end{array}$ & $\begin{array}{l}\text { Arambewela et al., } \\
2005 \text {. }\end{array}$ \\
\hline \multicolumn{7}{|c|}{ Plants show Sodium-Glucose Transporter-2 Inhibitory activity. } \\
\hline $\begin{array}{l}\text { Phyllanthus } \\
\text { amarus } \\
\text { (Bhui amla, } \\
\text { Jaramla) }\end{array}$ & $\begin{array}{l}\text { Whole } \\
\text { plant }\end{array}$ & $\begin{array}{l}\text { Tannins } \\
\text { Flvonoids }\end{array}$ & Methanol & $\begin{array}{l}\text { Antioxidant } \\
\text { Anti-inflammetory } \\
\text { Antitumor } \\
\text { Antiviral } \\
\text { Antihyperglycemic } \\
\text { Hepato-protective } \\
\text { Immuno-modulatory }\end{array}$ & $\begin{array}{l}\text { The methanolic } \\
\text { extract was } \\
\text { found to reduce } \\
\text { the blood sugar } \\
\text { in alloxanized } \\
\text { diabetic rats. }\end{array}$ & Shetti et al., 2012. \\
\hline
\end{tabular}

If a person's pancreas does not work properly or body cells does not response to insulin, blood glucose level gets higher and ultimately increases the risk of many secondary complications like cardiovascular disease, neuropathy, nephropathy, retinopathy, hair loss, foot and skin damage etc.

In present seneario for treatment of such type of complex metabolic disorders, differet kinds of medicinal system are available. Allopathy medicines are mostly used for treatment of diabete mellitus which bind the target site of body system and suppress the illness rather then removing it. Allopathy work by different mechanisms like improving insulin release in response to meals (sulfonylureas and meglitinides), reducing the resistance of the body cells to the effect of insulin (metformin and glitazones), preserve the function of the $\beta$-cells of the pancreas (Pioglitazone), stimulate the $\beta$-cells in the pancreas to release more insulin (sulfonylureas and meglitinides), $\alpha$-glucosidase inhibitory activity (Acarbose), inhibiting the SGLT2 transporter (Gliflozins), slowing the absorption of sugar from the gut (acarbose), DPP-4 inhibitiory activity (gliptins), Sodium-Glucose Transporter-2 Inhibitory activity (forxiga-dapagliflozin and canagliflozin).

There are certain side effects associated with the allopathic medicines, which make these medicines harmful to human body if taken for 
a prolonged period of time. So herbal drugs can be the best for the treatment of diabetes because these are of natural sources and have less or no side effect on human body.

\section{Herbal remedies for management of diabetes mellitus}

Many plants have been investigated for their beneficial use in different types of diseases. There are about 600 plants, which are stated to have anti-diabetic property (Murray, 1995). Herbal drugs with antidiabetic activity can be classified into four categories according to their mode of action (Wadkar et al., 2008)-

The first group of plant drugs act like insulin, the classical example of this group is Momordica charatia.

The second group of herbal drugs is those acting on the $\beta$-cells of pancreas to increase the production of insulin, this group includes Allium cepa and Pterocarpus marsupium.

The third group of herbal drugs act by enhancing glucose utilization in diabetic patients, this group includes Gingiber officinale.

The last group of herbal plants with hypoglycemic potency act by miscellaneous mechanism. This group includes leguminous plants.

Wide arrays of plant derived active principles representing numerous phytochemicals have demonstrated consistent anti-diabetic activity and their possible use in the treatment of diabetes mellitus (Saminathan and Kavimani, 2015; Mamun Rashid et al., 2014).

The summary of 112 plants reported to have significant anti-diabetic activity of the active compounds, used in herbal formulations in India is shown in Table 2.

\section{In vitro production of plant secondary metabolites}

Tropical zones of the globe are abundant in medicinal flora. Increase in demand for these plants in industries is leading to frequent and rapid harvesting from natural habitations resulting in erosion of natural habitat and compromization with quality of the product. Hence, there is an urgent need for take up sustainable harvesting measures by balancing the commercial demand with the conservation of the valuable plants and their contribution to biodiversity.

There is great interest in developing alternatives to the intact plant for the production of plant secondary metabolites. Plant cell cultures are capable of producing pharmaceutically important bioactive molecules, equally or in enhanced levels as compared to mother plants. The application of these techniques for bioactive molecules production is increasing rapidly (Mulabagal et al., 2004; Kuruppusamy, 2009). Attempts have successfully been made in generating a range of compounds such as alkaloids, flavonoids, terpenes, steroids, glycosides, etc through tissue culture.

A total of about 28,000 patents are reported to be registed in plant cell culture related products production, especially associated with cosmetic, food and pharmaceutical industries (Marisol et al., 2016). Plants producing secondary metabolites with antidiabetic property like Allium sativum, Azadirach indica, Camellia sinensis, Coscinium fenustratum, Ginko biloba, Momordica charantia, Mucura pruriens, Psoralea cordifolia, Scoparia dulcis, Tinospora cordifolia and Withania somnifera were also cultured in vitro for the active compounds production (Kuruppasamy, 2009). Similarly large scale cultivation of cell suspension cultures, organ cultures in bioreactors was reported in Catharanthus 
roseus, Panax ginseng, and stevia rebaudiana (Ozlem et al., 2010).

Plant cells can also transform natural or artificial compounds, introduced into the cultures, through a variety of reactions such as hydrogenation, dehydrogenation, isomerization, glycosylation, hydroxylation, and opening of a ring and addition of carbon atoms. Many attempts have been made to use plant cell cultures for production of plant secondary metabolites, but most of these attempts have not been cost effective, and only few commercially viable systems have been created (Alferman et al., 2003).

This review summaries main group of secondary metabolites produced by plants and the techniques commonly applied for their isolation, identification and characterization. It also summaries potential 112 anti- diabetic plants, their explored plant parts producing secondary metabolites containing various pharmaceutiacal activities along with specific therapeutic and prophylactic function against diabetis. The crude extracts, however, contain a wide range of bioactive molecules whose composition of components varies from preparation to preparation. In case of herbal medicine pharmacopoeia on herbal products is not available. Hence, standardization and quality control parameters for the raw material as well as finished products are highly essential. Isolation of individual compounds and analysis of pharmaceutical properties and role of each biomolecule present in the extract hold grate importance in human trails. Although, at present increase in awareness on herbal medicine, validation of their pharmacological properties of crude extracts in appropriate experimental animal model has tricked up momentum tremendously, it is highly necessary to collect sound experimental data on toxicity studies, animal and human clinical studies for their worldwide acceptability.

\section{Acknowledgments}

All the authors are thankful to SOS in Biochemistry, jiwaji University for the support.

\section{References}

Abdel-Zaher, A.O., Salim, S.Y., Assaf, M.H., and Abdel-Hady, R.H., 2005. Antidiabetic activity and toxicity of Zizyphus spina-christi leaves. Journal of Ethnopharmacology. 101(1-3):129138.

Adebajo, A.C., Iwalewa, E.O., Obuotor, E.M., Ibikunle, G.F., Omisore, N.O., Adewunmi, C.O., Obaparusi, O.O., Klaes, M., Adetogun, G.E., Schmidt, T.J., and Verspohl, E.J. 2009. Pharmacological properties of the extract and some isolated compounds of Clausena lansium stem bark: Anti-trichomonal, antidiabetic, antiinflammatory, hepatoprotective and antioxidant effects. Journal of Ethnopharmacology. 122(1): 10-19.

Adeneye, A.A., Ajagbonna, O.P., and Ayodele, O.W., 2007. Hypoglycemic and antidiabetic activities on the stem bark aqueous and ethanol extracts of Musanga cecropioides in normal and alloxan-induced diabetic rats. Fitoterapia. 78(78): 502-505.

Agrawal, H., Kaul, N., Paradkar, A.R., and Mahadik, K.R. 2009. Standardization of crude extract of neem seed kernels (Azadirachta Indica A. Juss) and commercial neem based formulations using HPTLC and extended length packed columns SFC Method. Chromatographia. 62(3): 183-195.

Ahmed, L., Lakhani, M.S., Gillett, M., John, A., and Raza, H. 2001. Hypotriglyceridemic and hypocholesterolemic effects of anti-diabetic Momordica charantia (karela) fruit extract in streptozotocin-induced diabetic rats. Diabetes Research and Clinical Practice. 2001; 51(3): 155-161.

Alarcon-Aguilara, F.J., Roman-Ramos, R., PerezGutierrez, Aguilar-Contreras, A., ContrerasWeber, C.C., and Flores-Saenz, J.L. 1998. Study of the hypoglycemic effect of plants used as antidiabetics. Journal of Ethnopharmacology. 61: 101-110.

Alfermann, A., Petersen, M., and Fuss, E. 2003. Production of natural products by plant cell biotechnology: Results, problems and perspectives. In: M Lamier, W Rucker, eds, Plant Tissue Culture 100 Years Since Gottlieb Haberlandt. Springer, New York. 153-166. 
Alimohammadi, S., Hobbenaghi, R., Javanbakht, J., Kheradmand, D., Mortezaee, R., Tavakoli, M., Khadivar, F., and Akbari, H. 2013. Protective and antidiabetic effects of extract from Nigella sativa on blood glucose concentrations against streptozotocin (STZ)-induced diabetic in rats: an experimental study with histopathological evaluation. Diagnostic Pathology. 8: 137-314.

Ananthan, R., Latha, M., Ramkumar, K.M., Pari, L., Baskar, C., and Narmatha, B.V. 2003. Effect of Gymnema montanum leaves on serum and tissue lipids in alloxan diabetic rats. Experimental Diabesity Researcg. 4(3): 183-189.

Anzana, P., Md. Morshedul, A., Md. Anwarul, H., Bhowmik, A., Ali, L., and Begum, R. 2013. Study of the Hypoglycemic Effect of Tamarindus indica Linn. Seeds on non-diabetic and diabetic model Rats. British Journal of Pharmaceutical Research. 3(4): 1094-1105.

Arambewela, L.S.R., Arawwawala, L.D.A.M., and Ratanasooriya, W.D. 2005. Antidiabetic activities of aqueous and ethanolic extract of Piper betel leaves in rats. Journal of Ethnopharmacology. 102: 239-245.

Aransiola, E.F., Daramola, M.O., Iwalewa, E.O., Seluwa, A.M., and Olufowobi, O.O. 2014. AntiDiabetic Effect of Bryophyllum pinnatum Leaves. International Journal of Biological, Veterinary, Agricultural and Food Engineering. 8 (1): 95-99.

Arumugam, G., Manjula, P., and Paari, N. 2013. A review: Anti diabetic medicinal plants used for diabetes mellitus. Journal of Acute Disease. 196-200.

Arunachalam, K., and Parimelazhaga, T. 2013 Antidiabetic activity of Ficus amplissima Smith. bark extract in streptozotocin induced diabetic rats. Journal of Ethnopharmacology. 147(2): 302-310.

Attele, A.S., Zhou, Y.P., Xie, J.T., Wu, J.A., Zhang, L., Dey, L., Pugh, W., Rue, P.A., Polonsky, K.S., and Yuan, C.S. 2002. Antidiabetic effects of Panax ginseng berry extract and the identification of an effective component. Diabetes. 51(6): 1851-1858.

Ayyanar, M., and Babu, P.S. 2012. Syzygium cumini(L.) Skeels: A review of its phytochemical constituents and traditional uses. Asian Pacific Journal of Tropical Biomedicine. 2(3): 240-246.

Bagherzade, G., Dourandishan, M. and Malekaneh, M. 2014. Antidiabetic Effects of Otostegia persica Root in Alloxan-induced Diabetic Rats. Pure and Applied Chemical Sciences. 2 (1): 1-9.

Baker, C., and Thormsberg, C. 1983. Inoculums Standardization in Antimicrobial Susceptility
Tests. Evaluation of overnight age Culture. Journal of Clinical Microbiology. 17(3): 140457.

Bhat, Z.A., Ansari, S.H., Mukhtar, H.M., Naved, T., and Siddique, J.I. 2005. Effect of Aralia Cachemirica Decne, roots extracts on blood glucose level in normal and glucose loaded rats. Pharmazie. 60(9): 712-713.

Bhatia, A., and Mishra, T. 2010. Hypoglycemic activity of Ziziphus mauritiana aqueous ethanol seed extract in alloxan-induced diabetic mice. Pharmaceutical biology. 48(6): 604-610.

Bindu, R., 2013 Antidiabetic and antihyperlipidemic effects of alcoholic and aqueous leaf extracts of Limonia acidissima, Linn. in alloxan induced diabetic rats. International Conference and Exhibition on Pharmacognosy, Phytochemistry \& Natural Products. Pharmacognosy. 2(3): 241.

Bothara, S.B., and Vaidya, S.K. 2016. Evaluation of antioxidant and antidiabetic effect of Lpomoea reniformis chois in alloxan induced diabetic rats. International Journal of Pharmacy and Pharmaceutical Research. 6(3): 252-273.

Buchanan, B., Gruissem, W., and Jones, R. 2000. Biochemistry \& Molecular Biology of Plants, Eds. American Society of Plant Physiologists, Chapter 24: 1250-1318.

Chakraborty, U., and Das, H. 2010. Antidiabetic and antioxidant activities of Cinnamomum tamalaLeaf Extracts in Streptozotocin-Treated Diabetic Rats. Global Journal of Biotechnology \& Biochemistry. 5(1): 12-18.

Chauhan, A., Sharma, P.K., Srivastava, P., Kumar, N., and Dudhe, R. 2010. Plants having potential anti-diabetic activity: A review. Der Pharmacia Lettre. 2(3): 369-387.

Chauhan, K., Sharma, S., Rohatgi, K., and Chauhan, B. 2012. Antihyperlipidemic and antioxidant efficacy of Catharanthus roseus Linn. (Sadabhar) in streptozotocin induced diabetic rats. Asian Journal of Pharmaceutical and Health Sciences. 2012; 2(1): 235-243.

Chen, C.C., Hsu, C.Y., Chen, C.Y., and Liu, H.K. 2008. Fructis corni suppresses hepatic gluconeogensis related gene transcription, enhances glucoseresponsiveness of pancreatic beta-cells, and prevents toxininduced beta-cells death, Journal of Ethnopharmacology. 117(3): 483-490.

Chikhi, I., Allali, H., Dib, M.E.A., Medjdoub, H., and Tabti, B. 2014. Antidiabetic activity of aqueous leaf extract of Atriplex halimusL. (Chenopodiaceae) in streptozotocin-induced diabetic rats. Asian Pacific Journal of Tropical Disease. 4(3): 181-184. 
Chimezie, A., Ibukun, A., Teddy, E., and Francis, O. 2008. HPLC analysis of nicotinamide, pyridoxine, riboflavin and thiamin in some selected food products in Nigeria. African Journal of Pharmacy and Pharmacology. 2(2): 29-36.

Chitra, V., and Leelamma, S. 1999. Coriandrum sativum mechanism of hypoglycaemic action. Food Chemistry. 67(3): 229-231.

Choudhary, S., Pathak, A.K., Khare, S., and Kushwah, S. 2011. Evaluation of antidiabetic activity of leaves and fruits of Ficus religiosa Linn. International Journal of Pharmaceutical and Life Sciences. 2(12): 1325-1327.

Coulibaly, F.A., 2014. Evaluation of the antidiabetic activity of the extracts of Vitellaria Paradoxa in Oryctolagus cuniculus rabbit (lagomorph). The Experiment. 24(3): 1673-1682.

Dachtler, M., Frans, H.M., de Put, V., Frans, V., Stijn, C.M., and Fritsche, B.J. 2003. On-line LCNMR-MS characterization of sesame oil extracts and assessment of their antioxidant activity. European Journal of Lipid Science and Technology. 105(9): 488-496.

Dallak, M., Bashir, N., Abbas, M., Elessa, R., Haidara, M., and Khalil, M. 2009. Concomitant down regulation of glycolytic enzymes, upregulation of gluconeogenic enzymes and potential hepatonephro- protective effects following the chronic administration of the hypoglycemic, insulinotropic Citrullus colocynthispulp extract. American Journal of Biochemistry and Biotechnology. 5(4): 153-161.

David, H.P., Rangachari, B., and Harshit, R.S. 2012. Antidiabetic activity of methanol extract of Acorus calamus in STZ induced diabetic rats. Asian Pacific Journal of Tropical Biomedicine. S941-S946

Dewanjee, S., Das, A.K., Sahu, R., and Gangopadhyay, M. 2009. Antidiabetic activity of Diospyros peregrina fruit: effect on hyperglycemia, hyperlipidemia and augmented oxidative stress in experimental type 2 diabetes. Food and Chemical Toxicology. 47(10): 2679-2685.

Dhar, P., Gembitsky, I., Rai, P.K., Rai, N.K., Rai, A.K., and Watal, G. 2013. A Possible Connection Between Antidiabetic and Antilipemic Properties of Psoralea corylifolia Seeds and the Trace Elements Present: A LIBS Based Study. Food Biophysics. 8(2): 95-103.

Dheer, R., and Bhatnagar, P. 2010. A Study of the antidiabetic activity of Barleria prionitis Linn. Indian Journal Pharmacology. 42(2): 70-73.

Di, X., Kelvin, K.C., Chan, H.W.L., and Carmen, W.H. 2003. Fingerprint profiling of acid hydrolyzates of polysaccharides extracted from the fruiting bodies and spores of Lingzhi by highperformance thin-layer chromatography. Journal of Chromatography A. 1018(1): 85-95.

Edeog, H.O., Okwu, D.E., and Mbaebie, B.O. 2005. Phytochemical constituents of some Nigerian medicinal plants. African Journal of Biotechnology 4(7): 685-688.

Eidia, A., Eidib, M., and Esmaeilia, E. 2006. Antidiabetic effect of garlic (Allium sativum L.) in normal and streptozotocin-induced diabetic rats. Phytomedicin. 13: 624-629.

El-Sayed, A., and Cordell, G.A. 1981. Catharanthamine: A new antitumor bisindole alkaloid from Catharanthus roseus. Journal of Natural Product. 44(3): 289-293.

Eshrat, H.M., and Hussain, A. 2002. Reversal of diabetic retinopathy in streptozotocin induced diabetic rats using traditional indian antidiabetic plant, Azadirachta indica (L.). Indian Journal of Clinical Biochemistry. 17 (2): 115123.

Eze, E.D., Mohammed, A., Musa, K.Y., and Tanko, Y. 2012. Evaluation of Effect of Ethanolic Leaf Extract of Mucuna pruriens on blood glucose levels in Alloxan-induced diabetic Wistar rats. Asian Journal of Medical Sciences. 4(1): 23-28.

Ezike, A.C., Akah, P.A., Okoli, C.C., and Okpala, C.B. 2010. Experimental evidence for the antidiabetic activity of Cajanus cajan leaves in rats. Journal of Basic and Clinical Pharmacy. 1: 25-30.

Faraz, M., Mohammad, K., Naysaneh, G., and Hamid, R.V. 2003. Phytochemical screening of some species of Iranian plants. Iranian Journal of Pharmaceutical Research. 2: 77-82.

Feshani, A.M., Kouhsari, S.M., and Mohammadi, S. 2011. Vaccinium arctostaphylos, a common herbal medicine in Iran: molecular and biochemical study of its antidiabetic effects on alloxan-diabetic Wistar rats. Journal of Ethnopharmacology. 133(1): 67-74.

Fransworth, N.R., and Soejarto, D.D. 1991. Global importance of medicinal plants. In: Conservation of medicinal plants, edited by Akerele, O., Heywood, V. and Synge, H. Cambridge university press, Cambridge. 25-51.

Frode, T.S., and Medeiros, Y.S. 2008. Animal models to test drugs with potential antidiabetic activity. Journal of Ethnopharmacology.115: 173-183.

Ganzera, M. 2008. Quality control of herbal medicines by capillary electrophoresis: Potential, requirements and applications. Electrophoresis. 29(17): 3489-3503.

Gopalakrishnan, S., and Kalaiarasi, T. 2013. Determination of biologically active 
constituents of the fruits of Cucumis sativus Linn. using GC- MS analysis. International Journal of Biological and Pharmaceutical Research. 4(7): 523-527.

Gray, A.M., and Flatt, P.R. 1998. Actions of the traditional anti-diabetic plant, Agrimony eupatoria (agrimony): effects on hyperglycaemia, cellular glucose metabolism and insulin secretion. British Journal of Nutrition. 80(1): 109-114.

Gregersen, S., Represent, P.B., Holst, J.J., and Hermansen, K. 2004. Antihyperglycemic effects of stevioside in Type 2 diabetic subjects. Metabolism Clinical and Experimental. 53: 7376.

Grover, J.K., Yadav, S., and Vats, V. 2002. Medicinal plants of India with antidiabetic potential. Journal of Ethnopharmacology. 81(1): 81-100.

Gunalan, G., Saraswathy, A., and Vijayalakshmi, K. 2012. HPTLC fingerprint profile of Bauhinia variegata Linn. Leaves. Asian Pacific Journal of Tropical Disease. S21-S25.

Gupta, R., Agnihotri, P.K., Johri, S., and Saxena, M. 2009.Hypoglycaemic Activity of Ethanol Extract of Cinnamomum tamala leaves in normal and streptozotocin diabetic rats. Iranian Journal of Pharmacology \& Therapeutics, 8(1): 17-21.

Gupta, R., and Gupta, R.S. 2009. Effect of Pterocarpus marsupium in streptozotocin-induced hyperglycemic state in rats: comparison with glibenclamide. Diabetologia Croatica. 38(2): 39-45.

Han, Q., Yu, Q.Y., Shi, J., Xiong, C.Y., Ling, Z.J., and He, P.M. 2011. Molecular characterization and hypoglycemic activity of a novel water-soluble polysaccharide from tea (Camellia sinensis) flower. Carbohydrate Polymers. 86(2): 797-805

Harborne, J.B. 1998. In: A guide to modern techniques of plant analysis. In: Phytochemical methods. 3rd edition. London: Chapman and Hall. 40137.

Harborne, J.B., 1999. Classes and functions of secondary products, in Walton, N.J., Brown, D.E. (Eds.), Chemicals from Plants, Perspectives on Secondary Plant Products, Imperial College Press. 1-25.

Harbourne, J.B., 1973. Phytochemical methods. In: A guide to modern techniques of plant analysis, London, Chapman and Hall. 221- 232.

He, W., Mi, Y.L., Song, Y., Moon, S., and Park, S. 2011. Combined genomic- metabolomic approach or the differentiation of geographical origins of natural products: Deer antlers as an example. Journal of Agricultural and Food Chemistry. 59(12): 6339-6345.
Hu, X., Li, S., Wang, L., Zhu, D., Wang, Y., Li, Y., Yang, Y., Zhang, Z., and Cheng, D. 2013. AntiDiabetic Activities of Aqueous Extract from Actinidia kolomikta Root Against $\alpha$ glucosidase. Journal of Pharmacognosy and Phytochemistry. 2(4): 53-57.

Hussain, Z., Waheed, A., and Qureshi, R.A. 2004. The effect of medicinal plants of Islamabad and Murree region of Pakistan on insulin secretion from INS-1 cells. Phytotherapy Research. 18(1): 73-77.

Hwang, S.M., Kim, J.S., Lee, Y.J., Yoon, J.J., Lee, S.M., Kang, D.G., and Lee, H.S. (2012). Antidiabetic atherosclerosis effect of Prunella vulgaris in $\mathrm{db} / \mathrm{db}$ mice with type-II Diabetes. American Journal of Chinese Medicine. 40(5): 937-951.

Igbe, I., Omogbai, E.K.I., and Ozolua, R.I. 2009. Hypoglycemic activity of aqueous seed extract of Hunteria umbellate in normal and streptozotocin-induced diabetic rats. Pharmaceutical Biology. 2009; 47(10): 10111016.

Ivorra, M., Paya, M., and Villar, A. 1988. Hypoglycemic and insulin release effect of tormentic acid: Anew hypoglycemic natural product. Planta Medica. 54: 282-286.

Jafri, S.A., Abass, S., and Qasim, M. 2011. Hypoglycemic Effect of Ginger (Zingiber officinale) in Alloxan Induced Diabetic Rats (Rattus norvagicus). Pakistan Veterinary Journal. 31(2): 160-162.

Jain, S.K., and Khurdiya, D.S. 2004. Vitamin C enrichment of fruit juice based ready-to-serve beverages through blending of Indian gooseberry (Emblica officinalis Gaertn.) juice. Plant Foods for Human Nutrition. 59(2): 63-66.

Jawla, S., Kumar, Y., and Khan, M.S.Y. 2012. Hypoglycemic activity of Bougainvillea spectabilisstem bark in normal and alloxaninduced diabetic rats. Asian Pacific Journal of Tropical Biomedicine. S919-S923

Jayasri, M.A., Gunasekaran, S., Radha, A., and Mathew, T.L. 2008. Anti-diabetic effect of Costus pictus leaves in normal and streptozotocin-induced diabetic rats. International Journal of Diabetes and Metabolism. 16: 117-122.

Jeonga, H.J., Kimb, J.S., Hyunc, T.K., Yanga, J., Kangd, H.H., Chod, J.C., Yeomd, H.M., and Kim, M.J. 2013. In vitro antioxidant and antidiabetic activities of Rehmannia glutinosa tuberous root extracts. Science Asia. 39: 605609. 
Jimenez, J., Risco, S., Ruiz, T., and Zarzuelo, A. 1986. Hypoglycemic Activity of Salvia lavandulifolia. Planta Medica. 52(4): 260-262.

Joshi, B., Lekhak, S., and Sharma, A. 2009. Antibacterial Property of Different Medicinal Plants: Ocimum sanctum, Cinnamomum zeylanicum, Xanthoxylum armatumand Origanum majorana. Kathmandu University Journal of Science, Engineering and Technology. 5(1): 143-150.

Kalia, A.N., 2005 Text Book of Industrial Pharmacognosy. Oscar publication.

Kang, J., Choi, M.Y., Kang, S., Kwon, H.N., Wen, H., and Lee, C.H. 2008. Application of a ${ }^{1} \mathrm{H}$ nuclear magnetic resonance (NMR) metabolomics approach combined with orthogonal projections to latent structure-discriminant analysis as an efficient tool for discriminating between Korean and Chinese herbal medicines. Journal of Agricultural and Food Chemistry. 56 (24): 11589-11595.

Karthiyayini, T., Rajesh, K., Kumar, K.L., Sahu, R., and Amit, R. 2009. Evaluation of antidiabetic and hypolipidemic effect of Cucumis sativus fruit in STZ-induced diabetic rats. Biomedical and Pharmacology Journal. 2(2): 351-355

Kasthuri, K.T., Radha, R., Jayshree, N., Anoop, A., and Shanthi, P. 2010. Development of GC-MS for a polyherbal formulation- MEGNI. International Journal of Pharmacy and Pharmaceutical Sciences. 2(2): 81-83.

Kavipriya, S., Tamilselvan, N., Thirumalai, T., and Arumugam, G. 2013. Anti-diabetic effect of methanolic leaf extract of Pongamia pinnataon streptozotocin induced diabetic rats. Journal of Coastal Life Medicine. 1(2): 113-117

Kesari, A.N., Gupta, R.K., Singh, S.K., Diwakar, S., and Wala, G. 2006. Hypoglycemic and antihyperglycemic activity of Aegle marmelosseed extract in normal and diabetic rats. Journal of Ethnopharmacology. 107(3): 374-379.

Khalil, O.A., Ramadan, K.S., Danial, E.N., Alnahdi, H.S., and Ayaz, N.O. 2012. Antidiabetic activity of Rosmarinus officinalis and its relationship with the antioxidant property. African Journal of Pharmacy and Pharmacology. 6(14): 1031 1036.

Khan, B.A., Abraham, A., and Leelamma, S. 1995. Hypoglycaemic action of Murraya Koenigii (curry leaf), Brassica juncea (mustard); mechanism of action. Indian Journal of Biochemistry and Biophysics. 32: 106-108.

Khan, K.H., 2009. Roles of Emblica officinalisin Medicine - A Review. Botany Research International 2 (4): 218-228.
Khan, K.Y., Khan, M.A., Niamat, R., Shah, G.M. Fazal, H., Seema, N., Hussain, I., Ahmad, L., Inayat, H., Jan, G., and Kanwal, F. 2012. Elemental content of some anti-diabetic ethnomedicinal species of genus Ficus Linn. using atomic absorption spectrophotometry technique. Journal of Medicinal Plants Research. 6(11): 2136-2140.

Khani, S.P., Vishwakarma, S.L., and Goyal, R.K. 2004. Anti-diabetic activity of Zingiber officinale in streptozotocin-induced type I diabetic rats. The Journal of pharmacy and pharmacology. 56(1): 101-105.

Kumar, C.H., Ramesh, A., Kumar, J.N.S., and ishaq, B.M. 2011. A review on hepatoprotective activity of medicinal plants. International Journal of Pharmaceutical Sciences and Research. 2(3): 501-515.

Kumar, D.S., Sharathnath, K.V., Yogeswaran, P., Harani, A., Sudhakar, K., Sudha, P., and Banji, D. 2010. A Medicinal Potency of Momordica charantia. International Journal of Pharmaceutical Sciences. 1(2): 95-100.

Kumar, E.K., and Janardhana, G.R. 2011. Antidiabetic activity of alcoholic stem extract of Nervilia plicata in streptozotocin-nicotinamide induced type 2 diabetic rats. Journal of Ethnopharmacology. 133(2): 480-483.

Kumar, R., Ilavarasan, T., Jayachandran, M., Deecaraman, P., Aravindan, N., Padmanabhan., and Krishan, M.R.V. 2008. Anti-diabetic activity of Syzygium cumini and its isolated compound against streptozotocin-induced diabetic rats. Journal of Medicinal Plants Research. 2(9): 246-249.

Kumar, R., Patel, D.K., Prasad, S.K., Sairam, K., and Hemalatha, S. 2012. Antidiabetic activity of alcoholic root extract of Caesalpinia digynain streptozotocin-nicotinamide induced diabetic rats. Asian Pacific Journal of Tropical Biomedicine. S934-S940.

Kumar, S., Kumar, V., and Prakash, O.M. 2011. Pharmacological Evaluation of Fractioned Extracts of Callistemon lanceolatus for Antidiabetic and Hypolipidemic Activities in Diabetic Rats. Journal of Pharmacy and Allied Health Science. 1(2): 58-63.

Kumar, V.K., Dawood, S.R., Rajkumar, B., and Sukumar, I.E. 2010. Antidiabetic potential of Lantana aculeata root extract in alloxaninduced diabetic rats. International Journal of Phytomedicine. 2(3): 299-303.

Kumar. P., Baraiya, S., Gaidhani, S.N., and Gupta, M.D. 2012. Antidiabetic activity of stem bark of Bauhinia variegata in alloxan induced 
hyperglycemic rats. Journal of Pharmacology and Pharmacotherapeutics. 3: 64-66.

Kumawat, B.K., Chand, T., and Singh, Y. 2012. Antidiabetic and antihyperlipidemic effects of alcoholic and aqueous stem bark extracts of Limonia acidissima Linn in alloxan induced diabetic rats. International Journal of phytomedicine. 4: 187-196.

Kumawat, N.S., Chaudhari, S.P., Wani, N.S., Deshmukh, T.A., and Patil, V.R. 2010. Antidiabetic activity of ethanol extract of Colocasia esculenta leaves in alloxan induced diabetic rats, International Journal of Pharmtech Research. 2: 1246-1249

Kuruppusamy, S., 2009. A review on trends in production of secondary metabolities from higher plats by in vitro tissue, organ and cell cultures. Journal of Medicinal Plant Research. 3(13): 1222-1239.

Lakshmi, V., Agarwal, S.K., Ansari, J.A., Mahdi, A.A., and Srivastava, A.K. 2014. Antidiabetic potential of Musa paradisiacain Streptozotocininduced diabetic rats. The Journal of Phytopharmacology, 3(2): 77-81

Latha, M., and Pari, L. 2004.Effect of an aqueous extract of Scoparia dulcis on blood glucose, plasma insulin and some polyol pathway enzymes in experimental rat diabetes. Brazilian Journal of Medical and Biological Research. 37(4): 577-586.

Li, S.L., Lai, S.F., Song, J.Z., Qiao, C.F., Liu, X., and Zhou, Y. 2010a. Decocting-induced chemical transformations and global quality of Du-ShenTang, the decoction of ginseng evaluated by UPLC-Q-TOF-MS/MS based chemical profiling approach. Journal of Pharmaceutical and Biomedical Analysis. 53: 946-957.

Li, S.L., Song, J.Z., Qiao, C.F., Zhou, Y., Qian, K.D., and $\mathrm{Xu}$, H.X. 2010b. UPLC--PDA-TOFMS based chemical profiling approach to rapidly evaluate chemical consistency between traditional and dispensing granule decoctions of traditional medicine combinatorial formulae. Journal of Pharmaceutical and Biomedical Analysis. 52: 468-478.

Lino, C.D.S., Diógenes, J.P.L., Pereira, B.A., Faria, R.A.P.G., Neto, M.A., Alves, R.S., Queiroz, M.G.R.D., Sousa, F.C.F.D., and Viana, G.S.B. 2004.Antidiabetic activity of Bauhinia forficata extracts in alloxan-diabetic rats. Biological and Pharmaceutical Bulletin 27(1): 125-127.

Lokesh, D., and Amit, S.D. 2006. Diabetes mellitusit's possible pharmacological evaluation techniquesand naturotherapy. International Journal of Green Pharmacy. 1: 15-28.
Lokman, F.E., Gu, H.F., Mohamud, W.N.W., Yusoff, M.M., Chia, K.L., and Ostenson, C.G. 2013. Antidiabetic Effect of Oral Borapetol B Compound, Isolated from the PlantTinospora crispa, by Stimulating Insulin Release. Evidence-Based Complementary and Alternative Medicine.727602: 1-7

Mahato, S.B., Sahu, N.P., and Ganguly, A.N. 1981. Steroidal glycosides of Tribulus terrestris. Journal of the Chemical Society, Perkin Transactions. 1: 2405-2410.

Maiti, R., Das, U.K., and Ghosh, D. 2005. Attenuation of hyperglycemia and hyperlipidemia in streptozolocin-induced diabetic rats by aqueous extract of seed of Tamarindus indica. Biological and Pharmaceutical Bulletin. 28: 1172-1176.

Mamun, Rashid, A.N.M., Hossain, M.S., Hassan, N., Dash, B.K., Sapon, M.A., and Sen, M.K. 2014. A review on Medicinal Plants with antidiabetic activity.

Journal of Pharmacognosy and Phytochemistry. 3(4):149-159.

Maries, R.J., and Farnsworth, N.R. 1995. Antidiabetic plants and their active constituents. Phytomedicine. 2(2): 137-189.

Marisol, O.V., Susan, H., Hong, S.M., Jang, M.O., Jin, Y.W., Lee, E.K., and Loake, G.J. 2016. Plant Cell culture strategies for the production of natural products. BMB Reports. 49(3):149-158.

Maroo, J., Vasu, V.T., and Gupta, S. 2003. Dose dependent hypoglycemic effect of aqueous extract of Enicostemma littorale Blume in alloxan induced diabetic rats. Phytomedicine.10: 196-199.

Meenakshi, P., Bhuvaneshwari, R., Rathi, M.A., Thirumoorthi, L., Guravaiah, D.C., and Jiji, M.J. 2010. Antidiabetic activity of ethanolic extract of Zaleya decandra in alloxan-induced diabetic rats. Applied Biochemistry and Biotechnology. 162: 1153-1159.

Mike, L.S., and Edward, K.H. 1999. LC/MS applications in drug development. Milestone Development Services, Pennington, New Jersey.

Mishra, A., and Garg, G.P. 2011. Anti diabetic activity of Alangium salvifolium in alloxan induced diabetic rats. International Research Journal of Pharmacy. 2(6): 101-105.

Mohamed, S., Thattakudian, S.U., Ramkanth, S., Azagu, S.M., Gnanaprakash, K., Angala, P.S., Thiruvengada, R.V.S., and Gauthaman, K. 2011. Protective effect of methanolic extract of Annona squamosaLinn in isoniazid-rifampicin induced hepatotoxicity in rats. Pakistan Journal of Pharmaceutical Sciences. 24(2): 129-134.

Mohammadi, J., Saadipour, K., Delaviz, H., and Mohammadi, B. 2011. Anti-diabetic effects of 
an alcoholic extract of Juglans regia in an animal model. Turkish Journal of Medical Sciences. 2011; 41(4): 685-691.

Moqbel, F.S., Naik, P.R., Habeeb, N., and Selvaraj, S. 2011. Antidiabetic properties of Hibiscus rosa sinensis L. leaf extract fractions on non- obese diabetic (NOD) mouse. Indian Journal of Experimental Biology. 49: 24-29.

Mukhtar, H.M., Ansari, S.H., Bhat, Z.A., and Naved, T. 2006. Antidiabetic activity of an ethanol extract obtained from the stem bark of Psidium guajava (Myrtaceae). Pharmazie. 61(8): 725 727.

Mulabagal, V., Chen, Y.L., Lo, S.F., Nalawade, S.M., Lin, C.Y., and Tsay, H.S. 2004. Studies on the production of some important secondary metabolites from medicinal plants by plant tissue cultures. Botanical Bulletin of Academia Sinica. 45:1-22.

Murra, M.T., 1995. Healing power of Herbs. 2nd edition, Gramercy Books NY. 357.

Nair, B.R., and Santhakumari, G. 1986. Anti diabetic activity of the seed kernel of Syzygium cumini Linn. Ancient Science of Life. 6(2): 80-84.

Nayak, B.S., and Lexley, M.P.P. 2006. Catharanthus roseus flower has wound healing activity in Sprague Dawley rats. BMC Complementary and Alternative Medicine. 6: 41.

Nelson, I.O., Chijioke, C.P., and Ghasi, S. 2012. Antidiabetic effect of crude leaf extracts of Ocimum gratissimum in neonatal streptozotocin-induced type-2 model diabetic rats. International Journal of Pharmacy and Pharmaceutical Sciences. 4(5): 77-83.

Nnamdi, C., Uwakwe, A., and Chuku, L. 2012. Hypoglycemic effects of aqueous and ethanolic extracts of Dandelion (Taraxacum officinale f.h. wigg.) Leaves and roots on streptozotocininduced albino rats. Global Journal of Research on Medicinal Plants and Indigenous Medicine. 1(6): 211-217.

Noor, H., and Ashcroft, S.J. 1989. Antidiabetic effects of Tinospora crispa in rats. Journal of Ethnopharmacology. 27(1-2): 149-61.

Ojewole, J.A.O., 2006. Antinociceptive, antiinflammatory and antidiabetic properties of Hypoxis hemerocallidea Fisch. \& C.A. Mey. (Hypoxidaceae) corm 'African Potato' aqueous extractin mice and rats. Journal of Ethnopharmacology. 130(1): 126-134.

Okoli, C.O., Ibiam, A.F., Ezike, A.C., Akah, P.A., and Okoye, T.C. 2010. Evaluation of antidiabetic potentials of Phyllanthus niruri in alloxan diabetic rats. African Journal of Biotechnology. 9 (2): 248-259.
Ong, K.W., Hsu, A., Song, L., Huang, D., and Tan, B.K. 2011. Polyphenols-rich Vernonia amygdalina shows anti-diabetic effects in streptozotocin-induced diabetic rats. Journal of Ethnopharmacology. 133(2): 598-607.

Orhan, N., Aslan, M., Süküroğlu, M., and Deliorman Orhan, D. 2013. In vivo and in vitro antidiabetic effect of Cistus laurifolius L. and detection of major phenolic compounds by UPLC-TOF-MS analysis. Journal of Ethnopharmacology. 146(3): 859-865.

Ozlem, Y.C., Aynur, G., and Fazilet, V.S. 2010. Large scale cultivation of plant tissue culture in bioreactors. Transworld Research Network. 154.

Ozougwu, Jevas, C., 2011. Anti-diabetic effects of Allium cepa (onions) aqueous extracts on alloxan-induced diabetic Rattus novergicus. Journal of Medicinal Plants Research. 5(7): 1134-1139.

Pandhare, R., Balakrishnan, S., Mohite, P., and Khanage, S. 2012. Antidiabetic and antihyperlipidaemic potential of Amaranthus viridis (L.) Merr. in streptozotocin induced diabetic rats. Asian Pacific Journal of Tropical Disease. S180-S185.

Pasch, H., Heinz, L.C., Macko, T., and Hiller, W. 2008. High-temperature gradient HPLC and LC-NMR for the analysis of complex polyolefins. Pure and Applied Chemistry. 80(8): 1747-1762.

Patil, P.S., and Rajani, S. 2010. An advancement of analytical techniques in herbal research. Journal of Advanced Scientific Research. 1(1): 8-14.

Pepato, M.T., Folgadol, V.B.B., Kettelhut, I.C., and Brunette, I.L. 2001. Lack of antidiabetic effect of a Eugenia jambolana leaf decoction on rat streptozotocin diabetes. Brazilian Journal of Medical and Biological Research. 34: 389-395.

Pietta, P., Mauri, P., Rava, A., and Sabbatini, G. 1991. Application of micellar electrokinetic capillary chromatography to the determination of flavonoid drugs. Journal of Chromatography. 549: 367-373.

Poongothai, K., Ponmurugan, P., Ahmed, K.S., Kumar, B.S., and Sheriff, S.A. 2011. Antihyperglycemic and antioxidant effects of Solanum xanthocarpum leaves (field grown \& in vitro raised) extract on alloxan induced diabetic rats. Asian Pacific Journal of Tropical Medicine 4(10): 778-785.

Pradeep, S., Kumar, P., Khajuria, D.K., and Rao, S.G. 2010. Preclinical evaluation of antinociceptive effect of Withania Somnifera (Ashwagandha) in diabetic peripheral neuropathic rat models. Pharmacologyonline. 2: 283-298. 
Prisilla, D.H., Balamurugan, R., and Shah, H.R. 2012. Antidiabetic activity of methanol extract of Acorus calamus in STZ induced diabetic rats. Asian Pacific Journal of Tropical Biomedicine. S941-S946.

Punitha, D., Thandavamoorthy, A., Arumugasamy, K., Suresh, S.N., Danya, U., and Udhayasankar, M.R. 2012. Anti-hyperlipidemic effect of ethanolic leaf extract of Gmelina arborea in streptozotocin induced male wistar albino rats. International Journal of Life science and Pharma Reviews. 2(3): 46-51.

Puri, D., 2001. The insulinotropic activity of Nepalese medicinal plant Biophytum sensitivum, preliminary experimental study. Journal of Ethnopharmacology. 78(1): 89-93.

Pushpangadan, P., 1995. Role of Traditional Medicine in Primary Health Care. In: Iyengar, P.K., Damodaran, V.K., Pushpangadan, P., Editors. Science for Health. Published By State Committee On Science, Technology And Environment, Govt. Of Kerala.

Rajalakshmi, M., Eliza, J., Cecilia, E.P., Nirmala, A., and Daisy, P. 2009. Anti-diabetic properties of Tinospora cordifolia stem extracts on streptozotocin- induced diabetic rats. African Journal of Pharmacy and Pharmacology. 3(5): 171-180.

Rajathi, M., Modilal, D., and Daisy, P. 2011. Hypoglycemic Effects of Elephantopus Scaber in Alloxan-Induced Diabetic Rats. Indian Journal of Novel Drug delivery. 3(2): 98-103.

Ramchander, T., Rajkumar, D., Sravanprasad, M., Goli, V., Dhanalakshmi, C.H., and Arjun. 2012. Antidiabetic activity of aqueous methanolic extract of leaf of Tamarindus indica. International Journal of Pharmacy and Pharmaceutical Research. 4(1): 5-7.

Ramkumar, K.M., Vanitha, P., Uma, C., Suganya, N., Bhakkiyalakshmi, E., and Sujatha, J. 2011. Antidiabetic activity of alcoholic stem extract of Gymnema montanum in streptozotocin induced diabetic rats. Food and Chemical Toxicology. 49(12): 3390-3394.

Ranilla, L.G., Apostolidis, E., Genovese, M.I., and Shetty, K. 2009. Evaluation of indigenous grains from the Peruvian Andean region for antidiabetics and antihypertensive potential using in vitro methods. Journal of Medicinal Food. 12(4): 704-713.

Ravi, K., Sivagnanam, K., and Subramanian, S. 2004. Anti-diabetic activity of Eugenia jambolana seed kernels on streptozotocin-induced diabetic rats. Journal of Medicinal Food. 7(2): 187-191.

Ray, D., Sharatchandra, K.H., and Thokchom, I.S. 2006. Antipyretic, antidiarrhoeal, hypoglycaemic and hepatoprotective activities of ethyl acetate extract of Acacia catechu Willd. in albino rats. Indian Journal of Pharmacology. 38: 408-413.

Reddy, J., and Hemachandran, J. 2014. Comparative evaluation of the antidiabetic and hypoglycaemic potentials of the parts Musa paradisiacal plant extracts. International Journal of Scientific and Research Publications. 4(4): 15.

Ronningen, K.S., Iwe, T., Halstensen, T.S., Spurkland, A., and Thorsby, E. 1989. The amino acid at position 57 of the HLA-DQ beta chain and susceptibility to develop insulin-dependent diabetes mellitus. Human Immunology. 26(3): 215-25.

Sabu, M.C., and Kuttan, R. 2009. Antidiabetic and antioxidant activity of Terminalia belerica. Robx. Indian Journal of Experimental Biology. 47: 270-275.

Sadak, B.S., Guru, S.M., Mannur, I.S., Sree, V.P., Pushpa Latha, B., Radha Madhavi, Y.R., and Bhaskar, M. 2010. Pharmaceutical Application of Curcuma Longa on Alloxan Induced Type 1 Diabetes and Antioxidant Cascade in Liver of Male Albino Rats. Asian Journal of Experimental. Biological Science. 1 (3): 627632.

Saghir, A.J., Syed, S.H., Aftab, N., Kalsoom., and Javed, I. 2011. Hypoglycemic effect of Aloe vera extract in Alloxan-induced diabetic albino rats. Medicinal Journal of Islamic World Academic Science. 19(3): 127-130

Sahm, D.F., and Washington, J.A. 1990. Antibacterial susceptibility Test Dilution Methods: Manuals of Clinical Microbiology. Lennette EH, $5^{\text {th }}$ Edn. America Society of Microbiology Washington DC. 1105-1116.

Saini, R., and Patil, S.M. 2012. Anti-Diabetic Activity Of Roots Of Quercus infectoria Olivier In Alloxan Induced Diabetic Rats. International Journal of Pharmaceutical Sciences and Research. 3(4): 1318-1321.

Salahuddin, Md., and Jalalpure, S.S. 2010. Antidiabetic activity of aqueous fruit extract of Cucumis trigonus Roxb. in streptozotocin-induceddiabetic rats. Journal of Ethnopharmacology. 127(2): 565-567.

Saminathan, K., and Kavimani, S. 2015. Current Trends of Plants Having Antidiabetic Activity: A Review. Journal of Bioanalysis and Biomedicine. 7(2): 055-065.

Santhan, S., Janarthan, M., and Zuber, A.M. 2013. Evaluation of anti-diabetic and nephro protective activity of $95 \%$ ethanolic extract of Canthium dicoccum whole plant by using albino 
rats. Journal of Chemical and Pharmaceutical Sciences. 6(4): 218-222.

Santhosha, D., Ramesh, A., Sravan, Prasad, M., Sathis, K. D., Pawan, K. B., and Dhanalakshmi, C.H. 2011. Punarnava- A Review. Research Journal of Pharmaceutical, Biological and Chemical Sciences. 2 (4): 427.

Sarah, N., Oluwatosin, A., and Edith, A. 2009. Oral Administration of Extract from Curcuma longa Lowers Blood Glucose and Attenuates AlloxanInduced Hyperlipidemia in Diabetic Rabbits. Pakistan Journal of Nutrition. 8 (5): 625-628.

Sarasa, D., Sridhar, S., and Prabakaran, E. 2012. Effect of an antidiabetic extract of Trigonella foenum graecum on normal and alloxan induced diabetic mice. International Journal of Pharmacy and Pharmaceutical Sciences. 4(1): 63-65.

Saravanan, J., Shajan, A., Joshi, N.H., Varatharajan, R., and Valliappan, K. 2010. A simple and validated RP-HPLC method for the estimation of methylcobalamin in bulk and capsule dosage form. International Journal of Chemical and Pharmaceutical Science. 1(2): 323-324.

Sathya, A., and Siddhuraju, P. 2012. Role of phenolics as antioxidants, biomoleculeprotectors and as anti-diabetic factors evaluation on bark and empty pods ofAcacia auriculiformis. Asian Pacific Journal of Tropical Medicine. 5(10):757-765.

Seshiah, V., and Balaji, V. 2000. Current Concepts in Management of Diabetes Mellitus in Pregnancy: Role of Insulin Pumps and Analogues. International Journal of Diabetes in Developing Countries. 20: 109-111.

Seyyed, A.M., Kowthar, J., Masoumeh, J., Hoda, B., and Mohammad, K.G.N. 2010. Evaluation of the antidiabetic and antilipaemic activities of the hydroalcoholic extract of Phoenix Dactylifera palm leaves and its Fractions in Alloxaninduced diabetic rats. Malaysian Journal of Medical Science. 17(4): 4-13.

Shahraki, M.R., Arab, M.R., Mirimokaddam, E., and Palan, M.J. 2007. The effect of Teucrium polium (Calpoureh) on liver function, serum lipids and glucose in diabetic male rats. Iranian Biomedical Journal. 11(1): 65-68.

Shajeela, P.S., Kalpanadevi, V., and Mohan, V.R. 2012. Potential antidiabetic, hypolipidaemic and antioxidant effects of Nymphaea pubescens extract in alloxan induced diabetic rats. Journal of Applied Pharmaceutical Science 2(2): 83-88.

Shankar, P., Kumar, V., and Rao, N. 2005. Evaluation of antidiabetic activity of Ginkgo biloba in streptozotocin induced diabetic rats.
International Journal of Pharmacy and Technology. 4 (1): 16-19.

Shao, Y.U., Poobsasert, O., and Kennelly, E.J. 1997. Steroidal saponins from Asparagus officinalis and their cytotoxic activity. Planta Medica. 35: 1084-87

Sharma, G.N., Dubey, S.K., Sharma, P., and Sati, N. 2011. Review Article Medicinal Values of Bael (Aegle marmelos) (L.) Corr. International Journal of Current Pharmaceutical Research. 1(3): 13-22.

Sharmin, R., Khan, M.R.I., Akhter, M.A., Alim, A., Islam, M.A., Anisuzzaman, A.S.M., and Ahmed, M. 2013.Hypoglycemic and Hypolipidemic Effects of Cucumber, White Pumpkin and Ridge Gourd in Alloxan Induced Diabetic Rats. Journal of Scientific Research. 5(1): 161-170.

Shetti, A.A., Sanakal, R.D., and Kaliwal, B.B. 2012. Antidiabetic effect of ethanolic leaf extract of Phyllanthus amarus in alloxan induced diabetic mice. Asian Journal of Plant Science and Research. 2(1): 11-15.

Shirwaikar, A., Issac, D., and Malini, S. 2004. Effect of Aerva lanata on cisplatin and gentamicin models of acute renal failure. Journal of Ethnopharmacology. 90(1): 81-86.

Shokeen, P., Anand, P., Murali, Y.K., and Tandon, V. 2008. Antidiabetic activity of $50 \%$ ethanolic extract of Ricinus communis and its purified fractions. Food and Chemical Toxicology. 46(11): 3458-3466.

Shyur, L.F., and Yang, N.S. 2008. Metabolomics for phytomedicine research and drug development. Current Opinion in Chemical Biology. 12: 6671 .

Sidhu, A.K., Wani, S.J., Tamboli, P.S., and Patil, S.N. 2012. In vitro evaluation of anti-diabetic activity of leaf and callus extracts of Costus pictus. International Journal of Science and Research. 3(6): 1622-1625.

Singh, A., Singh, K., and Saxena, A. 2010. Hypoglycaemic activity of different extracts of various herbal plants. International Research Journal of Pharmacy 1(1): 212-224.

Singh, B.N., Singh, B.R., Singh, R.L., Prakash, D., Sarma, B.K., and Singh, H.B. 2009. Antioxidant and anti-quorum sensing activities of green pod of Acacia nilotica L. Food and Chemical Toxicology. 47: 778-786.

Singh, L.W.,2011. Traditional medicinal plants of Manipur as antidiabetics. Journal of Medicinal Plants Research. 5(5): 677-687.

Singh, S.K., Kesari, A.N., Gupta, R.K., Jaiswal, D., and Watal, G. 2007. Assessment of antidiabetic potential of Cynodon dactylon extract in 
streptozotocin diabetic rats. Journal of Ethnopharmacology. 114(2):174-179.

Sirintorn, Y., Wanlaya, J., Damrong, S., Wijit, B., and Sirichai, A. 2009. Insulin secreting and aglucosidase inhibitory activity of Coscinium fenestratum and postprandial hyperglycemia in normal and diabetic rats. Journal of Medicinal Plants Research. 3(9): 646-651.

Snehalatha, and Ramachnadaran. 2009. Insight into the Mechanism of Primary Prevention of Type 2 Diabetes: Improvement in Insulin Sensitivity and Beta cell function. In: "Genetic and Epigenetic Basis of Complex Diseases. Conference in Centre for Cellular and Molecular Biology.

Sobia, T., Sidra, M., Javeria, H., Maryam, H., and Bushra, U. 2012. An Overview of medicinal importance of Swertia chirayita. International Journal of Applied Science and Technology. 2(1): 298- 304.

Somasundaram, G., Manimekalai, K., Salwe, K.J., and Pandiamunian, J. 2012. Evaluation of the antidiabetic effect of Ocimum sanctum in type 2 diabetic patients. International Journal of Life science and Pharma Research. 2 (3): 75-81.

Sombra, L.L., Gómez, M.R., Olsina, R., Martínez, L.D., and Silva, M.F. 2005. Comparative study between capillary electrophoresis and high performance liquid chromatography in 'guarana' based phytopharmaceuticals. Journal of Pharmaceutical and Biomedical Analysis. 36: 989-994.

Soni, K., and Naved, T. 2010. HPTLC- Its applications in herbal drug industry. The Pharma Review. 112-117.

Srivastava, B., Sinha, A.K., Gaur, S., and Barshiliya, Y. 2012. Study of hypoglycaemic and hypolipidemic activity of Eugenia Jambolana pulp and seed extract in Streptozotocin induced diabetic albino rats. Asian Journal of Pharmacy and Life Science. 2 (1); 10-19.

Srivsatava, R., Srivastava, S.P., Jaiswal, N., Mishra, A., Maurya, R., and Srivastava, A.K. 2011. Antidiabetic and antidyslipidemic activities of Cuminum cyminum L. in validated animal models. Medicinal Chemistry Research. 20: 1656-1666.

Subbulakshmi, G., and Naik, M. 2001. Indigenous foods in the treatment of diabetes mellitus. Bombay Hospital Research Journal. 43: 548561.

Suhashini, R., Sindhu, S., and Sagadevan, E. 2014. In vitro Evaluation of Antidiabetic Potential and Phytochemical Profile of Psoralea corylifolia Seeds. International Journal of Pharmacognosy and Phytochemical Research. 6(2): 414-419.
Suryanarayan, P., Saraswat, M., Petrash, J.M., and Reddy, G.B. 2007. Emblica officinalis and its enriched tannoids delay streptozotocin-induced diabetic cataract in rats. Molecular Vision. 24(13): 1291-1297.

Susana, B.G., Wilfredo, M.C., María, I.M., Alfredo, G., César, A.C., and Sara, S.S. 2010. Hypoglycemic activity of leaf organic extracts from Smallanthus sonchifolius: Constituents of the most active fractions. Chemico-Biological Interactions. 185(2): 143-152.

Thevenod, F. 2008. Pathophysiology of diabetes mellitus type 2: Roles of obesity, insulin resistance and $\beta$-cell dysfunction. Diabetes Basel Karger. 19: 1-18.

Tirgar, P.R., Shah, K.V., Rathod, D., Desai, T.R., and Goyal, R.K. 2011. Investigation Into Mechanism of Action of Anti- Diabetic Activity of Emblica Officinalis on Streptozotocin Induced Type I Diabetic Rat. Pharmacologyonline. 2: 556-575.

Tripathi, K.D., 2003. Essentials of Medical Pharmacology, 5th edition, JayPee Brothers Medical Publishers (Pvt) Ltd, New Delhi. 23553.

Upwar, N.K., Patel, R., Waseem, N., and Mahobia, N.K. 2011. Hypoglycemic Effect of Methanolic Extract of Berberis aristata Dc Stem on Normal and Streptozotocin Induced Diabetic Rats. International Journal of Pharmacy Pharmaceutical Science. 3 (1): 222-224.

Verma, N., Singh, A.P., Amresh, G.P.K., and Sahub, P.K. 2010. Different approaches for treatment of type 2 diabetes mellitus with special reference to traditional medicines: a review. The Pharmaceutical Research. 3: 27-50.

Verma, R.S., Padalia, R.C., Yadav, A., and Chauhan, A. 2010. Essential oil composition of Aralia cachemirica fromUttarakhand, India. Records of Natural Products. 4(3): 163-166.

Vetrichelvan, T., and Jegadeesan, M. 2002. Anti diabetic activity of alcoholic extract of Aerva lanata (L.) Juss. ex schultes in rats, Journal of Ethnopharmacology. 80(2-3): 103-107.

Vijayanand, N., Sivasangari Ramya, S., and Rathinavel, S. 2014. Antidiabetic activity of Cynodon dactylon (L.) Pers. Extracts in alloxan induced rats. International Journal of Pharmacy and Pharmaceutical Sciences, 6(4): 348-352.

Wadkar, K.A., Magdum, C.S., Patil, S.S., and Naikwade, N.S. 2008. Anti diabetic potential and Indian medicinal plants. Journal of Herbal Medicine, Toxicology. 2: 45-50.

Wang, H., and He, R. 1993. HLA-DQA and DQB alleles contribute to susceptibility to insulin- 
dependent diabetes mellitus. Chinese Medical Sciences Journal. 8(4): 231-4.

Wani, V.K., Dubey, R.D., Verma, S., Sengottuvelu, S., and Sivakumar, T. 2011. Antidiabetic activity of methanolic root extract of Mukia maderaspatana in alloxan induced diabetic rats. International Journal of PharmTech Research. 3(1): 214-220.

Warjeet, S.L. 2011. Traditional medicinal plants of Manipur as antidiabetics. Journal of Medicinal Plants Research. 5: 677-687.

Wen, H.G., Lin, S.Y., Jia, L., Guo, X.K., Chen, X.G., and $\mathrm{Hu}, \mathrm{Z} . \mathrm{D} .2005$. Analysis of protoberberine alkaloids in several herbal drugs and related medicinal preparations by non-aqueous capillary electrophoresis. Journal of Separation Science. 28(1): 92-97.

Wu, T.S., and Shi, L.S. 1999. Alkaloids and other constituents from Tribulus terrestris. Phytochem. 50: 1411-1141.

Younas, J., and Hussain, F. 2014. In vitro Antidiabetic Evaluation of Allium sativum L. International Journal of Chemical and Biochemical Sciences. 5: 22-25.
Yuan, X., Hu, X., Liu, Y., Sun, H., Zhang, Z., and Cheng, D. 2014. In vitro and In vivo AntiDiabetic Activity of Extracts from Actinidia kolomikta. International Journal of Biology. 6(3): 1-10.

Zhang, Q., and Ye, M. 2009. Chemical analysis of the Chinese herbal medicine Gan-Cao (licorice). Journal of Chromatography A. 1216(11): 19541969.

Zhang, R., Zhou, J., Jia, Z., Zhang, Y., and Gu, G. 2004. Hypoglycemic effect of Rehmannia glutinosa oligosaccharide in hyperglycemic and alloxan-induced diabetic rats and its mechanism. Journal of Ethnopharmacology. 90(1): 39-43.

Zheng, X.K., Zhang, L., Wang, W.W., Wu, Y.Y., Zhang, Q.B., and Feng, W.S. 2011. Antidiabetic activity and potential mechanism of total flavonoids of Selaginella tamariscina (Beauv.) Spring in rats induced by high fat diet and low dose STZ. Journal of Ethnopharmacology. 137(1): 662-668.

\section{How to cite this article:}

Neha Gupta, Tejovathi Gudipati and Prasad, G.B.K.S. 2018. Plant Secondary Metabolites of Pharmacological Significance in Reference to Diabetes Mellitus: An Update. Int.J.Curr.Microbiol.App.Sci. 7(05): 3409-3448. doi: https://doi.org/10.20546/ijcmas.2018.705.398 